NBER WORKING PAPER SERIES

\title{
PERMANENT AND TRANSITORY RESPONSES TO CAPITAL GAINS TAXES: EVIDENCE FROM A LIFETIME EXEMPTION IN CANADA
}

\author{
Adam M. Lavecchia \\ Alisa Tazhitdinova \\ Working Paper 28514 \\ http://www.nber.org/papers/w28514 \\ NATIONAL BUREAU OF ECONOMIC RESEARCH \\ 1050 Massachusetts Avenue \\ Cambridge, MA 02138 \\ February 2021
}

We are grateful to Alan Auerbach, Jon Bakija, Youssef Benzarti, Tim Dowd, William Gentry, Ross Hickey, Arjan Lejour, Kevin Milligan, Jim Poterba, Emmanuel Saez and seminar participants at Williams College, UBC, 7th Annual Mannheim Conference, Finances of the Nation Seminar, and the International Online Public Finance Seminar for helpful comments. We thank Ae Jin Kim for research assistance. This research was supported by funds to the Canadian Research Data Centre Network (CRDCN) from the SSHRC, the Canadian Institute for Health Research (CIHR), the Canadian Foundation for Innovation (CFI), and Statistics Canada. Although the research and analysis are based on data from Statistics Canada, the opinions expressed do not represent the views of Statistics Canada. The views expressed herein are those of the authors and do not necessarily reflect the views of the National Bureau of Economic Research.

NBER working papers are circulated for discussion and comment purposes. They have not been peer-reviewed or been subject to the review by the NBER Board of Directors that accompanies official NBER publications.

(C) 2021 by Adam M. Lavecchia and Alisa Tazhitdinova. All rights reserved. Short sections of text, not to exceed two paragraphs, may be quoted without explicit permission provided that full credit, including $\odot$ notice, is given to the source. 
Permanent and Transitory Responses to Capital Gains Taxes: Evidence from a Lifetime Exemption in Canada

Adam M. Lavecchia and Alisa Tazhitdinova

NBER Working Paper No. 28514

February 2021

JEL No. G51,H24,H31

\begin{abstract}
Using panel data on a $20 \%$ random sample of Canadian taxpayers, we study behavioral responses to the cancellation of a lifetime capital gains exemption that resulted in increased capital gains taxation for some individuals. The unique setting allows us to distinguish between short-term avoidance responses and permanent responses to capital gains taxes. We show that the exemption did not change the number of taxpayers reporting positive capital gains, and thus unlikely resulted in increased participation in capital markets. However, the exemption cancellation slightly increased capital gains realizations of the existing traders.
\end{abstract}

Adam M. Lavecchia

Department of Economics

McMaster University

Kenneth Taylor Hall, Room 412

1280 Main Street West

Hamilton, Ontario

L8S 4M4

Canada

laveccha@mcmaster.ca

Alisa Tazhitdinova

Department of Economics

University of California at Santa Barbara

North Hall

Santa Barbara, CA 93106

and NBER

tazhitda@ucsb.edu 
How does taxation affect the realization of capital gains? The answer to this question is central to several ongoing debates about the equity-efficiency tradeoff of taxing capital gains income. For example, the elasticity of capital income with respect to the net-of-tax rate is an input into formulas for optimal tax rates on capital (Saez and Stancheva (2018)). The elasticity of capital gains realizations with respect to taxes is also important for estimating the impact of tax reforms on government revenues (Gravelle (2020); Agersnap and Zidar (2020)). In spite of its importance, evidence on the responsiveness of capital gains realizations to changes in taxation is mixed, largely due to limitations in data and identifying variation.

In this paper, we exploit the unexpected cancellation of a $\$ 100,000$ CAD (nominal) lifetime capital gains exemption in 1994 and longitudinal tax return data on a $20 \%$ sample of Canadian tax filers to estimate the effect of taxes on short-run and long-run capital gains realizations. Introduced in 1985, the lifetime capital gains exemption (hereafter the LCGE) resulted in an effective marginal tax rate on capital gains of zero up to the $\$ 100,000$ threshold. Broadly speaking, the abrupt elimination of the LCGE in February 1994 affected tax filers in one of two ways depending on their expected path of lifetime capital gains realizations and past behavior. For individuals whose expected lifetime capital gains realizations were less than $\$ 100,000$, the elimination of the LCGE led to both an increase in the effective marginal tax rate on capital gains income and a negative shock to expected lifetime wealth. ${ }^{1}$ On the other hand, individuals who had already exhausted their $\$ 100,000$ exemption limit were unaffected by the 1994 reform.

We adopt a difference-in-differences research design that exploits the differences in remaining exemption space at the time the LCGE was cancelled to partition tax filers into one of several treatment groups and a comparison group. In particular, we assign individuals to treatment and control groups based on the sum of their 1985-1993 capital gains realizations that counted towards the LCGE

\footnotetext{
1 The increase in the effective marginal tax rate on capital gains from 1994 to 1995 meant that the after-tax real return to earning capital income fell sharply from 1995 onwards. Furthermore, the fact that realizations up to $\$ 100,000$ were subjected to taxation meant that lifetime wealth fell by an amount proportional to the tax filer's remaining exemption space multiplied by their marginal tax rate on capital gains income.
} 
limit. Tax filers that exhausted their LCGE space by 1993 are assigned to the control group. By construction, this group is unaffected by the 1994 reform. We assign tax filers whose 1985-1993 realizations were below the LCGE threshold to one of three treatment groups, depending on how far below the $\$ 100,000$ limit their pre-reform realizations were. While all tax filers with unused LCGE space experienced an immediate increase in their effective marginal tax rate, those with more remaining exemption space at the time of the exemption cancellation were arguably less likely to eventually reach the $\$ 100,000$ limit (conditional on covariates). ${ }^{2}$ As a result, the removal of the LCGE should have led to an increase in the medium- and long-run effective marginal tax rates for this group. Partitioning treated tax filers into three groups thus allows us to investigate how the cancellation of the LCGE affected individuals differently, depending on the extent to which their long-run incentives to realize capital gains income changed.

Our analysis generates two main results. First, we find that the removal of the LCGE led to a large increase in realizations in 1994, the last year it was available, for all treatment groups. Compared to the control group, the unconditional realized capital gains of treated tax filers approximately doubled, increasing by 0.9 to $1.1 \mathrm{log}$ points from 1993 to $1994 .{ }^{3}$ Furthermore, we show that this short-term increase in unconditional capital gains realizations is driven by responses along both the extensive (i.e. the likelihood of reporting capital gains) and the intensive margins (i.e. the amount of realized capital gains conditional on reporting positive gains).

Second, although responses by all three treatment groups are quantitatively similar in the short-run, our estimated medium to long-run responses (i.e. 3-5 years later) differ significantly across groups. For treated filers whose 1985-1993 realizations were close to $\$ 100,000$, and who were more likely to eventually exceed

\footnotetext{
${ }^{2}$ In Online Appendix F, we show that the all three treatment groups and the comparison group have similar time-invariant characteristics (e.g. age, gender) and that their time-varying covariates (e.g. marital status, broad income and taxable income) evolve similarly over time. This is reassuring and suggests that our estimated responses are unlikely to be driven by differences in life-circumstances and individual characteristics between groups. See Section 4.3 for a more detailed discussion.

${ }^{3}$ While all individuals with remaining exemption space had an incentive bring forward and report capital gains in 1994, only those with paper gains at the time of the announcement were able to take advantage of this opportunity. Since we do not observe investors' portfolios and, therefore, their unrealized gains, we cannot test the optimality of the behavior of tax filers.
} 
the limit in the absence of the elimination of the LCGE, we find that the 1994 reform had a small, statistically insignificant effect on 1995-1999 realized capital gains. However, for treated individuals whose 1985-1993 realized capital gains were far below the $\$ 100,000$ limit, we find that the elimination of the LCGE increased (unconditional) capital gains realizations by approximately $0.25 \mathrm{log}$ points (i.e. 25 percent). We show that this increase is primarily due increases along the intensive rather than extensive margin.

Taken together, our results suggest that the short-run elasticity of capital gains realizations with respect to the net-of-tax rate is large and positive (2.85 to 3.61), while the medium and long-run elasticities are much smaller and even negative in some cases $(-0.16$ to -1.12$)$. Our short-run estimates likely represent an upper bound on the potential magnitude of re-timing responses for two reasons. First, tax filers were able to take advantage of the expiring exemption and crystalize existing unrealized capital gains without selling their assets by filling out a form when completing their 1994 tax return. Since filling out this form was essentially costless compared to the potential tax savings, our estimated 1994 retiming responses are likely larger than what would be observed for a typical tax reform. Second, some taxpayers may have inflated their crystalized capital gains on assets that are not third-party reported (e.g. certain non-financial assets), since doing so would reduce their future tax liabilities without increasing their tax burden in $1994 .^{4}$

Our negative estimate of the long-run elasticity of capital gains realizations with respect to the net-of-tax rate is consistent with the wealth effect arising from the elimination of the LCGE being relatively important in our setting. This may not be surprising given that the sudden elimination of the LCGE represented a large negative shock to the lifetime wealth for tax filers that did not expect to exceed the $\$ 100,000$ limit and because the elimination of the LCGE was not viewed as a transitory tax change (Richardson and Moore (1995)). Our estimates suggest that this wealth effect is particularly important for young tax filers with substantial unused LCGE space at the time the cancellation was announced. To contrast, our estimates of the long-run elasticity for those with little unused

\footnotetext{
${ }^{4}$ During this time period, capital gains realizations through banks and brokerage accounts were third-party reported to Canada Revenue Agency.
} 
exemption space are small and statistically insignificant. ${ }^{5}$

Our interpretation of the estimated responses for tax filers with modest 19851993 realizations as being consistent with a negative wealth effect is grounded in economic theory. Generally speaking, the capital gains realization behavior of tax filers depends on responses along three margins: (i) savings/consumption decisions that affect the acquisition of assets that may generate capital gains, (ii) portfolio asset allocation decisions that determine the fraction of wealth allocated to assets that may generate capital gains and (iii) the decision about when to realize paper gains (i.e. timing decisions). In Online Appendix C, we develop three simple theoretical models that isolate each of these decisions margins. Along all three decision margins, we show that the effect of higher capital gains tax rates on capital gains realizations is theoretically ambiguous. ${ }^{6}$

We benchmark our empirical estimates against a number of sensitivity checks and find that our results are robust. In particular, we address three potential concerns with our empirical strategy and argue that our estimated null and positive long-term responses to the elimination of the LCGE are unlikely to be affected by estimation bias. One potential concern is that our estimates of the medium and long-run response to the LCGE are biased downwards because treated tax filers brought forward capital gains realizations to 1994, leading to mechanically lower realizations in subsequent years. However, to the extent that the realizations of tax filers in the treated group are lower than they otherwise would be in the 1995-1999 period because of a 1994 re-timing response, this would suggest the 'true' long-run response of capital gains realizations to taxes is even more positive than we find.

Another potential concern is that we misclassify individuals with pre-reform realizations below $\$ 100,000$ who would have eventually exceeded the limit in the

\footnotetext{
${ }^{5}$ Strictly speaking, interpreting differences in elasticity estimates between treatment groups as being driven by the relative importance of the wealth effect requires an assumption that tax filers in these groups have similar underlying structural elasticities. This assumption is plausible in our setting since all groups have similar demographic characteristics and income. If this is not the case, however, differences in the response to the elimination of the LCGE between groups may represent differences in underlying structural elasticities (e.g. due to different preferences or discount factors) rather than the relative importance of the wealth effect.

${ }^{6}$ Section 5 contains a detailed discussion of these theoretical results and their applicability to our setting.
} 
absence of the elimination of the LCGE as treated. While the elimination of the LCGE created an incentive to bring forward future expected realizations to 1994 to avoid taxation, the removal of the exemption would not have affected the long-run effective marginal tax rate on capital gains or the expected lifetime wealth for these individuals. This misclassification reduces our ability to identify long-run responses and will tend to attenuate our estimates towards zero. We address this concern in a number of ways . First, we estimate the causal effect of the elimination of the LCGE separately for three different treatment groups that vary in their 1985-1993 realizations and, therefore, their likelihood of being misclassified. In particular, tax filers with relatively low 1985-1993 realized capital gains (and substantial unused exemption space) are much less likely to be misclassified. Second, we check the sensitivity of our baseline results by estimating regression specifications on the sub-sample of tax filers over age 65. Arguably, our pre-reform proxy for lifetime capital gains is more accurate for this group given that they face less uncertainty about future earnings and retirement income needs. Finally, we drop individuals whose 1994 realization response pushes them over the $\$ 100,000$ LCGE limit. Reassuringly, our estimates are similar for all of these sensitivity checks.

A third potential concern is that we define treatment and control group status based on past behavior and this may introduce bias if capital gains are meanreverting. We argue that this concern is unlikely to materially affect our estimates because we define our treatment and control groups based on a long series of capital gains realizations (9 years). Furthermore, our event study estimates show no evidence of diverging pre-trends between the treatment and control groups, suggesting that mean-reversion is unlikely to drive our results.

An important feature of our setting is that the LCGE limit of $\$ 100,000$ was relatively low and did not affect the incentive to save or take risk (on the margin) for the most affluent Canadians. In spite of this, we argue that our estimates are informative for both researchers and policy makers because our treatment and control groups collectively earn between $30 \%$ and $60 \%$ of all capital gains income in Canada in a given year. By comparison, the share of capital gains income earned by those with extremely large capital gains realizations (who are excluded from our analysis) is typically between $20 \%$ and $40 \%$. Thus, while our 
estimates may not be externally valid for tax changes that primarily affect top earners, they are economically relevant.

Our results contribute to several active literatures in public finance. A number of papers study individual responses to capital gains taxes (Feldstein et al. (1980); Minarik (1981); Auten and Clotfelter (1982); Lindsey (1987); Poterba (1987); Auerbach and Poterba (1988); Auten et al. (1989); Slemrod and Shobe (1990); Gillingham and Greenless (1992); Burman and Randolph (1994); Bogart and Gentry (1995); Auerbach and Siegel (2000), Landsman et al. (2002); Dowd et al. (2015); Bakija and Gentry (2014); Dowd and McClelland (2019); Buhlmann et al. (2020); Agersnap and Zidar (2020)). ${ }^{7}$ Compared with prior work, our setting allows for an arguably cleaner identification of both short-run and long-run responses to capital gains taxes. In particular, the elimination of the LCGE led to an increase in the effective marginal tax rate on capital gains income that was very salient, affected a large fraction of the population and was relatively simple for tax filers to understand. Moreover, the tax change we study is very large compared to typical tax reforms: the elimination of the LCGE reduced the net-of-tax rate on income from realized capital gains from 1 to 1 minus $75 \%$ of a tax filer's effective marginal tax rate. To contrast, most prior work estimates the impact of changes to statutory tax rates that are small and often mean-reverting (Agersnap and Zidar (2020)).

A key feature of our setting is that we are able to estimate long-run responses to capital gains taxes without having to rely on potentially subjective measures of transitory and permanent tax changes, unlike prior work. The legislation to eliminate the LCGE was introduced as part of the Government of Canada's 1994 Budget as a way to help lower the federal budget deficit and was reaffirmed in the 1995 Budget. This reinforced the perception that the elimination of the LCGE was not a transitory policy change. Moreover, the fact that the elimination of the LCGE had no effect on individuals whose prior capital gains realizations exceeded the $\$ 100,000$ limit also allows us to construct a natural comparison group. This is advantageous because it allows us to assign treatment status based on immutable past behavior rather than endogenous marginal tax rates. Finally, the elimination

7 For a recent summary of the literature, see Stantcheva (2020). Also, a growing literature estimates the effects of capital gains taxes on investors' trading behavior and portfolio asset allocations (Alan et al. (2010); Buhlmann et al. (2020)). 
of the LCGE was the only policy that affected the tax treatment of capital gains and other investment income during the 1990-1999 period we study. This reduces the likelihood that our estimates are contaminated by other policy changes.

The expected effects of the introduction of the LCGE on savings and risk taking was discussed in a special issue of the Canadian Public Policy journal in 1995 (Mintz and Richardson (1995)). ${ }^{8}$ Our paper contributes to the small set of papers in this special issue by presenting estimates of the casual effect of capital gains taxes on capital gains realizations using a representative panel of Canadian tax returns.

Our findings also contribute to a literature that aims to understand individual savings responses to financial incentives (Bernheim (2002)). While our data do not allow us to observe changes in an individual's overall financial position (e.g. home equity and net debt are not observed), the absence of substantial long-run realization responses makes it less likely that individuals adjusted their savings along other margins. This is consistent with the results from several recent papers which find that contributions to tax-preferred savings accounts do not respond strongly to tax incentives (Chetty et al. (2014); Manoli and Weber (2016); Messacar (2018)). ${ }^{9}$

The remainder of the paper is structured as follows. In Section 1, we discuss the features of the Canadian personal income tax system and the tax treatment of capital gains that are relevant for our setting. Section 2 describes the longitudinal dataset of individual tax returns we use in the paper. In Section 3, we present descriptive time series evidence on capital gains realizations in Canada from 1982 to the present. In Section 4, we describe our empirical strategy for estimating the

${ }^{8}$ Notably, the papers in the special issue were presented at a symposium jointly sponsored by the federal Department of Finance and the Institute for Policy Analysis at the University of Toronto held on January 27-28, 1994. This event was held just a few weeks before the February 1994 budget that announced exemption's cancellation. As discussed by the editors of the special issue, the cancellation of the LCGE was completely unexpected at the time of the symposium.

${ }^{9}$ Our administrative tax return data contains information on annual contributions to taxdeferred retirement savings accounts as well as income from dividends and interest at the individual level. We use this information to investigate the extent to which the elimination of the LCGE affected income from sources other than realized capital gains. We find that these other forms of income were not significantly affected by the change in the tax incentive for saving caused by the elimination of the LCGE. 
causal effect of the elimination of the LCGE, present the main results and discuss several robustness checks. Section 5 concludes and discusses some promising avenues for future research.

\section{Institutional Setting}

Table 1 summarizes the tax rules applicable to income from realized capital gains and the top federal and provincial marginal income tax rates for the years we study. The tax rules for other years, as well as the tax treatment of other investment income (i.e. dividends and tax-deferred savings accounts) are summarized in Appendix Tables A.1-A.2.

In Canada, the tax unit is the individual (rather than the couple or family) and the period of taxation is the calendar year; and both the federal government and the provinces set income tax rates. Realized capital gains have been included in the tax base since 1972. ${ }^{10}$ An individual's taxable capital gains income is equal to their net (of losses) realized gains in a calendar year multiplied by a fixed parameter, called the inclusion rate. The inclusion rate was 50\% from 1972 to 1987, 66.7\% from 1988-1989, 75\% from 1990-2000 and 50\% from 2001 until the present (see column 2 of Table 1). Increases (resp. decreases) in the inclusion rate push the tax base more towards (resp. away from) a comprehensive income definition and increase (resp. decrease) the effective marginal tax rate on capital gains income.

Tax filers with net capital losses in a given year can use these losses to reduce their taxable capital gains income in any of the 3 preceding years or in any future year. Capital losses cannot be used to offset regular income (e.g. earnings). Realized capital gains from certain sources are exempt from taxation. Most notably, realized capital gains from the disposition of a tax filer's primary residence do not count towards taxable income (and were not even recorded on

\footnotetext{
${ }^{10}$ In 1962, Prime Minister John Diefenbaker set up a commission to study the entire federal tax system and recommend changes for Parliament to enact. The resulting Report of the Royal Commission on Taxation (often referred to as the Carter Commission) of 1966 recommended broad changes, most notably a shift towards a comprehensive definition of income as the base for taxation. A more detailed review of the history of the taxation of capital income in Canada can be found in Richardson and Moore (1995).
} 
tax forms until 2016). Since 1985 the proceeds from the sale of a qualified farm property or a qualified small business property are also exempt from taxation, up to a lifetime limit of $\$ 500,000$. Finally, in Canada, a tax filer's death results in a "deemed disposition" and, therefore, a capital gains liability on any appreciated assets. Married couples can avoid or delay tax liabilities from deemed dispositions from one spouse through a "spousal rollover," which defers the disposition until the death of the second spouse.

The Lifetime Capital Gains Exemption (LCGE) was introduced by the federal government in 1985 with the goal of encouraging risk taking and competitiveness. The LCGE exempted from taxation the realized capital gains from the disposition of property other than farm property and small business property up to a lifetime limit. Examples of income eligible for the LCGE included realized capital gains from the sale of financial assets such as stocks, bonds and mutual funds and the proceeds from the sale of secondary residences and rental properties. The LCGE limit was phased in gradually from $\$ 20,000$ in 1985 , to $\$ 50,000$ in 1986-1987 and $\$ 100,000$ in 1988 onwards. $^{11}$

The LCGE was unexpectedly cancelled in February 1994 as part of the deficit reduction plans of the newly elected federal Liberal government. In fact, the cancellation was so unanticipated, that it was never discussed at a symposium on capital gains taxation jointly sponsored by the federal Department of Finance and the Institute for Policy Analysis at the University of Toronto that was held on January 27-28, 1994, just a few weeks before the February 1994 budget that announced exemption's cancellation (Mintz and Richardson (1995)). Although the planned reduction in the deficit was mostly achieved by reductions in the level and growth rate of federal spending, the LCGE was eliminated on the grounds that many of its beneficiaries were high income earners who should participate in the austerity effort (Richardson and Moore (1995)). ${ }^{12}$ The elimination of the LCGE was reaffirmed in subsequent federal Budgets, further reinforcing the

\footnotetext{
${ }^{11}$ Note that the use of LCGE reduced the remaining exemption space for the sale of qualified property. In other words, the $\$ 500,000$ exemption discussed earlier applied to the sum of all capital gains realizations.

12 The announcement that the LCGE was being eliminated was made as part of the 1994 federal Budget presented to Parliament by Minister of Finance Paul Martin on February 22, 1994.
} 
perception that the policy change was permanent. To ease the transition, the federal government allowed individuals to take advantage of any unused LCGE space in 1994 without having to sell their assets on a one-time basis. In particular, tax filers were able to crystalize unrealized capital gains (up to their remaining LCGE limit) by filling out a form (Form T664) when filing their 1994 return. $^{13}$ Even though individuals did not have to sell their assets, the crystalized capital gains generated by this one-time opportunity were recorded as realized capital gains income on tax returns and in our data.

Tables 1 and A.2 summarize the tax treatment of other forms of capital income. Interest income (both from assets held in Canada and overseas) and dividends received from foreign firms are taxed at an individual's ordinary marginal tax rate. In contrast, dividends from domestic firms (referred to as 'eligible dividends') receive preferential treatment. Taxable dividend income is equal to an individual's nominal dividend payment multiplied by one plus a gross-up factor. At the federal level, the gross-up factor has ranged from $25 \%$ to $50 \%$ over the past several decades but was constant at 25\% during the 1990-1999 period we focus on. To compensate for the fact that dividend income is grossed-up, individuals may also claim a (non-refundable) dividend tax credit. This tax credit for eligible domestic dividends was stable at $13.3 \%$ during the 1990-1999 period. ${ }^{14}$ Together, the gross-up factor and tax credit system is designed to offset the prepaid taxes on corporate profits.

The Canadian personal income tax system also features tax subsidies for retirement saving through Registered Retirement Savings Plans (RRSPs) and employer-sponsored Registered Pension Plans (RPPs). RRSPs are similar to Individual Retirement Accounts (IRAs) in the U.S. in that contributions are deductible from taxable income, investment income accumulates tax-free and

13 Form T664 allowed individuals to crystalize their unrealized capital gains by artificially and appropriately increasing the cost base of their assets up to their unused LCGE space. The untaxed crystalized (unrealized) capital gain is the difference between the new artificial cost base and the original cost base.

14 To illustrate how the gross-up and tax credit work, consider a tax filer with $\$ 100$ in eligible dividend income year $t$ and a marginal tax rate of $\tau_{t} \in[0,1)$. After the gross-up, the individual's federal taxable dividend income is $\$ 125(=\$ 100 \times 1.25)$; their federal dividend tax credit is $\$ 16.625(=\$ 125 \times 0.133)$. Their after-tax dividend income is $\$ 100-\$ 125\left(\tau_{t}-0.133\right)>$ $\$ 100\left(1-\tau_{t}\right)$. 
Table 1: Summary of Tax Rules and Rates

\begin{tabular}{|c|c|c|c|c|c|c|c|c|}
\hline \multirow[b]{3}{*}{ Year } & \multicolumn{3}{|c|}{ Capital Gains: } & \multicolumn{5}{|c|}{ Income Tax: } \\
\hline & \multirow[b]{2}{*}{$\begin{array}{c}\text { Inclusion } \\
\text { Rate }\end{array}$} & \multicolumn{2}{|c|}{ Lifetime Exemptions: } & \multicolumn{3}{|c|}{ Federal MTR: } & \multicolumn{2}{|c|}{ Provincial Top MTRs: } \\
\hline & & General & $\begin{array}{c}\text { Small } \\
\text { Business }\end{array}$ & $\begin{array}{l}\text { \# of Tax } \\
\text { Brackets }\end{array}$ & $\begin{array}{c}\text { Top MTR } \\
\text { Cutoff }\end{array}$ & $\begin{array}{c}\text { Top } \\
\text { MTR }\end{array}$ & Range & Median \\
\hline 1982 & 0.5 & 0 & & 10 & 53,376 & 34 & $13-33$ & 18 \\
\hline 1983 & 0.5 & 0 & & 10 & 56,592 & 34 & $13-33$ & 19 \\
\hline 1984 & 0.5 & 0 & & 10 & 59,424 & 34 & $13-33$ & 19 \\
\hline 1985 & 0.5 & 20,000 & 500,000 & 10 & 62,160 & 34 & $15-33$ & 19 \\
\hline 1986 & 0.5 & 50,000 & 500,000 & 10 & 62,657 & 34 & $15-28$ & 19 \\
\hline 1987 & 0.5 & 50,000 & 500,000 & 10 & 63,347 & 34 & $15-28$ & 19 \\
\hline 1988 & 0.667 & 100,000 & 500,000 & 3 & 55,000 & 29 & $12-26$ & 17 \\
\hline 1989 & 0.667 & 100,000 & 500,000 & 3 & 55,605 & 29 & $12-24$ & 17 \\
\hline 1990 & 0.75 & 100,000 & 500,000 & 3 & 56,550 & 29 & $13-24$ & 18 \\
\hline 1991 & 0.75 & 100,000 & 500,000 & 3 & 57,568 & 29 & $13-24$ & 18 \\
\hline 1992 & 0.75 & 100,000 & 500,000 & 3 & 59,180 & 29 & $13-24$ & 19 \\
\hline 1993 & 0.75 & 100,000 & 500,000 & 3 & 59,180 & 29 & $13-26$ & 20 \\
\hline 1994 & 0.75 & 100,000 & 500,000 & 3 & 59,180 & 29 & $13-27$ & 20 \\
\hline 1995 & 0.75 & 0 & 500,000 & 3 & 59,180 & 29 & $13-27$ & 20 \\
\hline 1996 & 0.75 & 0 & 500,000 & 3 & 59,180 & 29 & $13-26$ & 20 \\
\hline 1997 & 0.75 & 0 & 500,000 & 3 & 59,180 & 29 & $13-27$ & 19 \\
\hline 1998 & 0.75 & 0 & 500,000 & 3 & 59,180 & 29 & $13-27$ & 19 \\
\hline 1999 & 0.75 & 0 & 500,000 & 3 & 59,180 & 29 & $13-27$ & 19 \\
\hline 2000 & 0.667 & 0 & 500,000 & 3 & 60,009 & 29 & $13-25$ & 18 \\
\hline 2001 & 0.5 & 0 & 500,000 & 4 & 100,000 & 29 & $10-30$ & 17 \\
\hline
\end{tabular}

Notes: This table summarizes tax rules for capital gains and income tax rates. Information for years 2002-2015 is available in Appendix Table A.1. 
withdrawals are taxable. Individual contributions to RRSPs cannot exceed an annual limit: a certain percentage of the tax filer's annual earnings (18\%-20\% during our period of study) up to a maximum amount. The nominal value of the maximum RRSP contribution limit increased in recent decades from $\$ 5,500$ in 1982 to $\$ 27,830$ in 2020; since 1991 unused contribution from one year can be carried forward to future years. Annual contributions to employer-sponsored RPPs reduce an individual's RRSP contribution room.

\section{Data}

This paper uses individual tax return data from the Longitudinal Administrative Databank (LAD). ${ }^{15}$ The LAD is a representative panel of $20 \%$ of Canadian tax filers. Each year, $20 \%$ of new filers are selected into the sample. Once in the LAD, individuals are followed each year they file a return and are linked across years using their Social Insurance Number (SIN). ${ }^{16}$ Although the most recent version of the LAD spans the 1982-2016 period, most of our analysis below will be based on the 1990-1999 window around the elimination of the LCGE. Unless stated otherwise, all dollar amounts we report are in 1993 dollars, the year before the LCGE was eliminated. ${ }^{17}$

The LAD contains information on a tax filer's realized net capital gains and taxable net capital gains in all years. For 1994, reported capital gains include the unrealized crystalized gains claimed by tax filers taking advantage of the expiring LCGE. In other words, net realized capital gains in 1994 are the sum of realized capital gains for that year and the "deemed" realizations from the filing of Form T664. Unfortunately, the LAD does not contain a detailed breakdown

\footnotetext{
${ }^{15}$ See https://www23.statcan.gc.ca/imdb/p2SV.pl?Function=getSurvey\&SDDS=4107.

${ }^{16}$ Changes over time in the number of individual-year observations in the LAD reflect increases in the Canadian population and the fraction of individuals filing a return. Though unlikely to affect our estimates, two tax policy changes in the late 1980s increased fraction of individuals at the bottom of the income distribution that file a return. In Online Appendix B, we discuss these tax changes and show that they led to a very small increase in the number of low-income tax-filers.

17 From 1993 to 2016 (the last year of our data), the Canadian Consumer Price Index increased by 49.02 percent. Thus, to convert 1993 dollars to 2016 dollars, multiply 1993 dollar values by approximately 1.5 (see the Bank of Canada Inflation Calculator (https://www.bankofcanada.ca/rates/related/inflation-calculator/)).
} 
of capital gains by asset/security. This means that some of the capital gains we observe may be due to distributions from mutual funds or other investments that are outside of an individual's control. ${ }^{18}$ However, unless individuals in our 'treated' groups systematically began receiving more (or less) capital gains from these distributions after 1994 compared to the control group, the income from these passive sources simply adds noise to our dependent variable of interest.

Starting in 1986, the LAD also contains information on the capital gains exemptions claimed by the tax filers. Notably, we cannot distinguish whether these exemptions are claimed under the $\$ 100,000$ LCGE or the $\$ 500,000$ qualified small business exemption. ${ }^{19}$ The LAD also contains information on the capital losses claimed to offset current gains, though we do not observe the stock of losses tax filers have accumulated.

The LAD allows us to observe income from other sources including earnings, dividends (domestic/eligible and foreign/ineligible) and interest, as well as basic demographic characteristics (age, sex, family composition) and, where applicable, immigration status (e.g. year of landing in Canada, origin country). Furthermore, for all individuals selected into the LAD, some information on their spouse and children is available (if applicable). We use this information to investigate whether the response to the change in tax incentives affects tax filers differently depending on their marital status and family composition.

For the purposes of this study, we make a number of sample restrictions. First, we drop tax returns filed on behalf of deceased persons. As mentioned earlier, the realized capital gains for individuals that pass away during a calendar year may be due in part to the required deemed disposition at death. Second, to avoid bias from extreme observations, we drop year-person observations with realized annual capital gains exceeding $\$ 762,367$ in 1993 dollars (equivalent to just over $\$ 500,000$ in 1982 dollars or $\$ 1.1$ million in 2016 dollars).

Finally, Statistics Canada requires that all researchers working with the LAD

\footnotetext{
18 Most mutual funds and exchange traded funds (ETFs) are organized as trusts that are owned by unit holders. Any gains from trading activity generate capital income that is taxable. Since the trust is not taxable, any gains are distributed to the unit holders, regardless of whether or not the unit holder buys/sells units throughout the year.

${ }^{19}$ The elimination of the LCGE is clearly observable in the data with both the fraction of tax filers claiming an exemption and the mean exemption claimed falling by more than 80 percent after 1994.
} 
abide by statistical confidentiality rules. These rules do not allow the release of raw summary statistics for variables measured in dollars. ${ }^{20}$ Consequently, all summary statistics (both figures and tables) presented in this paper are calculated using the following two-step procedure. First, a small amount of noise is added to the variable underlying the summary statistic. Second, the resulting statistic (e.g. mean, median) is rounded according to the following rules. Dollar values of less than $\$ 1000$ are rounded to the nearest $\$ 10$, while dollar estimates above $\$ 1000$ are rounded to the nearest $\$ 100$. All sample size counts are rounded to the nearest 5. The counts shown are inflated to represent the full population of Canadian tax filers from the $20 \%$ LAD random sample.

\section{Time Series Evidence}

In this section, we present time series evidence on the evolution of realized capital gains in Canada from 1982 to 2016. We also compare this series to the performance of the Canadian stock market over the period we study. Figure 1 plots the unconditional mean of net realized capital gains (in 1993 dollars) from 1982 to 2016 on the left axis. The right axis plots the (inflation-adjusted) performance of the Standard and Poor's Toronto Stock Exchange Composite Index (TSECI). The shaded green area indicates the 1985-1994 period when the LCGE was in place. Average net realized capital gains increased during the first few years the LCGE was in place before falling back to prior levels by 1990. The absence of strong long-run response to the introduction of the LCGE cannot be attributed to poor conditions in financial markets since the stock market performed well during this period. The large spike in realized capital gains that is clearly observed in 1994 is a multiple of the average gains for any other year in the sample. ${ }^{21}$

Figure 2(a) plots the fraction of tax filers who report positive net capital gains each year from 1982-2016. The fraction of Canadian tax filers reporting

20 To contrast, output based on regression models does not require that noise be added to the data or the resulting estimates.

21 Appendix Figure D.2 breaks down responses by the amount of reported capital gains and suggests that the spike in 1994 realizations was not due to a large number of very small realizations. Most of the spike in 1994 can be attributed to an increase in the number of tax filers reporting large capital gains. 
Figure 1: Average Reported Capital Gains Over Time

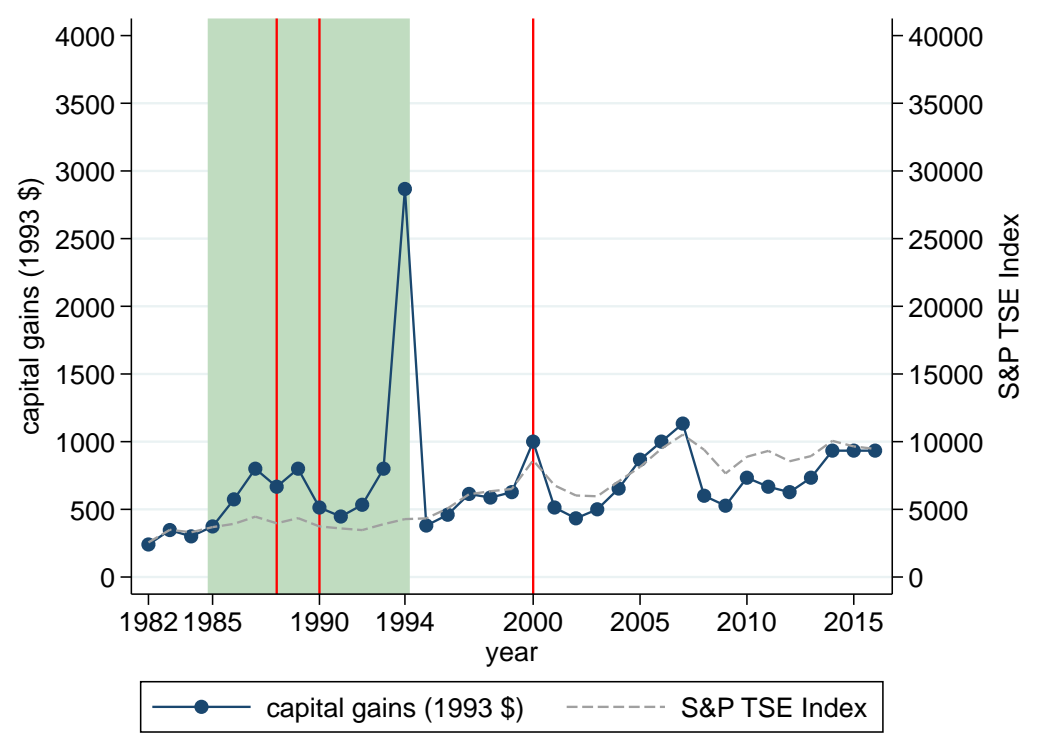

Notes: The green shaded area marks the period of time (1985-1994) when the LCGE was available. The red vertical lines indicate the years where the capital gains inclusion rate changed (from $50 \%$ to $66.6 \%$ in 1988, from $66.6 \%$ to $75 \%$ in 1990 and from $75 \%$ to $50 \%$ in 2000). The dashed grey line shows evolution of the inflation-adjusted values of the Standard and Poor's Toronto Stock Exchange Composite Index over the same time period.

positive capital gains has increased substantially over time, from approximately 2.5 percent of all filers in 1982 to nearly 10 percent in recent years. With the exception of a large spike in 1994, the fraction of tax filers reporting positive capital gains did not increase materially during the years the LCGE was available. In the years since the LCGE was eliminated, the fraction of Canadians reporting positive capital gains has tended to be positively correlated with the performance of the TSECI.

Figure 2(b) plots the average realized capital gains (in 1993 dollars) among tax filers reporting positive gains. After falling from 1982-1984, the average realized capital gain increased substantially from 1985-1990, before leveling off. One interpretation of this increase is that the introduction of the LCGE led to increased realizations among those reporting positive gains. However, another interpretation is that part of the observed increase may be due to a change in the composition of those reporting positive gains. Indeed, the fraction reporting 
Figure 2: Capital Gains Over Time - Extensive and Intensive Margin Responses

(a) Percent Positive

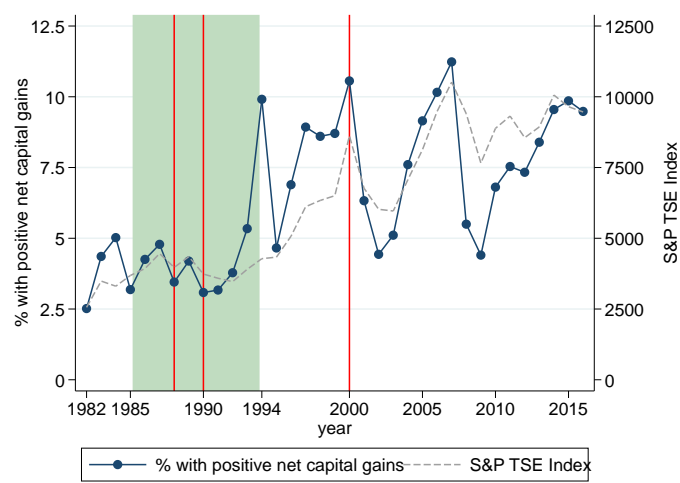

(b) Average Positive

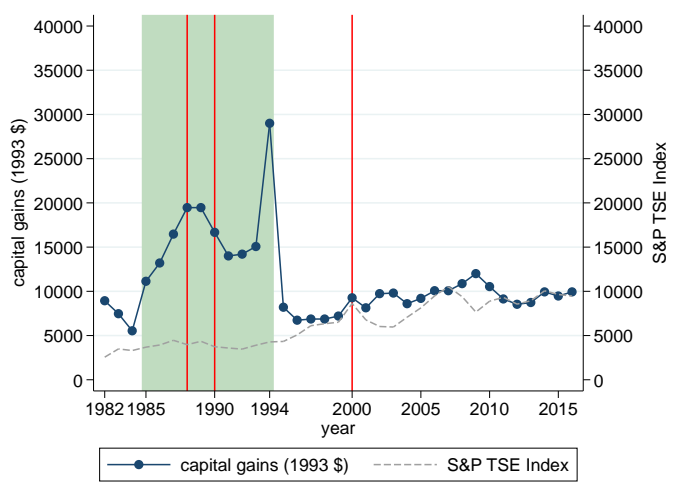

Notes: The green shaded area marks the period of capital gains exemption, 19851994. The red vertical lines mark capital gains inclusion rate changes: increase from $50 \%$ to $66.6 \%$ and further to $75 \%$ in 1988 and 1990 ; and a decrease from $75 \%$ to $50 \%$ in 2000. The dashed grey line shows the inflationadjusted values of the Standard and Poor's Toronto Stock Exchange Composite Index.

a positive capital gain fell from about 5 percent in 1984 to just over 2.5 percent in 1990. Furthermore, the average realized gain by positive contributors fell substantially after the elimination of the LCGE just as the fraction reporting positive gains began increasing.

The series in Figure 2(a) also exhibit small declines in 1988 and 1990, corresponding to the years the inclusion rate increased from $50 \%$ to $66.67 \%$ and from $66.7 \%$ to $75 \%$, respectively. Similarly, there is a clear spike in the series in 2000 when the inclusion rate decreased from $75 \%$ to $50 \%$.

Attributing the annual fluctuations in the series in Figures 1 and 2 to changes in the tax treatment of capital gains is challenging because of fluctuations in the business cycle and stock market, changes in the composition of tax filers reporting capital gains and the fact that there were multiple tax changes in the late 1980s. This motivates our choice to focus on the 1990-1999 period around the elimination of the LCGE when the policy environment was otherwise stable. Furthermore, focusing on this reform allows us to construct a credible comparison group with which we can compare those affected by the elimination of the LCGE. This is the focus of our analysis in Section 4. 


\section{Causal Analysis}

\subsection{Identification Approach}

The introduction and subsequent elimination of the LCGE dramatically changed the effective marginal tax rate on capital gains income for most tax filers. The majority of tax filers report relatively small amounts of capital gains over the life-cycle (see Figure D.1 in the Online Appendix). For these filers, the $\$ 100,000$ LCGE limit did not bind so its elimination in 1994 led to a large increase in the effective marginal tax rate on capital gains income. On the other hand, for the minority of tax filers with large capital gains, the LCGE created a one-time windfall that did not change their marginal incentives to realize capital gains. Our identification strategy exploits the different incentives faced by these groups around the 1994 elimination of the LCGE. Importantly, there were no other federal tax changes during this period.

In our setting, an ideal experiment would involve comparing the annual capital gains realizations of individuals who, in absence of the cancellation of the LCGE, would realize less than $\$ 100,000$ worth of capital gains during their lifetime, to those who would realize more than $\$ 100,000$. Unfortunately, the lifetime capital gains of individuals are not observed until they are deceased and tax filers face uncertainty about their lifetime capital gains (including the uncertainty about net financial returns which may be affected by changes in tax policy). Furthermore, the observed realizations of tax filers in the years after 1994 are endogenous to the elimination of the LCGE. Consequently, our empirical strategy relies on a proxy for lifetime capital gains and, in turn, the likelihood that an individual was affected by the cancellation of the LCGE.

We use the sum of reported 1985-1993 capital gains as a proxy for lifetime capital gains. Let $C G_{i t}$ denote tax filer $i$ 's reported net capital gain in year $t$. Our proxy for lifetime capital gains is $\operatorname{Proxy}_{i}=\sum_{t=1985}^{1993} C G_{i t}$. Our choice of this proxy is driven by several considerations. First, our proxy is based on pre-1994 capital gains and, therefore, is based on immutable pre-cancellation behavior. Second, capital gains exhibit strong mean-reversion so proxies based on just a few years of capital gains realizations are likely to rank individuals incorrectly. Relying on a large number of years gives us the greatest predictive power for 
lifetime capital gains.

We assign tax filers to the comparison group or one of three treatment groups based on the variable Proxy $y_{i}$. Our control group consists of tax filers whose 1985-1993 capital gains realizations were between $\$ 100,000$ and $\$ 133,333$ (1993 dollars). ${ }^{22}$ The pre-elimination realizations of this group exceeded the LCGE limit and, therefore, they should be unaffected by the 1994 reform. Tax filers with values of Proxy less than $\$ 100,000$ include both individuals whose expected future capital gains realizations would see them exceed the LCGE threshold and those whose expected future capital gains realizations would not see them exceed the LCGE threshold. Since the elimination of the LCGE may have affected the long-run incentives of these individuals differently, we partition tax filers whose values of Proxy $y_{i}$ are less than $\$ 100,000$ into three groups: (i) $\operatorname{Proxy}_{i} \in[\$ 66,667 ; \$ 100,000)$, (ii) $\operatorname{Proxy}_{i} \in[\$ 33,334 ; \$ 66,667$ ), and (iii) Proxy $_{i} \in[\$ 16,667 ; \$ 33,334)$. We exclude individuals with very small capital gains in 1985-1993 period from our analysis because they are substantially different from the tax filers in the other treatment and control groups. ${ }^{23}$ Our treatment groups includes individuals whose 1994 capital gains bring them above the $\$ 100,000$ LCGE limit. We intentionally include these individuals in our treatment groups because the decision to report large 1994 gains is endogenous to the exemption cancellation. Nevertheless, in a robustness checks described in Section 4.3, we show that dropping these filers does not change our results materially.

The average age of tax filers in all three of our treatment groups is similar to the average age of tax filers in the comparison group (see Online Appendix F). This suggests that individuals in all groups are at similar points in the lifecycle. Consequently, those with lower values of Proxy $y_{i}$ are less likely to have counterfactual capital gains realizations that would see them eventually exceed the $\$ 100,000$ LCGE limit. In sensitivity checks described in Section 4.3, we supplement our main regression specifications by restricting the sample to different age groups (young adults, middle age adults and senior citizens) and by adding group-by-age fixed effects and year-by-age fixed effects. We show that our results

\footnotetext{
${ }^{22}$ The 2016 dollar value of the nominal $\$ 100,000$ exemption in 1993 was $\$ 150,000$.

${ }^{23}$ In particular, tax filers with values of Proxy $y_{i}$ below $\$ 16,667$ are, on average, 10 years younger than those in the other groups and have annual earnings significantly below the other groups. Estimates for this group are available upon request.
} 
are qualitatively similar for all age groups and for various ways of accounting for age/life-cycle differences between tax filers.

Although we exclude individuals with both very large and very small reported capital gains during the 1985-1993 period, our analysis sample still comprises tax filers that account for a large share of annual capital gains. Figure 3(a) shows that each of our treatment and control groups accounts for between $5 \%$ to $20 \%$ of annual capital gains in Canada. Collectively, the tax filers in our analysis sample (treatment and control) account for nearly $60 \%$ of all capital gains reported in 1985-1994, and about 25\% in 1995-1999, as shown in Figure 3(b). Figure 3 also provides indirect support for our empirical strategy: the share of capital gains attributed to each of our treatment and control groups evolve similarly over time. The share of national capital gains earned by these groups decreases over time as they age (tax filers in our treatment and comparison groups were in their early $60 \mathrm{~s}$, on average, in 2000). ${ }^{24}$

Figure 3: Share of Capital Gains Received By Group

(a) Treatment Groups and Control

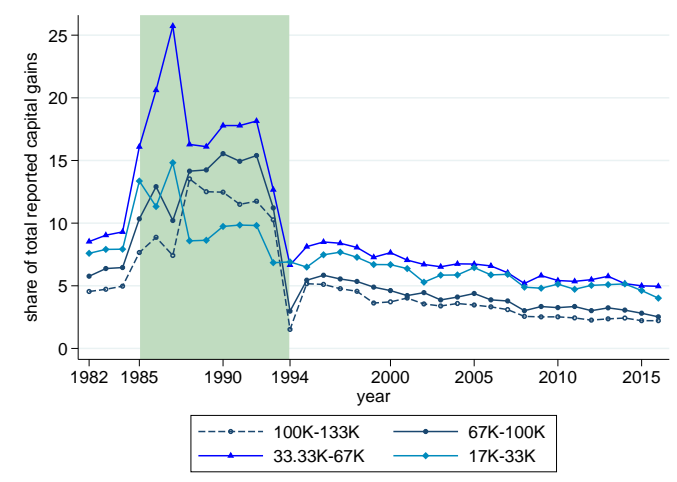

(b) Included vs Omitted Groups

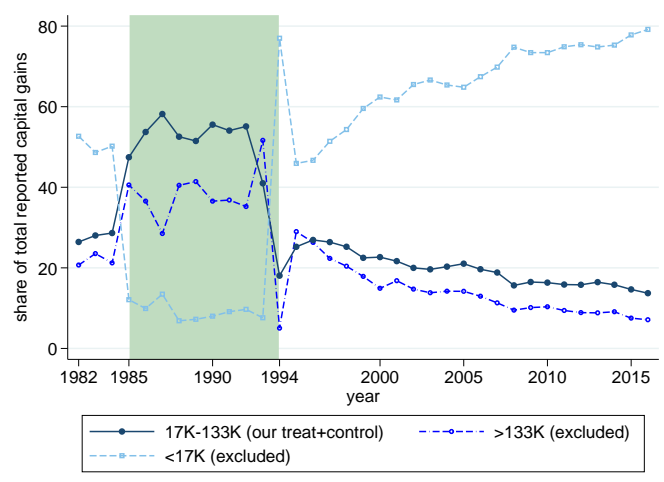

Notes: Figure 3(a) plots the share of capital gains in a given year that is reported by the control group or by one of the treatment groups. Figure 3(b) plots the share of capital gains in a given year that is reported (collectively) by our treated/control groups and by two omitted groups of tax filers: those with large capital gains and with small capital gains in 1985-1993.

For each treatment group $k$, we estimate the unconditional and intensive

${ }^{24}$ Figure 3(b) shows that the group of younger tax filers with low 1985-1993 capital gains (i.e. the $\operatorname{Proxy}_{i}<\$ 17 \mathrm{~K}$ group) accounts for an increasing share of national capital gains over time. This is likely due to a combination of age effects and the fact that this group represents the vast majority of tax filers in Canada. 
margin responses to the cancellation of the LCGE using the following statistical model:

$$
\ln \left(1+C G_{i t}\right)=\alpha+\beta \cdot \text { Treat }_{i}^{k}+\delta_{t}+\sum_{\substack{t=1990 \\ t \neq 1993}}^{1999} \gamma_{\tau} \cdot \mathbb{1}_{t=\tau} \cdot \text { Treat }_{i}^{k}+X_{i t}+\eta_{i}+e_{i t}
$$

where $C G_{i t}$ is inflation-adjusted capital gains in dollars for tax filer $i$ in year $t$, Treat $_{i}^{k}$ is an indicator variable for individuals treatment group $k, \delta_{t}$ are year fixed effects, $X_{i t}$ are individual controls (gender, age, age squared, family type, number of children, postal code fixed effects). The variable $e_{i t}$ is the error term. We estimate specification (1) both with and without individuals fixed effects $\eta_{i}$, as well as with and without controls for the natural logarithm of a tax filer's total (broad) income. We add $\$ 1$ to $C G_{i t}$ so that the dependent variable is defined for tax filers with no capital gains in any given year. Unless otherwise noted, all confidence intervals reported in the figures and tables below are based on heteroskedasticity robust standard errors. ${ }^{25}$

We estimate the effect of the cancellation of the LCGE on the likelihood of reporting realized capital gains (i.e. the extensive margin response) using the following linear probability model (LMP) regression model:

$$
\text { Positive_CG } G_{i t}=\alpha+\beta \cdot \text { Treat }_{i}^{k}+\delta_{t}+\sum_{\substack{t=1990 \\ t \neq 1993}}^{1999} \gamma_{\tau} \cdot \mathbb{1}_{t=\tau} \cdot \text { Treat }_{i}^{k}+X_{i t}+\eta_{i}+e_{i t}
$$

where Positive_CG $G_{i t}$ is equal to 1 if tax filer $i$ reports positive capital gains in year $t$ and zero otherwise. Our estimates of $\gamma_{\tau}$ in both equations (1) and (2) are unbiased if the counterfactual capital gains realizations of tax filers in the treated groups would have followed the path of the realizations of those in the control group after the removal of the LCGE in 1994 (i.e. parallel trends). Below, we present evidence suggesting that this assumption is plausible in our setting.

25 Estimates for specifications where the dependent variable is in levels are qualitatively similar and are available in Appendix Figure E.1. Specifications with individual fixed effects absorb term Treat $_{i}$ and any time-invariant controls $X_{i}$. 
Figure 4: Responses by Capital Gains Levels in 1982-1993

(a) Average Capital Gains

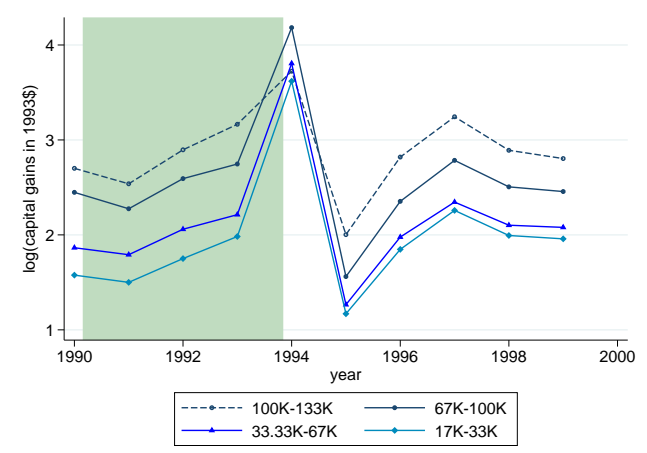

(b) Average Positive CGs

(c) Percent with Positive CGs
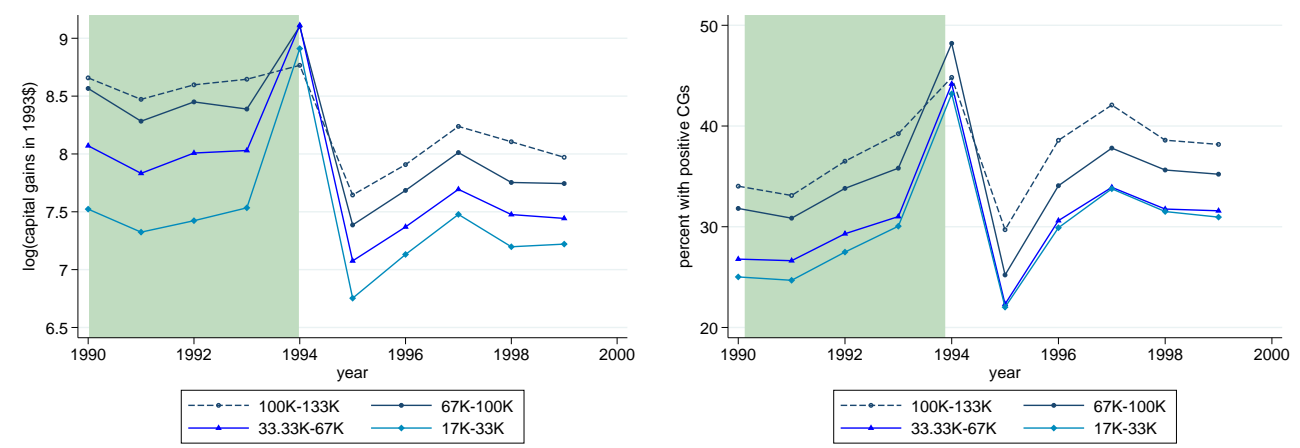

Notes: This figure plots: (a) the average natural logarithm of $\$ 1+$ realized capital gains by year, separately for all tax filers in the treated and control groups, (b) the average natural logarithm of $\$ 1$ + realized capital gains by year, separately for tax filers in the treated and control groups with positive gains, (c) the fraction of tax filers reporting positive capital gains by year, separately for all tax filers in the treatment and control groups. All dollar amounts are expressed in 1993 dollars.

\section{$4.2 \quad$ Results}

Figure 4(a) plots the average values of the natural logarithm of $\$ 1+C G_{i t}$, separately for tax filers in the different treatment groups and the control group. Figures 4(b) and (c) plot average capital gains for those reporting positive values and the fraction of tax filers that report positive capital gains, respectively.

Figure 4 confirms that, on average, individuals with higher values of Proxy realize more capital gains and are more likely to report positive capital gains each year. This suggests that our proxy for lifetime capital gains correctly ranks tax filers. Furthermore, while we see a pronounced spike in the amount of capital gains reported by tax filers in the treated groups (i.e. individuals with Proxy 
of less than $\$ 100,000)$ in 1994 , the control group continues to follow its pre-1994 trend. This behavior is consistent with tax filers in the control group having no tax-incentive to report large capital gains in 1994 because they already exhausted their LCGE limit.

Figure 4 also allows us to evaluate the plausibility of the parallel trends assumption by comparing the evolution of the pre-1994 capital gains realizations of tax filers in the treatment and control groups. Reassuringly, the pre-1994 trends in all three treatment groups and the comparison group are stable. Online Appendix F provides further evidence on the plausibility of the parallel trends assumption by showing that the demographic characteristics of tax filers in the treatment and control groups evolved similarly around 1994.

Having presented the raw data, we are now ready to report the estimates from our regression specifications. The $\gamma_{\tau}$ estimates (and the resulting confidence intervals) from specifications (1) and (2) are presented in Figures 5-7. The coefficients presented are based on a specification that include the individual controls (gender, age, age squared, family type, number of children, postal code fixed effects), group fixed effects and year fixed effects but does not include individual fixed effects. Although our estimates are similar with and without individual fixed effects, we exclude them in our baseline model because capital gains realizations are infrequent. This leads to noisier estimates, especially in specifications that restrict the sample to tax filers with positive realizations. In our baseline specifications, we also do not include controls for total (broad) income because it is mechanically correlated with the dependent variable. Nevertheless, Appendix Figures E.2 and E.3 in the Online Appendix present estimates from specifications that include the individual fixed effects and income controls, respectively. Reassuringly, our results are robust to the inclusion of these controls.

Figure 5 plots the $\gamma_{\tau}$ estimates when the dependent variable is the natural logarithm of $\$ 1$ plus the realized capital gains and the sample is all tax filers in the treatment and control groups. Three things stand out in this figure. First, the realized capital gains of tax filers in each of the treated groups evolved in a similar way as the control group in the years leading up to the cancellation of the LCGE (even after controlling for individual demographic characteristics). Second, the realized capital gains of filers in all three treatment groups increases significantly 
Figure 5: Unconditional Changes in Capital Gains Realizations
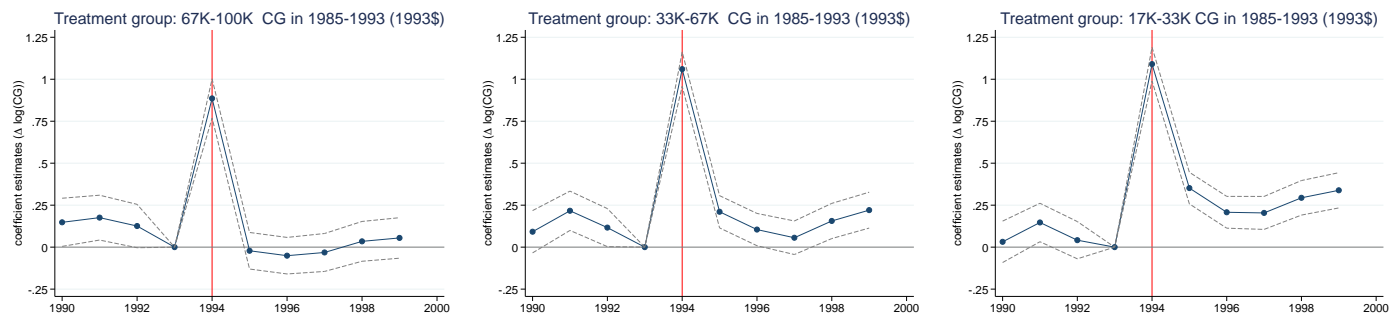

Notes: Figure 5 plots the estimates of coefficients $\gamma_{\tau}$ from estimating specification (1) described in Section 4.1 when the dependent variable is the natural logarithm of unconditional realized capital gains (i.e. $\$ 1$ plus $C G_{i t}$ ). In all panels, the control group is tax filers with values of $\operatorname{Proxy}_{i} \in[100,000,133,333)$. The treatment group in the left panel is tax filers with values of $\operatorname{Proxy}_{i} \in[66,667,100,000)$. The treatment group in the middle (resp. right) panel is tax filers with values of Proxy $\in[33,334,66,667$ ) (resp. Proxy Pr $\left._{i}[16,667,33,334)\right)$. Number of observations: 289,735; 525,650; 596,595.

relative to the control group in 1994 (the omitted interaction term is for 1993). The coefficient estimates of approximately 0.8-1.0 suggest that tax filers in the treatment groups increased their capital gains realizations by 80 to 100 percent relative to the control group from 1993 to 1994. Third, the $\gamma_{\tau}$ estimates during the 1995-1999 years are either close to zero or small and positive. These estimates suggest that the cancellation of the LCGE had no effect on the medium/long-run capital gains realizations of tax filers in the highest treatment group (i.e. Proxy $\in$ $[\$ 66,667, \$ 100,000))$ and a modest positive effect on medium/long-run capital gains realizations of those in the medium (i.e. Proxy $\in[\$ 33,335, \$ 66,667)$ ) and low (i.e. Proxy Pr $_{i}[\$ 16,667, \$ 33,334)$ treatment groups.

Our estimates of the short-run effects of the elimination of the LCGE in 1994 are consistent with prior evidence that capital gains realizations are relatively easy to manipulate and re-time in the short-run (Burman and Randolph (1994); Auerbach and Siegel (2000); Agersnap and Zidar (2020)). The short-run response to the removal of the LCGE we estimate is large in magnitude. This is not surprising because tax filers did not have to sell their assets to take advantage of the crystallization opportunity provided by the government. In spite of this opportunity, only $10 \%$ of all taxpayers reported positive net capital gains in 1994. A likely explanation is the fact that only those with paper gains as of February 1994 were able to take advantage of the crystallization opportunity. 
Moreover, the fact that the capital gains form financial assets were reported to the Canada Revenue Agency by third parties (i.e. banks and brokerages) made the false reporting of capital gains risky for certain assets. Since we do not observe the portfolios of tax filers (and, therefore, their unrealized paper gains), we cannot determine the extent to which indivduals left money on the table by failing to take advantage of the 1994 crystalization opportunity.

The estimates reported in Figure 5 suggest that the cancellation of the LCGE did not lead to a large drop in reported realized capital gains in the medium-tolong run. Rather, our estimates suggest a small, statistically insignificant effect for individuals with values of $\operatorname{Proxy}_{i} \in[66,667,100,000)$ and an approximately $25 \%$ increase for tax filers with $\operatorname{Proxy}_{i} \in[16,667,33,333)$. All else equal, an increase in the effective marginal tax rate on capital gains income should lead tax filers to substitute away from reporting realized taxable gains. The fact that we do not observe a decrease in realized capital gains for any of the treatment groups suggests that the income/wealth effects arising from the removal of the LCGE offset the substitution effect. The importance of income/wealth effects appears to be especially important for tax filers with substantial unused exemption space at the time the LCGE was cancelled. In Appendix C, we develop three theoretical models of capital gains realization behavior and show that the income/wealth effect affects responses to capital gains taxes along the savings, spending and portfolio asset allocation decision margins. We discuss these models further in Section 5 .

We also explored the extent to which our estimates on unconditional realized taxable gains can be explained by responses along the extensive and intensive margins. Figures 6 and 7 present estimates of the effect of the cancellation of the LCGE on average positive capital gains realizations and the likelihood of reporting positive capital gains realizations, respectively. Our estimates suggest that the cancellation of the LCGE increased the fraction of tax filers in the treatment groups with Proxy $_{i} \in[66,667,100,000)$ and Proxy $_{i} \in[33,334,66,667)$ reporting positive realized capital gains by approximately 7.5 percentage points in 1994, with no statistically significant change in the medium/long-run. Furthermore, our estimates for these two treatment groups suggest that the average capital gains among those with positive realizations fell by approximately 10 
percent relative to the control group. However, our intensive margin estimates for these treatment groups are often not statistically significant at conventional levels.

Figure 6: Extensive Margin: Changes in Probability of Realizations
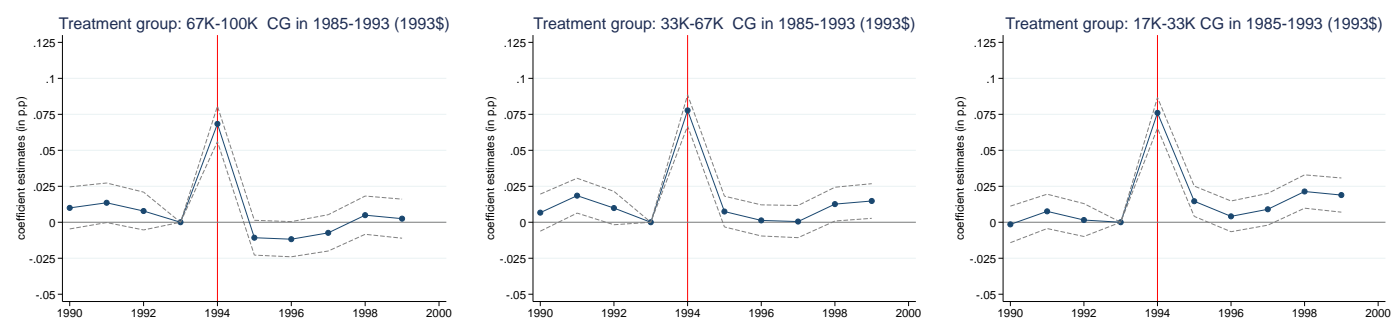

Notes: Notes: Figure 6 plots the estimates of coefficients $\gamma_{\tau}$ from estimating specification (2) described in Section 4.1 when the dependent variable is equal to 1 if a tax filer reports positive realized capital gains in a given year and zero otherwise. In all panels, the control group is tax filers with values of Proxy $\in$ (100,000,133,333). The treatment group in the left panel is tax filers with values of $\operatorname{Proxy}_{i} \in[66,667,100,000)$. The treatment group in the middle (resp. right) panel is tax filers with values of Proxy $\in[33,334,66,667$ ) $\left(\right.$ resp. Proxy Pr $\left._{i}[16,667,33,334)\right)$. Number of observations: 289,735; 525,650; 596,595.

For the Proxy $_{i} \in[16,667,33,334)$ treatment group, our estimates suggest that the cancellation of the LCGE increased the likelihood of reporting positive capital gains by 7.5 percentage points in the short-run and by less than 2.5 percentage points after 3-5 years. Our intensive margin estimates suggest that the average positive gains of this treatment group increased by approximately $125 \%$ in 1994 and by 25\%-30\% over the following 3-5 years.

Taken together, our results suggest that in the short-run, the effects of the elimination of the LCGE on unconditional capital gains are remarkably similar for all three treatment groups. Moreover, the responses along the intensive and extensive margins are similar for all three treatment groups in 1994. Over the medium and long-run, however, the effects of the elimination of the LCGE are heterogeneous and vary across the three treatment groups. For tax filers with 1985-1993 capital gains close to the $\$ 100,000$ limit, the cancellation of the LCGE had no effect on the likelihood of reporting positive capital gains and a modest negative but statistically insignificant effect on the amount of realized capital gains reported. To contrast, the cancellation of the LCGE increased both the likelihood of reporting positive capital gains and the average positive realized 
Figure 7: Intensive Margin: Changes in Positive Capital Gains Realizations
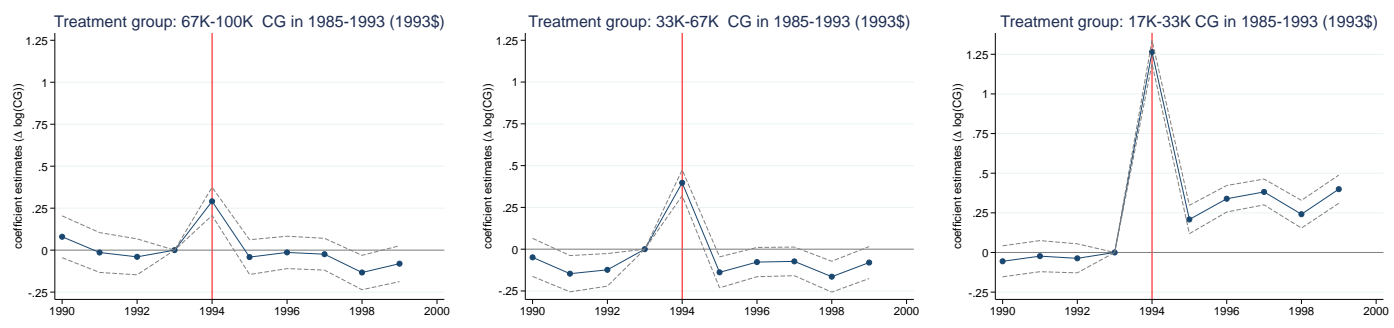

Notes: Figure 7 plots the estimates of coefficients $\gamma_{\tau}$ from estimating specification (1) described in Section 4.1 when the dependent variable is the natural logarithm of realized capital gains (i.e. $\$ 1$ plus $C G_{i t}$ ) on the sample of tax filers with positive realizations. In all panels, the control group is tax filers with positive realizations and values of Proxy $\in$ $[100,000,133,333)$. The treatment group in the left panel is tax filers with positive realizations and values of $\operatorname{Proxy}_{i} \in[66,667,100,000)$. The treatment group in the middle (resp. right) panel is tax filers with positive realizations and values of Proxy $\in[33,334,66,667$ ) (resp. Proxy $y_{i} \in[16,667,33,334)$ ). Number of observations: 105,105; 171,335; 186,125.

capital gains for tax filers with substantial unused exemption room (i.e. Proxy $\in$ $[16,667,33,334)$.

\subsection{Robustness Checks and Heterogeneity Analysis}

In this section we discuss potential threats to our identification assumptions and present the results from a number of sensitivity checks. Broadly speaking, threats to our identification assumptions can be separated into one of three categories: (i) mechanical bias in our estimates due to re-timing responses, (ii) bias due to the misclassification of some tax filers in the treatment groups, and (iii) bias due to the presence of mean-reversion. Towards the end of the section, we discuss how responses to the elimination of the LCGE varied with individuals' demographic characteristics.

\subsubsection{Robustness Checks}

Re-timing responses. One potential concern is that our estimates of the longrun effects of the LCGE are mechanically biased downwards because some individuals may have brought forward to 1994 realizations that would have been realized in the 1995-1999 period or later. However, to the extent that our $\gamma_{\tau}$ es- 
timates are mechanically biased because of this re-timing behavior, this suggests that the 'true' medium- and long-run responses to capital gains taxes are even more positive than we find.

Misclassification. Another potential threat to our estimates of the shortrun and long-run sensitivity of capital gains realizations to taxes is that we could be mistakenly classifying some tax filers as treated when they should be allocated to the control group. In particular, some tax filers with 1985-1993 capital gains less than $\$ 100,000$ might have been holding substantial unrealized capital gains at the time of the 1994 reform. These individuals might very well have exceeded the LCGE limit during the 1995-1999 period in the absence of the reform. For these filers, the removal of the LCGE created an incentive to bring forward future unrealized capital gains but did not affect their expected future effective marginal tax rate. The presence of these individuals in our treatment groups attenuates our estimates because some treated tax filers did not experience a change in their long-run incentive to realize capital gains.

We assess the importance of this potential misclassification on our baseline estimates in three ways. First, the likelihood of misclassifying tax filers as treated in the way mentioned above should decrease as we consider individuals with lower values of the Proxy (i.e. those with smaller 1985-1993 realized capital gains). This is supported by the fact that tax filers in all three treatment and control groups are similar in age and, therefore, are likely to be at similar points in the life-cycle (see Figure F.1 in the Online Appendix). Provided that the control group is a good counterfactual for those with low 1985-1993 realizations (i.e. the Proxy $_{i} \in[16,667,33,334)$ treatment group), our empirical strategy still allows us to identify the long-run response of realizations to capital gains taxes. Our estimates in Figures 5-7 make clear that the medium and long-run responses to the cancellation of the LCGE are larger in magnitude (and positive) for tax filers with low 1985-1993 realizations, precisely those for whom we are the least likely to misclassify.

A second way to assess the potential misclassification of treated individuals is to restrict the sample to tax filers whose cumulative pre-1994 realizations are a more accurate proxy for their lifetime gains. Arguably, the pre-1994 realizations of older tax filers are a better proxy for their lifetime gains. In Figure 8, we 
Figure 8: Capital Gains Realizations of 65+ Year Olds

Panel A: Unconditional Capital Gains
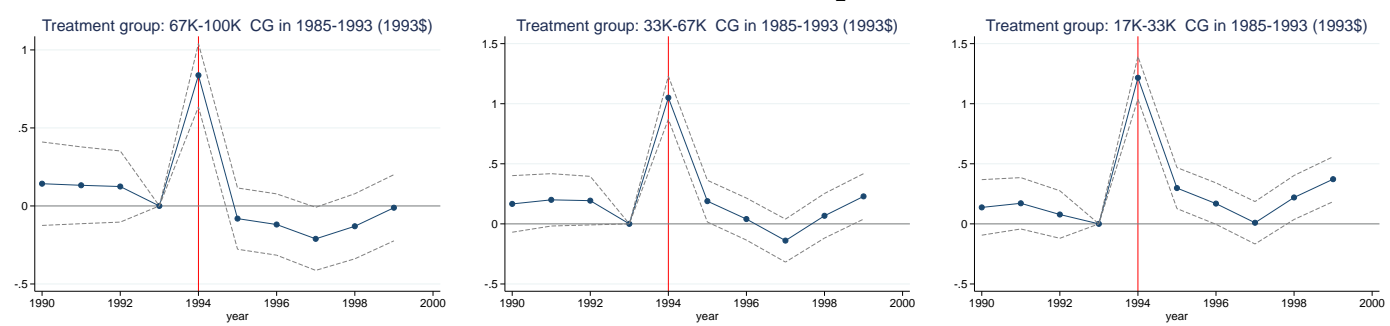

Panel B: Intensive Margin: Positive Capital Gains
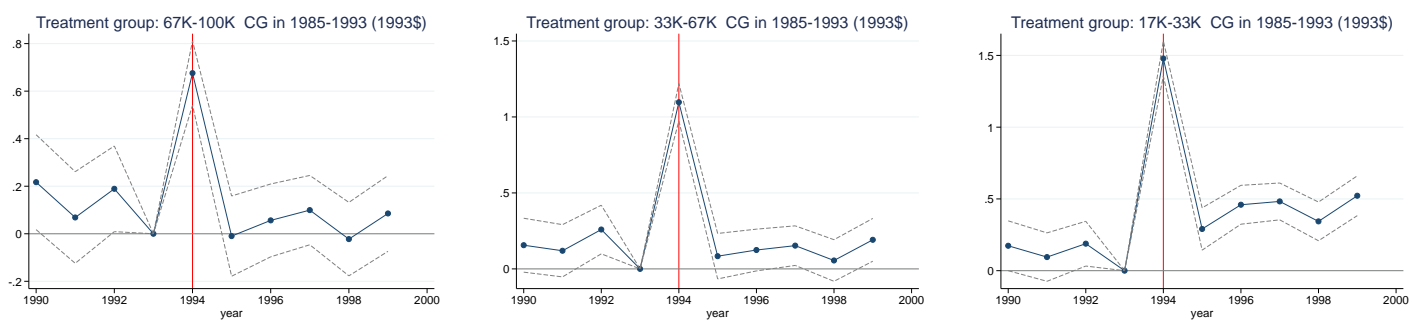

Notes: Figure 8 plots the estimates of coefficients $\gamma_{\tau}$ from estimating specification (1) described in Section 4.1 when the dependent variable is the natural logarithm of unconditional realized capital gains (i.e. $\$ 1$ plus $C G_{i t}$ ) and the sample is restricted to tax filers over age 65. In Panel $\mathrm{B}$, the sample is further restricted to tax filers with positive realized capital gains income. In all panels, the control group is tax filers with values of Proxy $_{i} \in[100,000,133,333)$. The treatment group in the left panel is tax filers with values of $\operatorname{Proxy}_{i} \in[66,667,100,000)$. The treatment group in the middle (resp. right) panel is tax filers with values of Proxy $\in[33,334,66,667)$ (resp. Proxy $\in$ $[16,667,33,334)$ ). Number of observations in Panel A (left, middle, right): 109,120; 192,410; 206,385. Number of observations in Panel B (left, middle, right): 38,080; 58,425; 59,265.

restrict the sample to tax filers over age 65. These filers are likely in the asset decumulation phase of the life-cycle and are less likely to be misclassified. ${ }^{26}$ Our results are qualitatively similar to those reported in Figures 5 - 7. In particular, the cancellation of the LCGE approximately doubled the realized capital gains of tax filers in all treatment groups in 1994. The cancellation of the LCGE had no statistically significant effect on the realizations of tax filers with high prereform capital gains (i.e. those with $\operatorname{Proxy}_{i} \in[66,667,100,000)$ ). To contrast, the cancellation of the LCGE increased the medium- and long-run realizations of those with low 1985-1993 capital gains.

As a third sensitivity check against the potential misclassification concern, we

${ }^{26}$ Figure E.7 in the Online Appendix reports the analogous estimates for other age groups. 
drop individuals whose 1994 capital gains bring them above the $\$ 100,000$ LCGE limit. This leads to an approximately $18 \%$ drop in the sample. Perhaps not surprisingly, tax filers with higher values of Proxy $y_{i}$ (and, therefore, less unused exemption space) were more likely to be dropped than filers with modest 19851993 realizations. Intuitively, by dropping filers that were easily able to exhaust their unused LCGE space in 1994, we are left with tax filers in the treatment group that definitely experienced an increase to their medium-run and long-run effective marginal tax rate on capital gains income. The results from this sensitivity check are reported in Online Appendix Figure E.4. Reassuringly, our estimates are very similar (especially for those with modest 1985-1993 realizations).

Mean-reversion. A third concern is that capital gains realizations are likely to be mean-reverting. Mean reversion could be problematic in our setting since our treatment and control groups are defined based on past capital gains realizations. To alleviate this concern, we defined our treatment and control groups based on capital gains over a nine year period (i.e. 1985-1993). This relatively long horizon should reduce the likelihood that our estimates are biased due to mean reversion. The estimates presented in Figures $5-7$ support this view. In particular, there is no evidence that the pre-trends of tax filers in any of the treatment groups are converging or diverging from those of the comparison group. In order for mean reversion to bias our results, it would have to be the case that the realizations of tax filers in all treated groups (with fewer1985-1983 capital gains) began increasing compared to the control group (whose 1985-1993 gains were higher) precisely in 1994, even after following a similar path in the preceding years.

We present evidence from additional checks against mean reversion in the Online Appendix. In Appendix Figure E.5, we extend the event window from 1990-1999 to 1984-2006. Recall that our main analysis focuses on the 1990-1999 period because no other tax changes occurred during these years. Our estimates based on the wider 1984-2006 window are noisier, but provide strong evidence against mean-reversion trends for our treated and control groups. Second, we consider specifications that attempt to control more flexibly for age/life-cycle effects. In Online Appendix Figure E.6, we present estimates that replace the cubic polynomial in age with Proxy $_{i} \times$ Age and Year $\times$ Age fixed effects. It is 
Figure 9: Heterogeneity by Married/Single

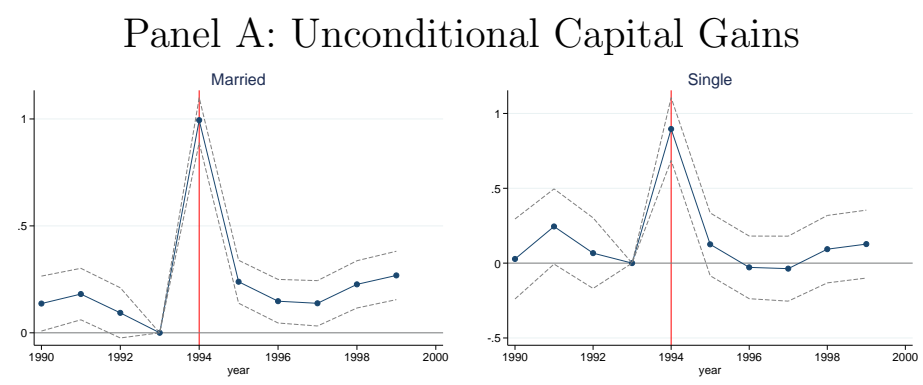

Panel B: Intensive Margin: Positive Capital Gains
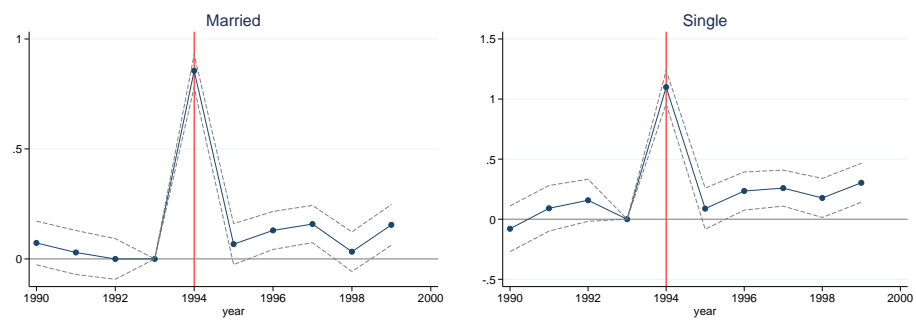

Notes: Figure 9 plots the estimates of coefficients $\gamma_{\tau}$ from estimating specification (1) described in Section 4.1 when the dependent variable is the natural logarithm of unconditional realized capital gains (i.e. $\$ 1$ plus $C G_{i t}$ ) and the sample is restricted to married (left panel) or to unmarried/single (right panel) tax filers, respectively. In Panel B, the sample is further restricted to tax filers with positive realized capital gains income. In all panels, the control group is tax filers with values of Proxy $_{i} \in[100,000,133,333)$ and the (pooled) treatment group is tax filers with values of Proxy $\in$ [16,667,100,000). Number of observations in Panel A (left, right): 938,640; 256,085. Number of observations in Panel B (left, right): 289,635; 89,255.

reassuring that our estimates are nearly identical to our baseline estimates.

\subsubsection{Heterogeneity Analysis}

Figure 9 investigates how capital gains responses vary by marital status. In Canada, the tax unit is the individual rather than the couple or family. As a result, capital income derived from assets that are jointly-held can can be claimed by either spouse. This provides an additional margin along which tax filers can respond to changes in tax rates on capital gains income. ${ }^{27}$ The left (resp. right) panel in Figure 9 presents estimates from specification (1) when the sample is restricted to married (resp. single) tax filers. For ease of presentation, we pool

\footnotetext{
27 Appendix D.4 presents additional time-series analysis about how married tax filers split capital gains income.
} 
all three treatment groups. ${ }^{28}$ Both the 1994 re-timing and medium/long-run responses are similar for single and married tax filers.

Figure 10: Who Reported Capital Gains in 1994?

(a) By Previous CG Reports

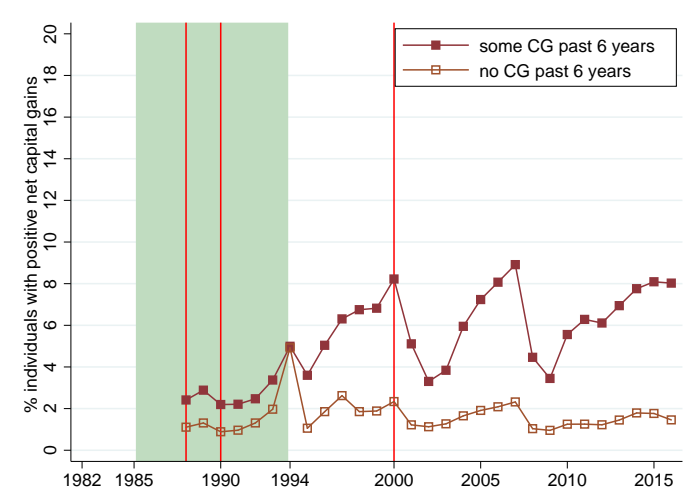

(b) Average Reported CG

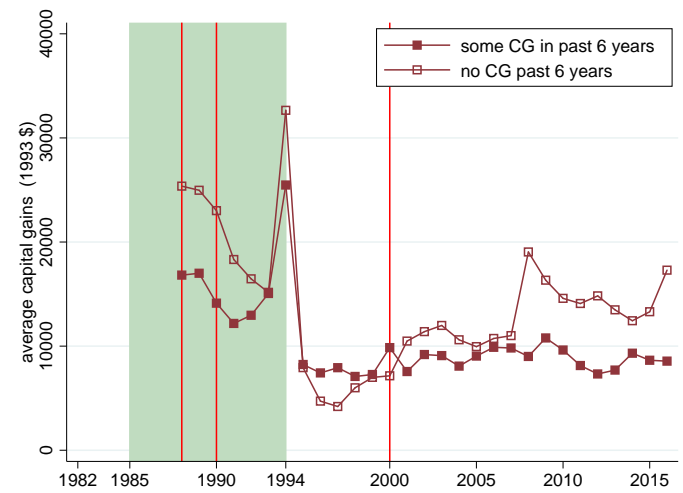

Notes: Figure 10(a) plots the likelihood of reporting positive capital gains income over time for two groups: tax filers that report no realizations in the past 6 years (open markers) and those that report some realizations in the past 6 years (dark markers). Figure 10(b) plots average realized capital gains income over time for the same two groups. The green shaded area marks the period of capital gains exemption, 1985-1994. The red vertical lines mark capital gains inclusion rate changes: increase from $50 \%$ to $66.6 \%$ and further to $75 \%$ in 1988 and 1990; and a decrease from $75 \%$ to $50 \%$ in 2000.

We also explore whether the 1994 re-timing response is driven by "frequent" or "infrequent" realizers. Our definition of frequent realizers is tax filers who report positive realized capital gains in any of the preceding 6 years (calculated on a rolling basis). Figure 10(a) plots the fraction of tax filers that report positive realized capital gains each year from 1982-2016, separately for frequent and infrequent realizers. ${ }^{29}$ While frequent realizers are more likely to realize capital gains in any given year, the re-timing response is larger for infrequent realizers. For infrequent realizers, the likelihood of reporting positive capital gains income increases from around 1 percent in the early 1990s to approximately 5 percent in 1994, an increase of 500 percent. To contrast, among frequent realizers, the likelihood of reporting positive capital gains income increases only by approximately 150 percent (from about 2 to 5 percentage points) over the same period.

28 We presents estimates for each treatment group separately in Appendix Figure E.8.

29 Figure D.3 in the Online Appendix presents similar figures for tax filers in different age groups using the same "frequent realizer" definition. 
Furthermore, Figure 10(a) shows that frequent realizers appear to be driving the increase in the participation in capital markets in the late 1990s and 2000s. We find similar patterns for average realized capital gains; on average, infrequent realizers experienced a larger change in realized capital gains in 1994 than frequent realizers (see Figure 10(b)).

A limitation of our tax return data is that it does not allow us to discern whether the differing 1994 re-timing responses between frequent and infrequent realizers is driven by differences in savings behavior, differences in the baseline asset allocations or differences in the frequency of adjusting their portfolios, conditional on asset allocation. The ability to crystalize gains by filling out form T664 in 1994 made it beneficial for all investors to report capital gains in 1994.

Finally, we also investigate whether the cancellation of the LCGE led to substitution away from capital gains income and towards other types of investment income, such as interest and dividend income or contributions to tax-deferred RRSPs. Appendix Figure G.2 presents the $\gamma_{\tau}$ estimates for these specifications. The results suggest that the cancellation of the LCGE had no statistically significant effect on dividend income receipt. The estimates for investment (interest) income are inconclusive as the pre-trends are stable for specifications with some treatment groups but not others. Given that we do not estimate statistically significant long-run effects of the cancellation of the LCGE for most treatment groups, it is not surprising that we do not detect economically meaningful effects on other dependent variables.

\section{Implied Elasticities and Interpretation of the Results}

In this section we convert our event study estimates into elasticities and discuss the results. To facilitate a comparison of our estimates with those in the literature, we report a number of different elasticity concepts.

Elasticity estimates. Some papers in the literature report estimates of the elasticity of realizations with respect to the marginal tax rate on capital gains

income. Let $e_{1}=\frac{\Delta \log (C G)}{\Delta \log \left(\tau_{C G}\right)}$ denote this elasticity. To calculate this elasticity, we need to divide our difference-in-differences $\gamma_{\tau}$ estimates by the corresponding 
percentage change in $\tau_{C G}$. However, the removal of the LCGE increased the effective marginal tax rate on capital gains income from a baseline of zero. As a result, $\Delta \log \left(\tau_{C G}\right)$ is not defined in our setting. To overcome this, we assume that the behavioral response to the removal of the LCGE is symmetric. In other words, we compute $e_{1}$ assuming that the response to the cancellation of the LCGE is equal to -1 times the response to a tax decrease from $\tau_{C G}$ to zero (i.e. $\left.\Delta \log \left(\tau_{C G}\right) \approx 1\right)$. The second elasticity concept we report is the percentage change in realized capital gains income in response to a one percent increase in the net-oftax rate: $e_{2}=\frac{\Delta \log (C G)}{\Delta \log \left(1-\tau_{C G}\right)}$. This concept is used in a recent study by Agersnap and Zidar (2020). The third elasticity concept we report is $e_{3}=\frac{\Delta \log (C G)}{\Delta \tau_{C G}}$. This semielasticity measures the percentage change in realized capital gains in response to a one percentage point increase in the effective marginal tax rate on capital gains income.

Table 2 reports elasticity estimates for all three concepts. We report elasticities for all three treatment groups for the total (unconditional) response to the cancellation of the LCGE, as well as the intensive and extensive margin responses. The numerators for the total unconditional (resp. intensive margin) elasticities use the $\gamma_{\tau}$ estimates from Figure 5 (resp. Figure 7). The numerators for the extensive margin elasticities are the $\gamma_{\tau}$ estimates from Figure 6 and the baseline participation rates in 1993: $\Delta \%$ Positive_C $G_{\tau}=\gamma_{\tau} /$ Positive_C $_{-}$1993. Standard errors for each elasticity are calculated using the delta method.

Table 2 reports elasticity estimates for all three treatment groups and for three horizons: the short-run, the medium-run and the long-run. Our short-run elasticity estimate is based on the 1994 (re-timing) response to the cancellation of the LCGE. The medium-run (resp. long-run) elasticity estimate measures the percentage change in 1997 (resp. 1999) realizations (i.e. 3 and 5 years after the cancellation of the LCGE, respectively). Note that the $e_{2}$ elasticity concept will be of a different sign than the $e_{1}$ and $e_{3}$ concepts. This is because the former measures the percentage change in realizations with respect to a one percent increase in the net-of-tax rate $1-\tau_{C G}$, while the latter measure how realizations change when the marginal tax rate increases. For brevity, the discussion below will focus on the $e_{2}$ elasticity concept.

Our short-run elasticity estimates for all three treatment groups are large in 
Table 2: Summary of Elasticity Estimates

\begin{tabular}{|c|c|c|c|c|c|c|c|c|c|c|}
\hline & \multirow{3}{*}{$\begin{array}{c}\text { Average MTR } \\
\text { in } 1995 \\
\end{array}$} & (1) & $(2)$ & $(3)$ & (4) & $(5)$ & $(6)$ & $(7)$ & $(8)$ & (9) \\
\hline & & \multicolumn{3}{|c|}{ Total Response } & \multicolumn{3}{|c|}{ Intensive Margin } & \multicolumn{3}{|c|}{ Extensive Margin } \\
\hline & & $e_{1}$ & $e_{2}$ & $e_{3}$ & $e_{1}$ & $e_{2}$ & $e_{3}$ & $e_{1}$ & $e_{2}$ & $e_{3}$ \\
\hline \multicolumn{11}{|c|}{ Short-run - 1994: } \\
\hline \multirow[t]{2}{*}{$67 \mathrm{~K}-100 \mathrm{~K}$} & $36 \%$ & -0.89 & 2.85 & -3.32 & -0.29 & 0.93 & -1.08 & -0.19 & 0.61 & -0.71 \\
\hline & & $(0.06)$ & $(0.19)$ & $(0.22)$ & $(0.04)$ & $(0.13)$ & $(0.15)$ & $(0.02)$ & $(0.06)$ & $(0.07)$ \\
\hline \multirow[t]{2}{*}{$33 \mathrm{~K}-67 \mathrm{~K}$} & $35 \%$ & -1.06 & 3.48 & -4.04 & -0.4 & 1.31 & -1.53 & -0.25 & 0.82 & -0.95 \\
\hline & & $(0.05)$ & $(0.16)$ & $(0.19)$ & $(0.04)$ & $(0.13)$ & $(0.15)$ & $(0.02)$ & $(0.07)$ & $(0.08)$ \\
\hline \multirow[t]{2}{*}{$17 \mathrm{~K}-33 \mathrm{~K}$} & $35 \%$ & -1.09 & 3.61 & -4.18 & -1.26 & 4.17 & -4.83 & -0.25 & 0.83 & -0.96 \\
\hline & & $(0.05)$ & $(0.17)$ & $(0.19)$ & $(0.04)$ & $(0.13)$ & $(0.15)$ & $(0.02)$ & $(0.07)$ & $(0.08)$ \\
\hline \multicolumn{11}{|c|}{ Medium-run - 1997: } \\
\hline \multirow[t]{2}{*}{$67 \mathrm{~K}-100 \mathrm{~K}$} & $36 \%$ & -0.03 & 0.1 & -0.11 & -0.02 & 0.06 & -0.07 & -0.02 & 0.06 & -0.07 \\
\hline & & $(0.06)$ & $(0.19)$ & $(0.22)$ & $(0.05)$ & $(0.16)$ & $(0.19)$ & $(0.02)$ & $(0.06)$ & $(0.07)$ \\
\hline \multirow[t]{2}{*}{$33 \mathrm{~K}-67 \mathrm{~K}$} & $35 \%$ & 0.06 & -0.2 & 0.23 & -0.07 & 0.23 & -0.27 & 0 & 0 & 0 \\
\hline & & $(0.05)$ & $(0.16)$ & $(0.19)$ & $(0.04)$ & $(0.13)$ & $(0.15)$ & $(0.02)$ & $(0.07)$ & $(0.08)$ \\
\hline \multirow[t]{2}{*}{$17 \mathrm{~K}-33 \mathrm{~K}$} & $35 \%$ & 0.2 & -0.66 & 0.77 & 0.38 & -1.26 & 1.46 & 0.03 & -0.1 & 0.11 \\
\hline & & $(0.05)$ & $(0.17)$ & $(0.19)$ & $(0.04)$ & $(0.13)$ & $(0.15)$ & $(0.02)$ & $(0.07)$ & $(0.08)$ \\
\hline \multicolumn{11}{|c|}{ Long-run - 1999: } \\
\hline \multirow[t]{2}{*}{$67 \mathrm{~K}-100 \mathrm{~K}$} & $36 \%$ & 0.05 & -0.16 & 0.19 & -0.08 & 0.26 & -0.3 & 0.01 & -0.03 & 0.04 \\
\hline & & $(0.06)$ & $(0.19)$ & $(0.22)$ & $(0.05)$ & $(0.16)$ & $(0.19)$ & $(0.02)$ & $(0.06)$ & $(0.07)$ \\
\hline \multirow[t]{2}{*}{$33 \mathrm{~K}-67 \mathrm{~K}$} & $35 \%$ & 0.22 & -0.72 & 0.84 & -0.08 & 0.26 & -0.31 & -0.18 & 0.59 & -0.69 \\
\hline & & $(0.05)$ & $(0.16)$ & $(0.19)$ & $(0.05)$ & $(0.16)$ & $(0.19)$ & $(0.02)$ & $(0.07)$ & $(0.08)$ \\
\hline \multirow[t]{2}{*}{$17 \mathrm{~K}-33 \mathrm{~K}$} & $35 \%$ & 0.34 & -1.12 & 1.3 & 0.4 & -1.32 & 1.53 & 0.06 & -0.2 & 0.23 \\
\hline & & $(0.05)$ & $(0.17)$ & $(0.19)$ & $(0.05)$ & $(0.17)$ & $(0.19)$ & $(0.02)$ & $(0.07)$ & $(0.08)$ \\
\hline
\end{tabular}

Notes: This table calculates elasticities of capital gains with respect to the marginal effective tax rate on capital income using three different concepts: $e_{1}=\Delta \log (C G), e_{2}=$ $\frac{\Delta \log (C G)}{\Delta \log \left(1-\tau_{C G}\right)}$, and $e_{3}=\frac{\Delta \log (C G)}{\Delta \tau_{C G}}$. The total (unconditional) and intensive margin elasticities are based on the $\Delta \log (C G)=\gamma_{\tau}$ estimates in Figures 5 and 7 . Extensive margin elasticities are calculating using the same formula but with $\Delta \%$ Positive_CG $=$

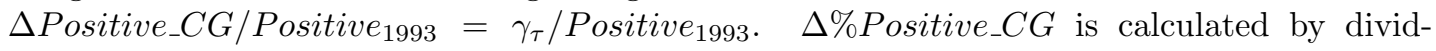
ing the $\triangle$ Positive_CG $=\gamma_{\tau}$ estimates in Figure 6 by 1993 average of Positive_CG $(0.36$, 0.31 and 0.30 respectively). Standard errors are calculated using the delta method. 
magnitude. For the total response to the cancellation of the LCGE, our short-run elasticity estimates range from 2.8 to 3.6. Tax filers with low 1985-1993 realizations (i.e. those with $\operatorname{Proxy}_{i} \in[16,667,33,334)$ ) are more elastic than filers with high pre-reform realizations. As discussed in Section 4.2, the total response to the cancellation of the LCGE is driven by responses on the intensive and extensive margins, although the former is larger in magnitude for all treatment groups. Interestingly, the short-run elasticities we estimate in Table 2 are similar to the short-run (i.e. 0-2 year) elasticity estimates for the United States in Agersnap and Zidar (2020). In a recent review, Stantcheva (2020) notes that prior work finds that the $e_{1}$ elasticity ranges from -6.4 to -1.1 . Our short-run elasticities for this elasticity concept range from -1.09 to -0.89 (see column 1).

Our medium-run (resp. long-run) $e_{2}$ estimates range from -0.66 to 0.1 (resp. -1.12 to -0.16). As noted earlier, elasticity estimates are more negative for tax filers with low values of Proxy P $_{i}$ and closer to zero for tax filers with relatively high 1985-1993 realizations. Using the $e_{1}$ concept, our medium-run (resp. long-run) estimates range from -0.03 to 0.2 (resp. 0.05 to 0.34 ). These estimates are closer to the high end of the -1.7 to 0 range cited in Stantcheva (2020).

Interpretation of the results. Our negative estimates of the $e_{2}$ longrun elasticity of capital gains realizations with respect to the net-of-tax rate is consistent with the wealth affect arising from the elimination of the LCGE being relatively important. In Appendix C, we consider three simple models, each of which focuses on one decision margin that drives realized capital gains income. Comparative statics from all three models indicate that that capital gains realizations may increase or decrease following a marginal tax rate increase due to offsetting substitution and income/wealth effects.

The first model is used to predict the response along the savings margin. In this model, an increase in capital gains tax rate reduces savings via a substitution effect but increases savings via an income/wealth effect. Briefly, higher marginal tax rates cause lifetime wealth to fall by an amount proportional to counterfactual unrealized capital gains. This decrease in lifetime wealth may lead to increased levels of savings and, ultimately, higher future capital gains.

The second model focuses on spenders - individuals with large portfolios who are in the process of consuming their wealth. For these individuals, an increase 
in capital gains tax makes future consumption more expensive. The substitution effect then shifts consumption into the current period, thus implying lower capital gains realizations in the future. On the other hand, the income/wealth effect motivates agents to decrease current consumption in order to smooth consumption in the future. In this model, consumption smoothing is achieved via lowering capital gains in the current period and increasing capital gains income in the future. Once again, capital gains realizations may increase or decrease depending on the relative magnitudes of the income and substitution effects.

Finally, the third model focuses on portfolio asset allocation decisions. In this model, capital gains realizations depend on the fraction of an agent's portfolio that is allocated to equities versus fixed income assets (that pay interest income). Assuming that fixed income assets are not taxed (i.e. bonds are always held until maturity), higher capital gains taxes imply lower rewards to holding equities. Holding wealth constant, this leads to less equity holding and fewer capital gains realizations. At the same time, lower after-tax returns make it harder for individuals to achieve any desired level of consumption, necessitating an increase in equity holding higher capital gains realizations.

Although we don't observe the portfolios of tax filers and cannot isolate the mechanism driving the positive response to the removal of the LCGE, the models presented in Appendix C provide a theoretical foundation for our empirical results.

\section{Conclusion}

In this paper, we present estimates of the causal effect of the 1994 cancellation of the $\$ 100,000$ LCGE in Canada on realized capital gains and other types of capital income. Comparing tax filers who did not exhaust their LCGE limit to those that did, before and after the 1994 reform, we find that the unexpected cancellation of the exemption led to an immediate spike in realized capital gains in 1994 as tax filers exhausted their remaining LCGE space. We also find that the cancellation of the LCGE increased realized capital gains in the medium and long-run for tax filers with small pre-reform capital gains. In contrast, we estimate that the elimination of the LCGE had no statistically significant effect 
on the realization behavior of tax filers with larger pre-1994 capital gains. Our results are similar, qualitatively and quantitatively, when we restrict the sample to young, middle-age and older tax filers, respectively. Moreover, our estimates are similar for married and single tax filers.

Taken together, our results suggest that despite increasing the marginal effective tax rate on capital gains income for most tax filers, the elimination of the LCGE had little effect on capital gains realizations in the long run. We also find little evidence of substitution away from capital gains and towards other types of investment income, such as interest income and dividends.

One interpretation of our results is that the unexpected cancellation of the LCGE led to a large, negative wealth shock that offset the incentive for tax filers to substitute away from capital gains income. This wealth shock was largest for those with the most unused exemption space (i.e. those with modest pre-reform capital gains) and it is precisely this group that experienced the largest increase in realizations in the post-1994 period. While this explanation can reconcile our results, we remain cautious because it is possible that individuals with different pre-reform capital gains may have different underlying structural parameters (risk aversion, discount factors etc.) and it is these differences that are driving the heterogeneity in our estimates.

\section{References}

Agersnap, O. And O. M. Zidar (2020): "The Tax Elasticity of Capital Gains and Revenue-Maximizing Rates," Working Paper 27705, National Bureau of Economic Research.

Alan, S., K. Atalay, T. F. Crossley, And S.-H. Jeon (2010): "New evidence on taxes and portfolio choice," Journal of Public Economics, 94, 813823.

Auerbach, A. J. And J. Poterba (1988): "Capital Gains Taxation in the United States: Realizations, Revenue, and Rhetoric," Brookings Papers on Economic Activity, 1988, 595-637.

Auerbach, A. J. And J. M. Siegel (2000): "Capital-gains realizations of the rich and sophisticated," American Economic Review, 90, 276-282. 
Auten, G., L. E. Burman, and W. C. Randolph (1989): "Estimation and Interpretation of Capital Gains Realization Behavior: Evidence from Panel Data," National Tax Journal, 42, 353-374, number: 3 Reporter: National Tax Journal Publisher: National Tax Association.

Auten, G. E. And C. T. Clotfelter (1982): "Permanent versus Transitory Tax Effects and the Realization of Capital Gains," The Quarterly Journal of Economics, 97, 613-632.

BakiJa, J. And W. M. Gentry (2014): "Capital Gains Taxes and Realizations: Evidence from a Long Panel of State-Level Data," Mimeo.

Bernheim, B. D. (2002): "Taxation and Saving," in Handbook of Public Economics, ed. by A. J. Auerbach and M. Feldstein, Elsevier, vol. 3, 1173-1249.

Bogart, W. T. And W. M. Gentry (1995): "Capital Gains Taxes and Realizations: Evidence from Interstate Comparisons," The Review of Economics and Statistics, 77, 267-282, number: 2 Reporter: The Review of Economics and Statistics Publisher: The MIT Press.

Buhlmann, F., P. Doerrenberg, B. Loos, And J. Voget (2020): "How do taxes affect the trading behavior of private investors? Evidence from individual portfolio data," Mimeo.

Burman, L. E. And W. C. Randolph (1994): "Measuring Permanent Responses to Capital-Gains Tax Changes in Panel Data," The American Economic Review, 84, 794-809.

Chetty, R., J. N. Friedman, S. Leth-Petersen, T. H. Nielsen, and T. Olsen (2014): "Active vs. Passive Decisions and Crowd-Out in Retirement Savings Accounts: Evidence from Denmark," The Quarterly Journal of Economics, 129, 1141-1219, publisher: Oxford Academic.

Dowd, T. And R. MCClelland (2019): "The Bunching of Capital Gains Realizations," National Tax Journal, 72, 323-358, publisher: National Tax Association \& National Tax Journal.

Dowd, T., R. McClelland, and A. Muthitacharoen (2015): "New Evidence on the Tax Elasticity of Capital Gains," National Tax Journal, 68, 511-544, number: 3 Reporter: National Tax Journal.

Feldstein, M., J. Slemrod, And S. Yitzhaki (1980): "The Effects of Tax- 
ation on the Selling of Corporate Stock and the Realization of Capital Gains," The Quarterly Journal of Economics, 94, 777-791.

Gillingham, R. And J. S. Greenless (1992): "The Effect of Marginal Tax Rates on Capital Gains Revenue: Another Look at the Evidence," National Tax Journal, 45, 167-177, number: 2 Reporter: National Tax Journal Publisher: National Tax Association.

Gravelle, J. G. (2020): "Capital Gains Tax Options: Behavioral Responses and Revenues," CRS Report E41364, Congressional Research Service (CRS).

Landsman, W. R., D. A. Shackelford, and R. J. Yetman (2002): "The Determinants of Capital Gains Tax Compliance: Evidence from the RJR Nabisco Leveraged Buyout," Journal of Public Economics, 84, 47-74, number: 1 Reporter: Journal of Public Economics.

Lindsey, L. B. (1987): "Capital gains rates, realizations, and revenues," in The effects of taxation on capital accumulation, University of Chicago Press, 69-100, reporter: The effects of taxation on capital accumulation.

Manoli, D. And A. Weber (2016): "Nonparametric Evidence on the Effects of Financial Incentives on Retirement Decisions," American Economic Journal: Economic Policy, 8, 160-182.

Messacar, D. (2018): "Crowd-Out, Education, and Employer Contributions to Workplace Pensions: Evidence from Canadian Tax Records," The Review of Economics and Statistics, 100, 648-663.

Minarik, J. J. (1981): "Capital gains," How taxes affect economic behavior, 255-65, reporter: How taxes affect economic behavior Publisher: Brookings Institution Washington, DC.

Mintz, J. And S. R. Richardson (1995): "The Canadian Experience of the Lifetime Capital Gains Exemption," Canadian Public Policy, Special Supplement, 21.

PoterbA, J. M. (1987): "Tax Evasion and Capital Gains Taxation," The American Economic Review, 77, 234-239, number: 2 Reporter: The American Economic Review Publisher: American Economic Association.

Richardson, S. R. And K. E. Moore (1995): "Canadian Experience with the Taxation of Capital Gains," Canadian Public Policy / Analyse de Politiques, 21, S77-S99, reporter: Canadian Public Policy / Analyse de Politiques. 
Saez, E. AND S. Stancheva (2018): "A simpler theory of optimal capital taxation," Journal of Public Economics, 162, 120-142.

Slemrod, J. AND W. Shobe (1990): "The Tax Elasticity of Capital Gains Realizations: Evidence from a Panel of Taxpayers," NBER Working Paper 3237.

Stantcheva, S. (2020): "Dynamic Taxation," Annual Review of Economics, 12. 


\section{APPENDIX FOR ONLINE PUBLICATION}

\section{A Tax Rules and Tax Rates}

Table A.1: Summary of Tax Rules and Rates

\begin{tabular}{|c|c|c|c|c|c|c|c|c|}
\hline \multirow[b]{3}{*}{ Year } & \multicolumn{3}{|c|}{ Capital Gains: } & \multicolumn{5}{|c|}{ Income Tax: } \\
\hline & \multirow[b]{2}{*}{$\begin{array}{c}\text { Inclusion } \\
\text { Rate }\end{array}$} & \multicolumn{2}{|c|}{ Lifetime Exemptions: } & \multicolumn{3}{|c|}{ Federal Top MTR: } & \multicolumn{2}{|c|}{ Provincial Top MTRs } \\
\hline & & General & $\begin{array}{c}\text { Small } \\
\text { Business }\end{array}$ & $\begin{array}{l}\text { \# of Tax } \\
\text { Brackets }\end{array}$ & $\begin{array}{c}\text { Top MTR } \\
\text { Cutoff }\end{array}$ & $\begin{array}{l}\text { Top } \\
\text { MTR }\end{array}$ & Range & Median \\
\hline 2002 & 0.5 & 0 & 500,000 & 4 & 103,000 & 29 & $10-30$ & 17 \\
\hline 2003 & 0.5 & 0 & 500,000 & 4 & 104,648 & 29 & $10-30$ & 17 \\
\hline 2004 & 0.5 & 0 & 500,000 & 4 & 113,804 & 29 & $10-30$ & 17 \\
\hline 2005 & 0.5 & 0 & 500,000 & 4 & 115,739 & 29 & $10-30$ & 17 \\
\hline 2006 & 0.5 & 0 & 500,000 & 4 & 118,285 & 29 & $10-30$ & 17 \\
\hline 2007 & 0.5 & 0 & 750,000 & 4 & 120,887 & 29 & $10-28$ & 17 \\
\hline 2008 & 0.5 & 0 & 750,000 & 4 & 123,184 & 29 & $10-26$ & 17 \\
\hline 2009 & 0.5 & 0 & 750,000 & 4 & 126,264 & 29 & $10-26$ & 17 \\
\hline 2010 & 0.5 & 0 & 750,000 & 4 & 127,021 & 29 & $10-25$ & 16 \\
\hline 2011 & 0.5 & 0 & 750,000 & 4 & 128,800 & 29 & $10-25$ & 15 \\
\hline 2012 & 0.5 & 0 & 750,000 & 4 & 132,406 & 29 & $10-25$ & 15 \\
\hline 2013 & 0.5 & 0 & 750,000 & 4 & 135,054 & 29 & $10-27$ & 16 \\
\hline 2014 & 0.5 & 0 & 800,000 & 4 & 136,270 & 29 & $10-25$ & 17 \\
\hline 2015 & 0.5 & 0 & $1,000,000$ & 4 & 138,586 & 29 & $10-25$ & 17 \\
\hline
\end{tabular}

Notes: This table summarizes the tax rules for capital gains income and the federal and provincial top income tax rates and bracket cutoff for the years 2002-2016. 
Table A.2: Dividend Tax Rules and RRSP Rules

\begin{tabular}{ccccccc}
\hline \hline & \multicolumn{2}{c}{ Dividend Taxes: } & & \multicolumn{2}{c}{ RRSP: } \\
\cline { 2 - 3 } \cline { 5 - 6 } Year & Gross Up & Tax Credit & & Maximum Contribution: \\
\cline { 5 - 6 } \cline { 5 - 6 } 1982 & Factor & Rate & & Amount & Rate \\
1983 & 0.5 & 0.227 & & 5,500 & 0.2 \\
1984 & 0.5 & 0.227 & & 5,500 & 0.2 \\
1985 & 0.5 & 0.227 & & 5,500 & 0.2 \\
1986 & 0.5 & 0.227 & & 5,500 & 0.2 \\
1987 & 0.333 & 0.227 & & 7,500 & 0.2 \\
1988 & 0.25 & 0.167 & & 7,500 & 0.2 \\
1989 & 0.25 & 0.133 & & 7,500 & 0.2 \\
1990 & 0.25 & 0.133 & & 7,500 & 0.2 \\
1991 & 0.25 & 0.133 & & 11,500 & 0.2 \\
1992 & 0.25 & 0.133 & & 12,500 & 0.18 \\
1993 & 0.25 & 0.133 & & 12,500 & 0.18 \\
1994 & 0.25 & 0.133 & & 13,500 & 0.18 \\
1995 & 0.25 & 0.133 & & 14,500 & 0.18 \\
1996 & 0.25 & 0.133 & & 13,500 & 0.18 \\
1997 & 0.25 & 0.133 & & 13,500 & 0.18 \\
1998 & 0.25 & 0.133 & & 13,500 & 0.18 \\
1999 & 0.25 & 0.133 & & 13,500 & 0.18 \\
2000 & 0.25 & 0.133 & & 13,500 & 0.18 \\
2001 & 0.25 & 0.133 & & 13,500 & 0.18 \\
\hline \hline
\end{tabular}

Notes: This table lists the dividend gross-up factor, the dividend tax credit rates and the maximum annual contribution limit for Registered Retirement Savings Plans (RRSP) for the years 1982-2001. 


\section{B Changes in the Fraction of Individuals Filing a Tax Return}

Section 2 of the main paper describes the Longitudinal Administrative Databank (LAD) that we use. The LAD is a panel dataset of tax returns for a random 20 percent sample of Canadian tax filers. Each year, a randomly selected 20 percent of new Canadian tax filers are selected into the LAD. Once selected, tax filers are followed until they cease to file a tax return (i.e. upon death or emigration from Canada). Thus, the size of the LAD sample grows proportionately with the Canadian population and the fraction of residents that file a tax return.

The introduction of two refundable tax credits in the late 1980s increased the fraction of Canadian residents that file a tax return each year and, therefore, the size of the LAD sample. We argue that the increase in the number of tax filers is unlikely to have a large effect on our estimates. The Federal Sales Tax (FST) Credit (introduced in 1986) and the Goods and Services Tax (GST) Credit (introduced in 1989) reduce the net tax liabilities of low-income tax filers and help to dampen the regressivity of the federal value-added tax in Canada (formerly the FST, now the GST). Receipt of these tax credits is only available to low-income earners that file a tax return. Figure B.1 shows that the number of tax filers in the LAD increased sharply following the introduction of the tax credits in 1986 and 1989. Notably, the increase in the number of tax filers in these years was immediate and the growth in the LAD sample was stable after 1990. Since our baseline estimates are based on an event window from 1990-1999, it is unlikely that the increase in the fraction of Canadian residents filing a tax return in the 1980s will affect our results. Furthermore, the increase in the likelihood of filing

a tax return was concentrated among those with low-incomes and not moderate and high income earners who claim a large fraction of capital gains income. 
Figure B.1: Changes in the Number of Tax Filers in the LAD (1982-2016)

(a) Total Number of Tax Filers

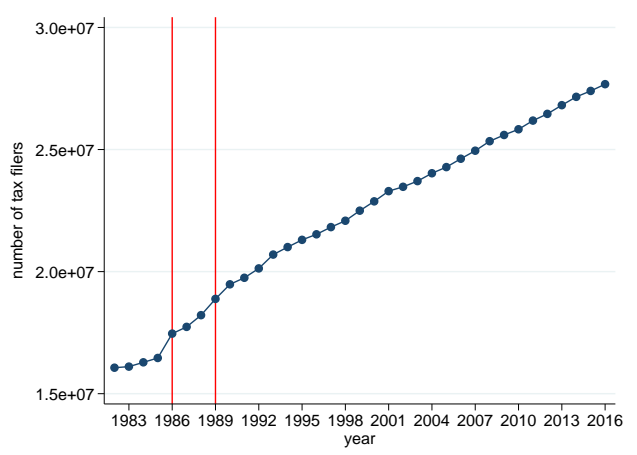

(b) Change in the Number of Filers

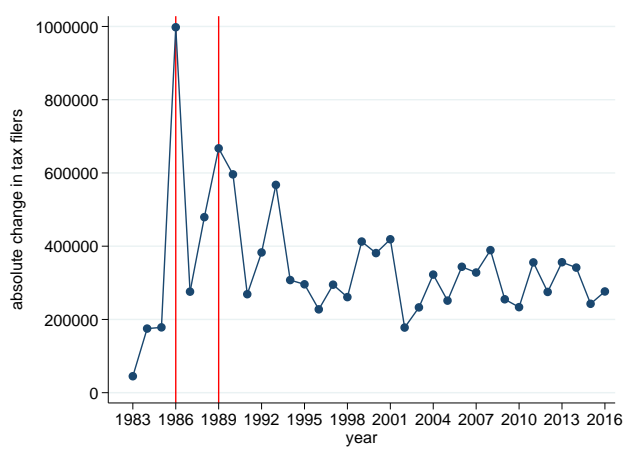

(c) Percentage Change in the Number of Tax Filers

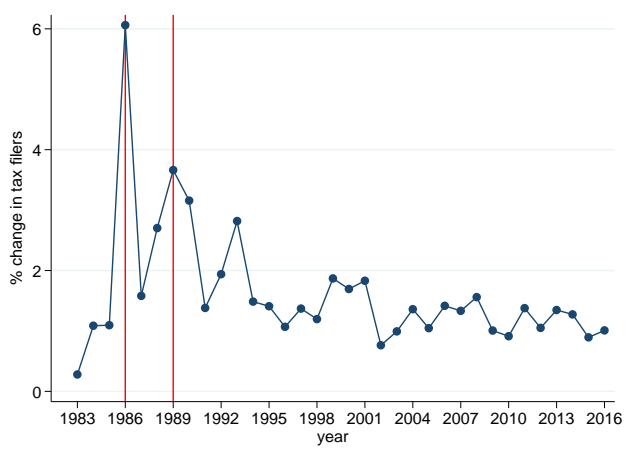

Notes: Figure B.1(a) plots the total number of tax filers in the LAD over the 19822016 period. Figure B.1(b) plots the (absolute) change in the number of tax filers in the LAD from one year to the next for the 1983-2016 period. The change in the number of tax filers for 1983 represents the difference between the number of tax filers in 1983 compared to 1982. Figure B.1(c) plots the percentage change in the number of tax filers in the LAD from one year to the next over the 1983-2016 period. 


\section{Theoretical Model}

In this Appendix, we set out three theoretical models that help us interpret our empirical results. The intuition for developing three different models stems from the desire to isolate the three economic choices that determine an individual's realized capital gains in any given year. Generally speaking, the capital gains realizations of an individual in year $t$ depend on (i) their past savings choices (i.e. their past decisions to defer income/consumption to the future; (ii) their choice about when to realize capital gains income on their existing assets; and (iii) their past portfolio asset allocation decisions. Changes to capital gains taxes may affect the choices of individuals along all three of these margins.

In order to isolate the impact of capital gains taxes on each of these margins, we develop three models, each of which focuses on one margin. Below, we show that capital gains taxes have a theoretically ambiguous effect on all three margins (savings, asset draw down and portfolio asset allocation). We discuss how offsetting substitution and income/wealth effects lead to this result. Two of the most important parameters governing the income/wealth effects in our models are risk aversion/diminishing marginal utility and the agent's initial asset level.

While our models are (very) stylized, they provide a useful lens through which to interpret our empirical results. Admittedly, more complicated (and possibly realistic) models that incorporate dynamics and interactions between the three aforementioned choices might add more nuance to the theoretical results below. However, we argue that the stylized models presented below provide a simple and intuitive way of illustrating the economic forces at work following a change in capital gains tax rates.

\section{C.1 Capital Gains Realizations of Individuals ("Savers")}

Consider a simple 2-period model. In each period an individual earns exogenous labor income $y_{t}$; furthermore, in period 1 , the individual is endowed with exogenous assets $A_{1}$. These assets, together with any savings that the individual chooses to undertake, grow at the exogenous real return rate $r$ and are subject to capital gains tax $\tau .{ }^{30}$ For simplicity, we assume no discounting. The individ-

\footnotetext{
${ }^{30}$ For ease of exposition, we assume that labor income is not taxable.
} 
ual chooses how much to consume each period in order to maximize her lifetime utility:

$$
\begin{aligned}
\max _{c_{1}, c_{2}} U\left(c_{1}, c_{2}\right) & =u\left(c_{1}\right)+u\left(c_{2}\right) \\
& =u\left(y_{1}-s_{1}\right)+u\left(y_{2}+\left(A_{1}+s_{1}\right)(1+r(1-\tau))\right) .
\end{aligned}
$$

With exogenous labor income, the individual's problem simplifies to choosing their optimal level savings $s_{1}$. The first order conditions with respect to $s_{1}$ is:

$$
\frac{d U}{d s_{1}}=-u^{\prime}\left(c_{1}\right)+u^{\prime}\left(c_{2}\right)(1+r(1-\tau))=0 .
$$

With a two-period model, we assume that the agent sells all of their assets and realizes all of their capital gains in period 2. Realized capital gains are equal to the agent's total asset position (initial assets plus period 1 savings) multiplied by the exogenous return rate: $C G_{2}=\left(A_{1}+s_{1}\right) r$. Thus, in this model realized capital gains in period 2 are determined by the agents initial assets and their period 1 savings decision. However, only the latter is under the agent's control so the effect of a change in the capital gains rate $\tau$ is proportional to the effect of the tax on period 1 savings: $\frac{d C G_{2}}{d \tau}=r \frac{d s_{1}}{d \tau}$. In order to determine the sign of $d s_{1} / d \tau$, we differentiate (3) with respect to $\tau$, which yields:

$u^{\prime \prime}\left(c_{1}\right) \frac{d s_{1}}{d \tau}+u^{\prime \prime}\left(c_{2}\right)\left[\frac{d s_{1}}{d \tau}(1+r(1-\tau))+\left(A_{1}+s_{1}\right)(-r)\right](1+r(1-\tau))+u^{\prime}\left(c_{2}\right)(-r)=0$

Rearranging, we find

$$
\frac{d s_{1}}{d \tau}=\frac{u^{\prime}\left(c_{2}\right) r+u^{\prime \prime}\left(c_{2}\right)\left(A_{1}+s_{1}\right) r(1+r(1-\tau))}{u^{\prime \prime}\left(c_{1}\right)+u^{\prime \prime}\left(c_{2}\right)(1+r(1-\tau))^{2}}
$$

Assuming that the individual experiences diminishing marginal utility of consumption, the denominator of (4) is negative. The sign of the numerator is theoretically ambiguous and depends on the relative magnitudes of the substitution effect (SE), captured by $u^{\prime}\left(c_{2}\right) r$, and an income/wealth effect (IE), $u^{\prime \prime}\left(c_{2}\right)\left(A_{1}+s_{1}\right) r(1+r(1-\tau))$. Notably, the latter term is larger in absolute value when realized capital gains (i.e $\left(A_{1}+s_{1}\right) r$ ) are larger and when agents are 
more risk averse.

The ambiguous response of savings to capital gains taxation implies that capital gain realizations may increase or decrease in response to a capital gain tax increase. If the substitution effect dominates, individuals will save less and will report less capital gains in the future. On the other hand, if the income/wealth effect dominates, individuals will save more in order to offset the negative effect of taxes on their lifetime wealth. This will lead to higher future capital gains realizations.

\section{C.2 Capital Gains Realizations of Retirees ("Spenders")}

In the previous model, we explicitly interpreted $s_{1}$ as flow savings (i.e income deferred for future consumption). Positive savings are likely to be optimal for individuals with relatively large labor income $y_{1}$ and relatively small assets $A_{1}$ and/or relatively small future labor earnings $y_{2}$. In that case, the amount of observed capital gains realizations depends on the period 1 savings decisions of the individual.

However, for individuals with large assets $A_{1}$, optimal "savings" $s_{1}$ are likely to be negative. In other words, instead of saving, these individuals will choose to actively draw down their wealth. Even if the agent optimally chooses to draw down their wealth (i.e negative $s_{1}$ ), the theoretically ambiguous sign of $d s_{1} / d \tau$ from subsection C.1 will still hold. A small increase to the capital gains tax rate $\tau$ may increase or decrease asset draw down (i.e. increase or decrease $s_{1}$. In this case, capital gains realizations will be driven by the agent's draw down and spending decisions. On one hand, an increase in $\tau$ makes second period consumption expensive which will incentive the agent to shift consumption to period 1 and lower period 2 capital gains realizations. On the other hand, the higher capital gains tax will decrease the agent's lifetime wealth. All else equal, the wealth effect will induce the agent to increase $s_{1}$, decrease the draw down of assets, increase period 2 capital gains realizations and increase period 2 consumption. Whether

$s_{1}$ (i.e. asset draw down) will increase or decrease will depend on which of these effects dominates. 


\section{C.3 Capital Gains Realizations of Portfolio Optimizers}

The third channel that affects capital gains realizations is an agent's portfolio asset allocation choices. Consider an individual who is endowed with some exogenous starting wealth $A_{0}$ and chooses how to allocate her portfolio across two assets: a risk-less bond with return $r^{b}$ and a risky equity with stochastic returns $r^{L}$ and $r^{H}$ such that $(1-\tau) r^{L}<r^{b}<(1-\tau) r^{H}$. In other words, we assume that the risky returns are subject to capital gains $\operatorname{tax} \tau$ while risk-less fixed income returns are tax-free. Finally, we assume that the high-state occurs with probability $p \in(0,1)$. The individual decides which share of her portfolio $\alpha \in[0,1]$ should be allocated to the risky asset by maximizing her expected utility ${ }^{31}$ :

$$
\begin{aligned}
\max _{\alpha} E[U(c)]=p u\left[c^{H}\right] & +(1-p) u\left[c^{L}\right] \\
=p u\left[A_{0} \alpha\left(1+r^{H}(1-\tau)\right)+A_{0}(1-\alpha)\left(1+r^{b}\right)\right] & \\
& +(1-p) u\left[A_{0} \alpha\left(1+r^{L}(1-\tau)\right)+A_{0}(1-\alpha)\left(1+r^{b}\right)\right] .
\end{aligned}
$$

The first order condition for $\alpha$ is:

$$
\frac{\partial U}{\partial \alpha}=p u^{\prime}\left(c^{H}\right)\left[A_{0}\left(r^{H}(1-\tau)-r^{b}\right)\right]+(1-p) u^{\prime}\left(c^{L}\right)\left[A_{0}\left(r^{L}(1-\tau)-r^{b}\right)\right]=0 .
$$

The individual's choice of $\alpha$ determines their capital gains realizations in the high and low state: $C G^{i}=\alpha A_{0} r^{i}, i \in\{L, H\}$. Thus, the impact of capital gains taxes on realizations depends on whether it increases or decreases the fraction of the agent's portfolio allocated to equities: $\frac{d C G^{i}}{d \tau}=A_{0} r \frac{d \alpha}{d \tau}$. Differentiating the first corder condition (5) with respect to $\tau$ gives

$$
\begin{aligned}
& p u^{\prime \prime}\left(c^{H}\right) A_{0}^{2}\left(r^{H}(1-\tau)-r^{b}\right)^{2} \cdot \frac{\partial \alpha}{\partial \tau}-p u^{\prime \prime}\left(c^{H}\right) A_{0}^{2}\left(r^{H}(1-\tau)-r^{b}\right) \alpha r^{H}-p u^{\prime}\left(c^{H}\right) A_{0} r^{H} \\
+ & (1-p) u^{\prime \prime}\left(c^{L}\right) A_{0}^{2}\left(r^{L}(1-\tau)-r^{b}\right)^{2} \cdot \frac{\partial \alpha}{\partial \tau}-(1-p) u^{\prime \prime}\left(c^{L}\right) A_{0}^{2}\left(r^{L}(1-\tau)-r^{b}\right) \alpha r^{L}-(1-p) u^{\prime}\left(c^{L}\right) A_{0} r^{L}=0
\end{aligned}
$$

\footnotetext{
${ }^{31}$ Assuming that the after-tax real return to equities in the low state, $r^{L}(1-\tau)$, is less than the risk-free return to bonds, $r^{b}$, ensures an interior solution for $\alpha$.
} 
Rearranging,

$\frac{\partial \alpha}{\partial \tau}=\frac{p r^{H}\left[u^{\prime \prime}\left(c^{H}\right) \alpha A_{0}\left(r^{H}(1-\tau)-r^{b}\right)+u^{\prime}\left(c^{H}\right)\right]+(1-p) r^{L}\left[u^{\prime \prime}\left(c^{L}\right) \alpha A_{0}\left(r^{L}(1-\tau)-r^{b}\right)+u^{\prime}\left(c^{L}\right)\right]}{p u^{\prime \prime}\left(c^{H}\right) A_{0}\left(r^{H}(1-\tau)-r^{b}\right)^{2}+(1-p) u^{\prime \prime}\left(c^{L}\right) A_{0}\left(r^{L}(1-\tau)-r^{b}\right)^{2}}$.

Note that $r^{H}(1-\tau)-r^{b}>0$ since otherwise individuals would never invest in risky assets. Assuming that the utility function $u(c)$ is strictly concave, $u^{\prime}(c)>0$ and $u^{\prime \prime}(c)<0$. Consequently, the denominator of (6) is negative while the numerator may be either positive or negative. Intuitively, higher capital gains taxes imply lower rewards to holding equities in both the high and low state. This leads the agent to allocate less of their portfolio to equities and lower capital gains realizations. At the same time, the lower after-tax returns to equities generate a negative wealth effect. When capital gains taxes increase, it is harder for risk-averse investors to hit a target level of assets. This tends to increase equity holding and leads to larger capital gains realizations. An examination of equation (6) makes clear that the wealth effect is large when the capital gains tax rate is initially low, when the return to equities in the high state is large (compared to the return to bonds) and when the investor is risk-averse.

Once again, capital gains realizations may increase or decrease in response to a capital gains tax increase, depending on the relative magnitudes of the income/wealth and substitution effects.

\section{Additional Time Series Evidence}

\section{D.1 Capital Gains Realizations Over The Life-cycle}

Figure D.1 uses information on the cohort of tax filers that were 30-35 years old in 1982 to illustrate how capital gains realizations evolve over the life-cycle. Focusing on this cohort allows us to observe how capital gains realization behavior changes over long 36-year period (from 1982-2016). Figure D.1(a) plots the fraction of individuals in this cohort who ever reported positive capital gains by age, while Figure D.1(b) plots the average value of the cumulative "lifetime" capital gains by age. Figure D.1 shows that over a 36 year period, just under $50 \%$ of tax filers in this cohort report positive capital gains on their tax return at least once. 
However, for most tax filers, the value of their cumulative capital gains are quite small. At the median (not shown), the average "lifetime" capital gains are zero; at the 75th percentile, the average "lifetime" capital gains are $\$ 100,000$; at the 99th percentile, the average is at just above $\$ 500,000$ (all 1993 dollars). Thus for the majority of individuals in Canada, a $\$ 100,000$ LCGE was equivalent to a zero marginal effective tax rate on capital gains income. ${ }^{32}$

\section{Figure D.1: Capital Gains Over Lifetime}

(a) Share with Positive CG

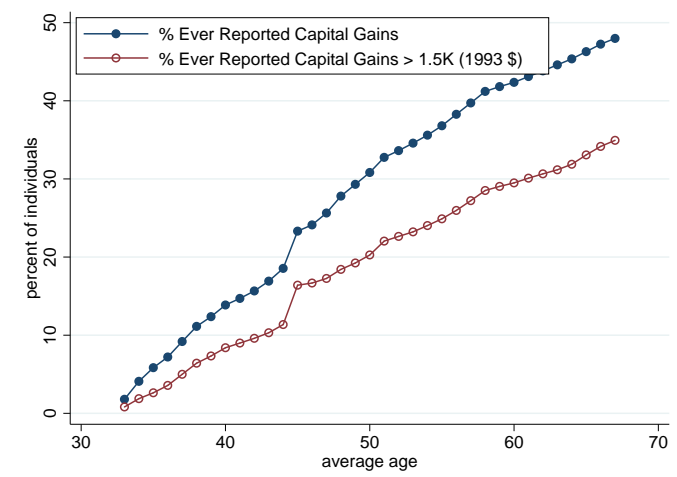

(b) Cumulative CG Over Lifetime

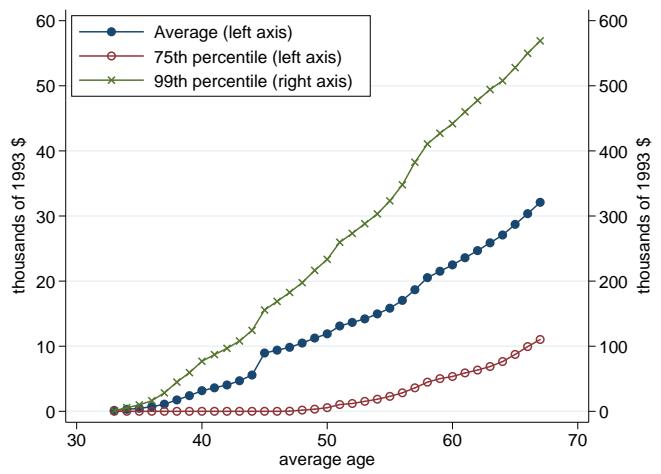

Notes: For Figure D.1, the sample is tax filers age 30-35 in 1982. Figure D.1(a) plots the fraction of tax filers that ever report positive capital gains by age. Figure D.1(b) plots the cumulative "lifetime" capital gains for the average tax filer, the tax filer at the 75th percentile and the tax filer at the 99th percentile.

${ }^{32}$ Because the value of the exemption was nominally fixed, the actual share of the population affected is strongly influenced by the inflation rate during a tax filer's lifetime. 


\section{D.2 Small vs Large Realizations}

Figure D.2: Capital Gains Over Time - Small vs Large Capital Gains

(a) Average Positive $\leq 1 \mathrm{~K}$

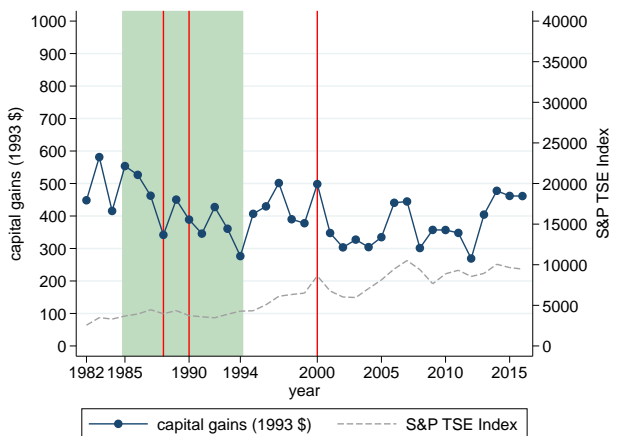

(c) Percent Positive $\leq 1 \mathrm{~K}$

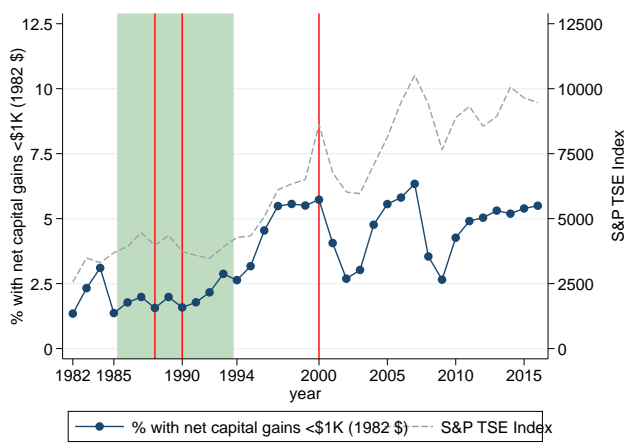

(b) Average Positive $>1 \mathrm{~K}$

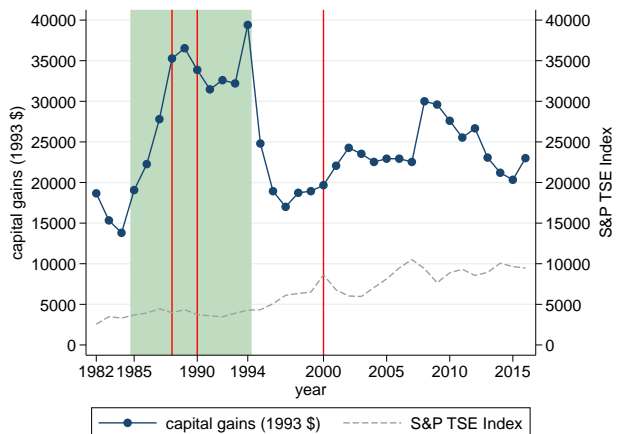

(d) Percent Positive $>1 \mathrm{~K}$

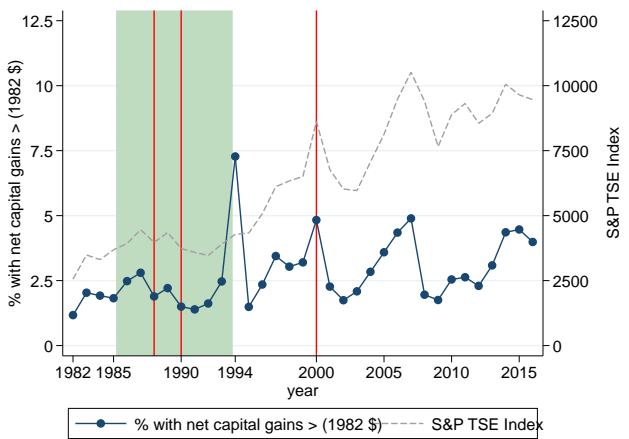

Notes: This figure plots the evolution of realized capital gains for those with large and small capital gains. Figure C.2(a) (resp. Figure C.2(b)) plots the average realized capital gain among those with positive gains of less (resp. greater) than $\$ 1,000$ from 1982 to 2016. Figure C.2(c) (resp. Figure C.2(d)) plots the fraction of tax filers with positive realized capital gains between $\$ 0.01$ and $\$ 1,000$ (resp. greater than $\$ 1,000$ ) from 1982 to 2016 . The green shaded area marks the 1985-1994 period in which the Lifetime Capital Gains Exemption (LCGE) was in place. The red vertical lines mark changes in the capital gains inclusion rate (from $50 \%$ to $66.6 \%$ in 1988, from $66.6 \%$ to $75 \%$ in 1990 and a decrease from $75 \%$ to $50 \%$ in 2000 ). The dashed grey line plots the evolution of the inflation-adjusted values of the Standard and Poor's Toronto Stock Exchange Composite Index. 
Figure D.3: Capital Gains Realizations History By Age

(a) Fraction of CG Realiz- (b) Fraction of CG Realiz- (c) Fraction of CG Realizers with Prior Realized CG: ers with Prior Realized CG: ers with Prior Realized CG:

Age $<40$

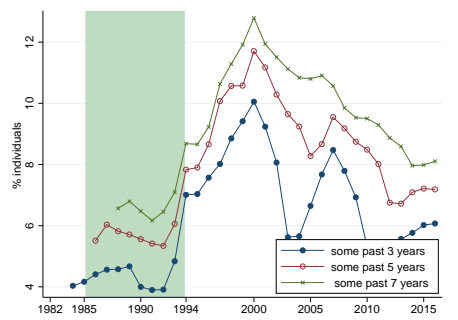

Age 40-60

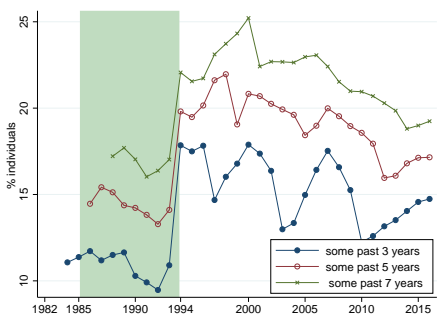

Age $>60$

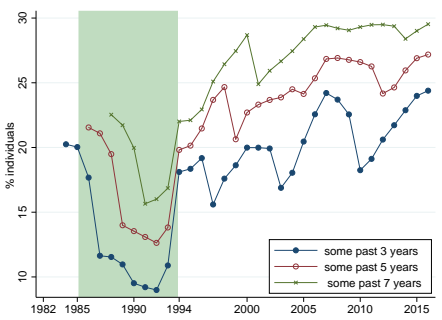

(d) Fraction of CG Re- (e) Fraction of CG Realizers (f) Fraction of CG Realizers alizers with and without with and without CG Re- with and without CG ReCG Realizations in Past 6 alizations in Past 6 Years: alizations in Past 6 Years: Years: Age $<40$

Age $40-60$

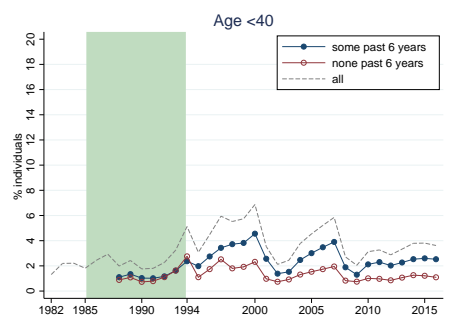

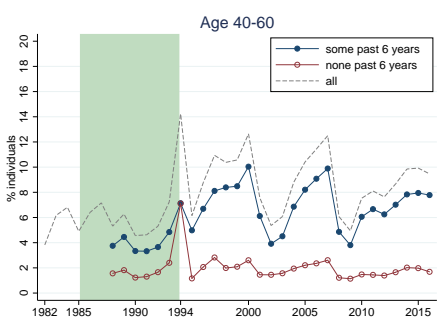

Age $>60$

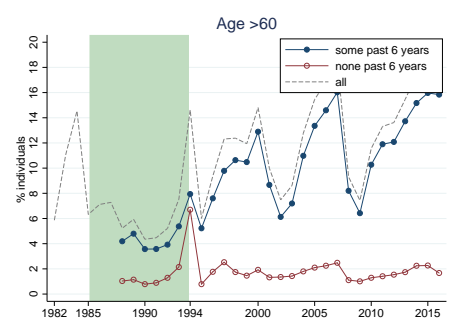

(g) Average CG Among Re- (h) Average CG Among Re- (i) Average CG Among Realizers with and without alizers with and without alizers with and without Prior Realizations in Past 6 Prior Realizations in Past 6 Prior Realizations in Past 6

Years: Age $<40$

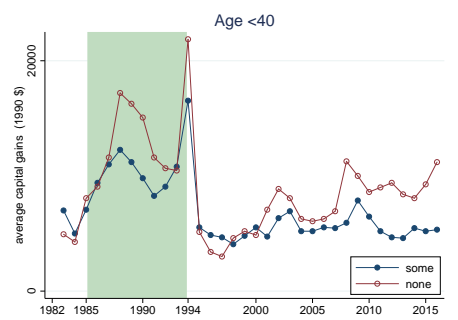

Years: Age 40-60

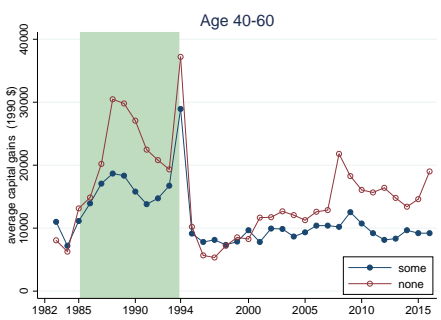

Years: Age $>60$

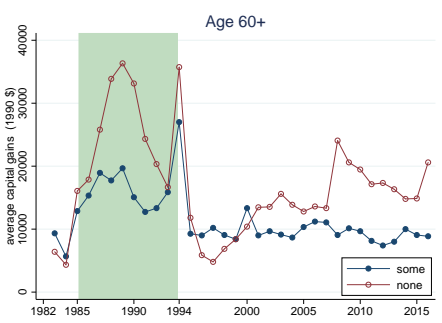

Notes: Figures C.3(a), C.3(b) and C.3(c) plot the fraction of tax filers with realized capital gains in the past 3, 5 and 7 years in the age groups: (a) under 40, (b) between 40 and 60 and (c) over 60. Figures C.3(d), C.3(e) and C.3(f) plot the fraction of tax filers with and without realized capital gains in the 6 years for the following age groups: (d) under 40, (e) between 40 and 60 and (f) over 60. Figures C.3(g), C.3(h) and C.3(i) plot the average realized capital gain in the current year, separately for tax filers with and without realized capital gains in the previous 6 years and the following age groups: (g) under 40, (h) between 40 and 60 and (i) over 60 . The green shaded area marks the 1985-1994 period in which the Lifetime Capital Gains Exemption (LCGE) was in place. The red vertical lines mark changes in the capital gains inclusion rate (from $50 \%$ to $66.6 \%$ in 1988 , from $66.6 \%$ to $75 \%$ in 1990 and a decrease from $75 \%$ to $50 \%$ in 2000). 


\section{D.3 Comparison with the U.S.}

Figures D.4 and D.5 compare the evolution of total realized capital gains in the U.S. and Canada. Figure D.4 compares total reported capital gains in Canada based on individual tax returns from the LAD dataset (i.e. totals scaled from a $20 \%$ random LAD sample) to the totals from the U.S. Department of the Treasury report.

Figure D.4: Total Reported Capital Gains Over Time - Comparison with the U.S. Series

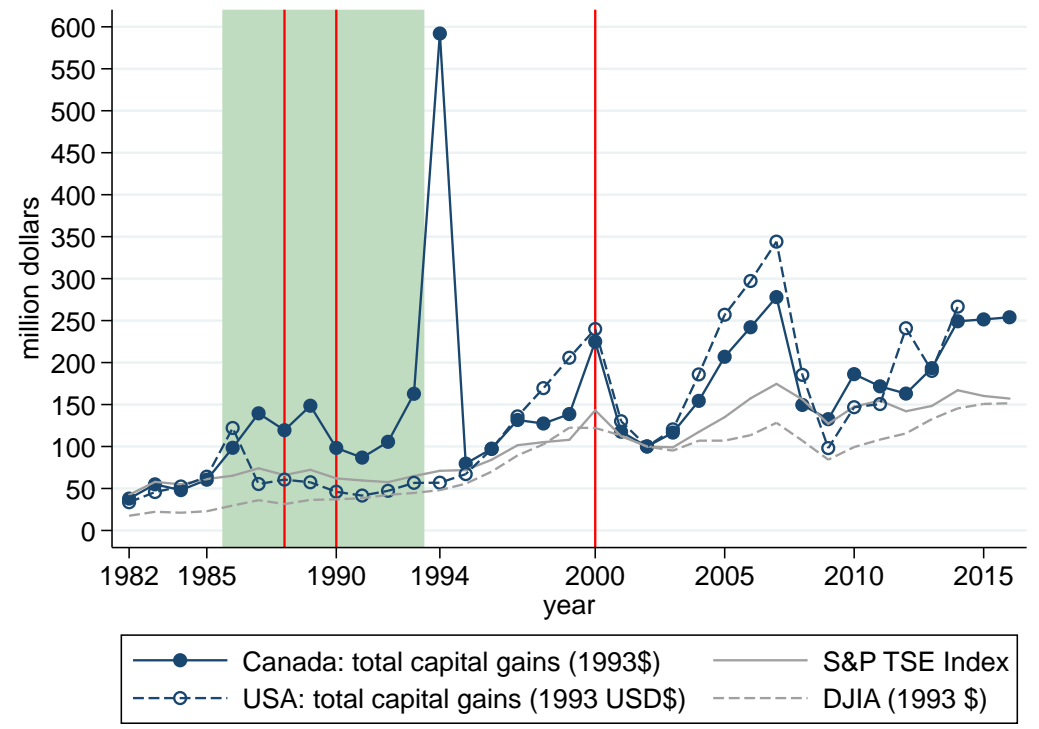

Notes: This figure plots total reported capital gains in millions of dollars in the U.S. and Canada from 1982 to 2016. The green shaded area marks the 1985-1994 period in which the Lifetime Capital Gains Exemption (LCGE) was in place. The red vertical lines mark changes in the capital gains inclusion rate (from $50 \%$ to $66.6 \%$ in 1988 , from $66.6 \%$ to $75 \%$ in 1990 and a decrease from $75 \%$ to $50 \%$ in 2000). The solid grey (resp. dashed) line shows evolution of the inflation-adjusted values of the Standard and Poor's Toronto Stock Exchange Composite Index (resp. Dow Jones Industrial Average) over the same time period.

Figure D.5 uses annual cross-sections of individual tax returns constructed by the Internal Revenue Service (IRS) and commonly known as the Statistics of Income (SOI) Public Use Files, for years 1982-2009. The SOI Public Use Files consist of stratified random samples of approximately 80,000-200,000 tax returns each year. All time-series are normalized to $100 \%$ in 2002. 
Figure D.5: Capital Gains Over Time - Comparison with the U.S. Series

(a) Average Positive CG

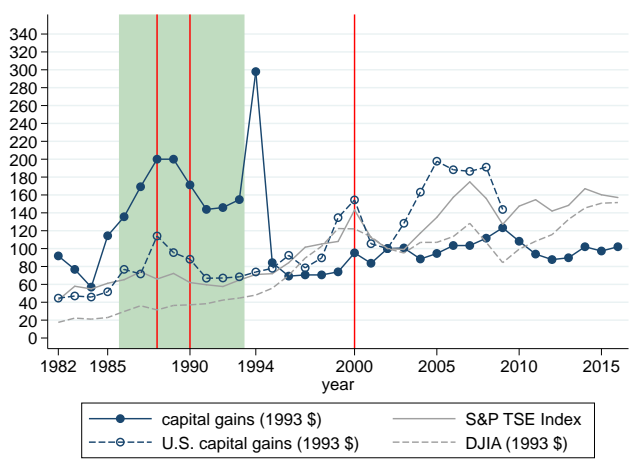

(d) Percent Positive

cr

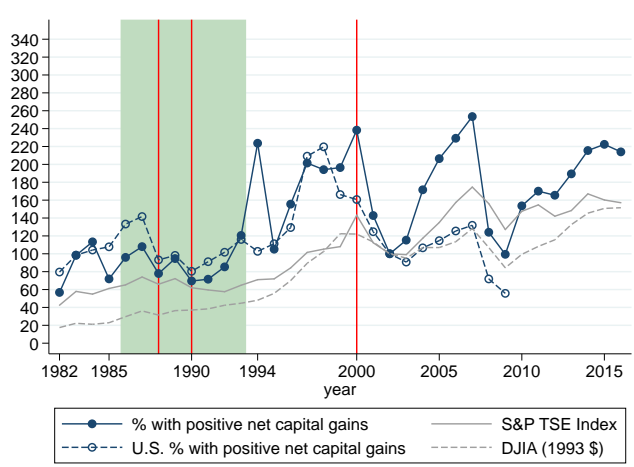

(b) Average Positive $>1 \mathrm{~K}$

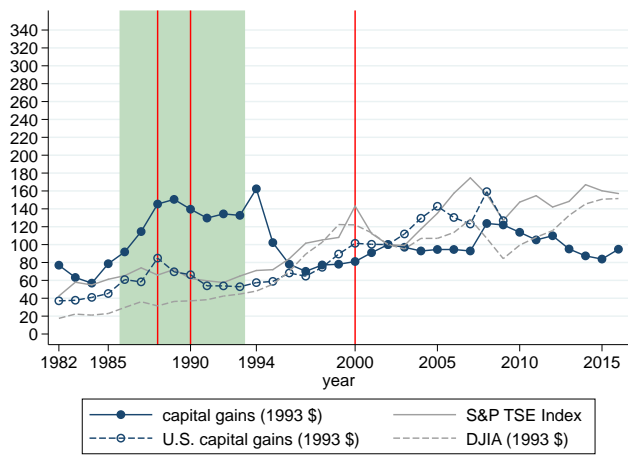

(e) Percent Positive $>1 \mathrm{~K}$

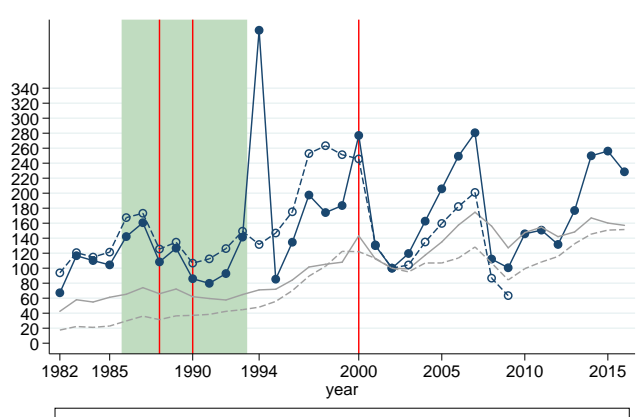

- \% with net capital gains > $>$ (1982 \$) $\longrightarrow$ S\&P TSE Inder (c) Average Positive $\leq 1 \mathrm{~K}$

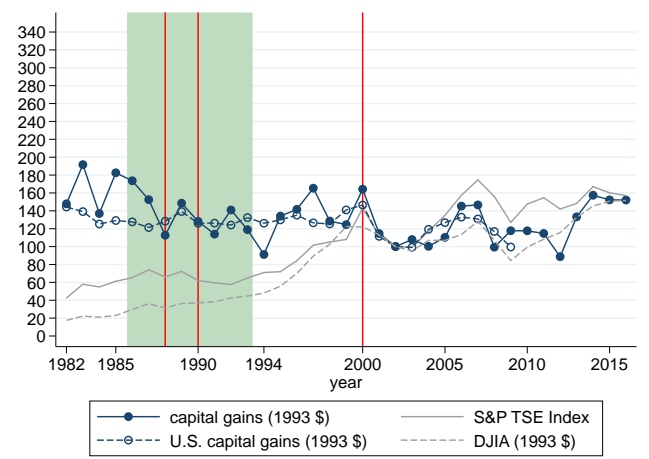

(f) Percent Positive $\leq 1 \mathrm{~K}$

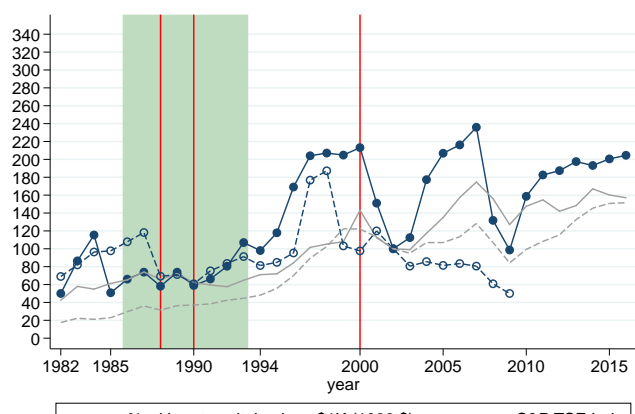

-1
-1

Notes: To account for differences in levels between Canada and the United States, all time-series are normalized to 100 in 2002. The green shaded area marks the 1985-1994 period in which the Lifetime Capital Gains Exemption (LCGE) was in place. The red vertical lines mark changes in the capital gains inclusion rate (from $50 \%$ to $66.6 \%$ in 1988, from $66.6 \%$ to $75 \%$ in 1990 and a decrease from $75 \%$ to $50 \%$ in 2000). The solid grey (resp. dashed) line shows evolution of the inflation-adjusted values of the Standard and Poor's Toronto Stock Exchange Composite Index (resp. Dow Jones Industrial Average) over the same time period. 


\section{D.4 Spousal Responses}

Figure D.6 is similar to figures Figures 1 and 2 in the main text. The figure plots the unconditional average realized capital gains, average realized capital gains among those with positive realizations and the fraction of individuals with positive capital gains realizations from 1982-2016, separately for single (unmarried) and married tax filers. The patterns described in Section 3 appear to carry over.

Figure D.6: Evolution of Realized Capital Gains By Marital Status

Panel A: Single (Unmarried) Tax Filers
(a) Unconditional Average
(b) Average Positive
(c) Percent Positive
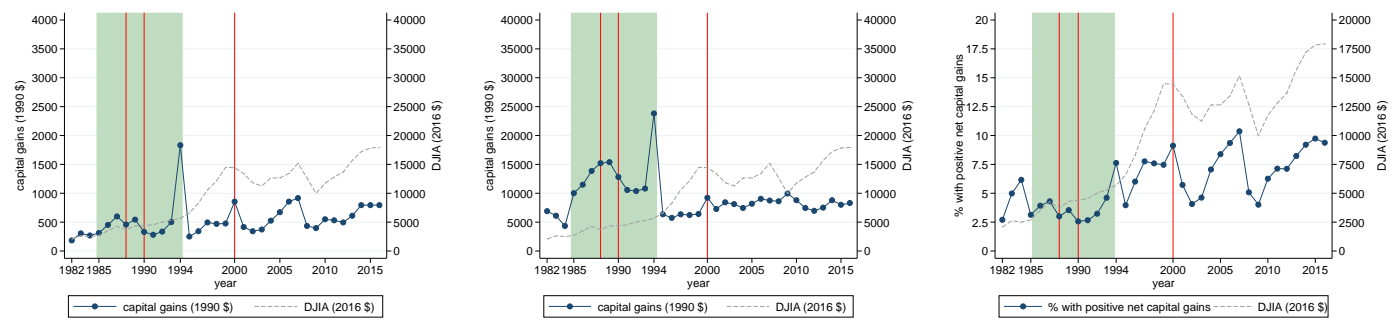

(d) Unconditional Average

Panel B: Married Tax Filers

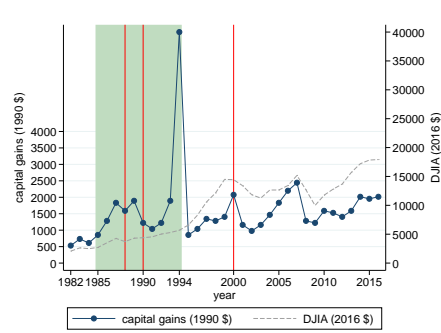

(e) Average Positive

(f) Percent Positive
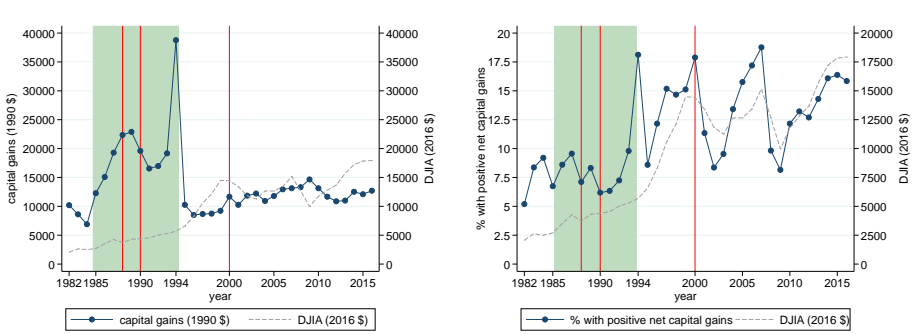

Notes: The green shaded area marks the 1985-1994 period in which the Lifetime Capital Gains Exemption (LCGE) was in place. The red vertical lines mark changes in the capital gains inclusion rate (from $50 \%$ to $66.6 \%$ in 1988, from $66.6 \%$ to $75 \%$ in 1990 and a decrease from $75 \%$ to $50 \%$ in 2000).

In Canada, the tax unit is the individual, not the family. Consequently, tax filers that are married (or who are in a common-law relationship) have an incentive to split realized capital gains evenly, if possible. ${ }^{33}$ Since wage income cannot be split but capital gains can be tentatively allocated to a lower earning

33 There are some small deviations from this rule, e.g. some credits depend on joint income and the personal exemption amount is partially sharable. 
spouse, couples with uneven incomes can reduce their combined tax liability if the lower earning partner/spouse reports all of the couple's combined realized capital gains income. This strategy was less advantageous during the period in which the LCGE was in place because the effective marginal tax rate on capital gains income for tax filers with remaining exemption space was zero. For partners that earn similar incomes, the optimal tax strategy is to split assets and the resulting capital gains income equally. The LCGE did not change this incentive. Consequently, after the elimination of the LCGE couples that did not exhaust their exemption room may have reverted to shifting capital gains income to the spouse with the lower effective marginal tax rate. To the extent that couples where both partners had unused exemption room were disproportionately in the treated groups, this would tend to result in larger (i.e. more positive) extensive margin estimates in the post-1994 years. However, this type of income shifting would not result in greater participation in capital markets.

Figure D.7 explores whether couples follow these optimal strategies. The results suggest a firm "no". For the vast majority of couples, the partner who earns the most gross income also reports the most capital gains income. In fact, for the majority of couples, capital gains income is reported on only one of the returns and it is typically on the tax return of the higher-earning partner. Nonetheless, Figure D.7 also documents that from 1982 until approximately 2000, the share of capital gains income reported by the higher earner (resp. lower earner) decreased (resp. increased). The figure provides suggestive evidence that the introduction of the LCGE slowed down this trend, consistent with the hypothesis that some couples responded to the introduction of the lifetime exemption by using up the exemption space of the high-income (and, therefore, the high effective MTR) spouse. 
Figure D.7: Split of Capital Gains within Couples by Shares of Gross Income

(a) Share Reported

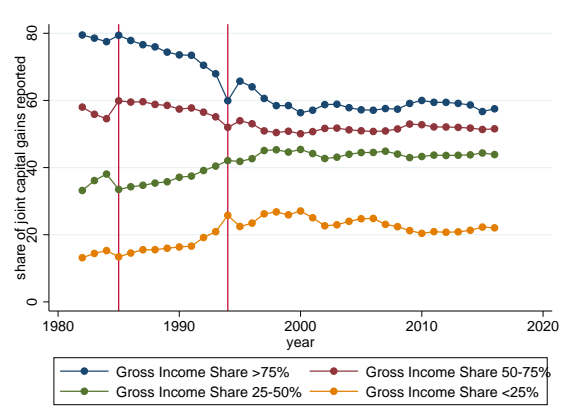

(b) Percent with Higher Share

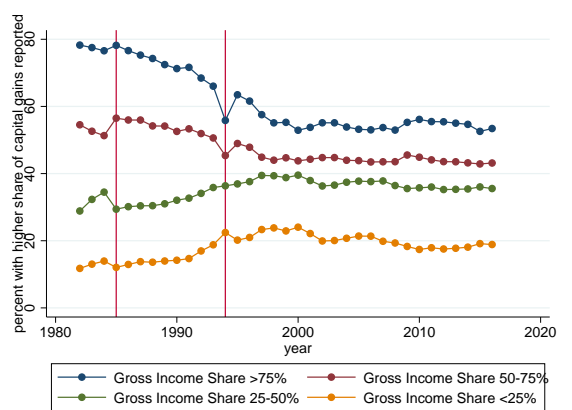

Notes: The sample in this figure is all tax filers that are married or in a common-law relationship and report positive capital gains income. Married couples are partitioned into four groups based on each tax filer's share of the family's gross (total) income. Figure C.7(a) plots the average share of the family's capital gains income reported by tax filers in each of the four groups from 1982-2016. Figure C.7(b) plots the fraction of tax filers that report more capital gains income than their spouse over the 1982-2016 period, separately for each of the four groups. The red vertical lines mark the introduction and elimination of the Lifetime Capital Gains Exemption (LCGE), respectively. 


\section{E Additional Robustness Checks}

Figure E.1: Main Results: Estimates in Levels

Panel A: Unconditional Realized Capital Gains
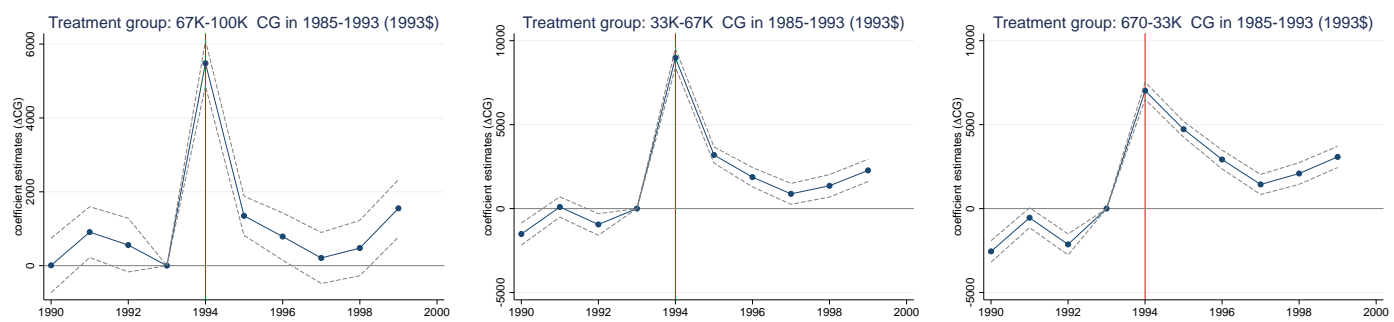

Panel B: Intensive Margin: Conditional on Positive Realized Capital Gains
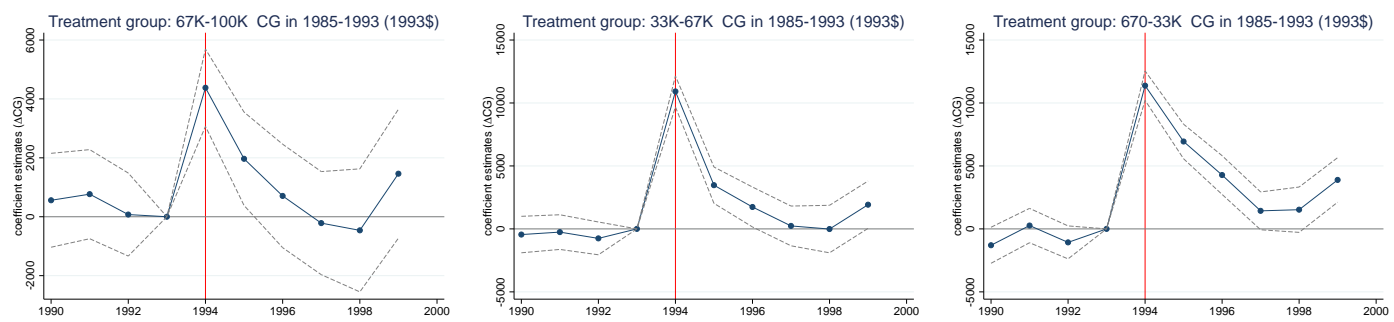

Notes: Each figure plots the estimates of coefficients $\gamma_{\tau}$ from specification (1) described in Section 4.1. The dependent variable is a tax filer's realized capital gain in the current tax year (i.e. in levels). The sample in Panel A is comprised of all tax filers with 1985-1993 realized capital gains between $\$ 100,000-\$ 133,333$ (the control group) and one of the following three treatment groups: (i) 1985-1993 realized capital gains between $\$ 66,667-\$ 100,000$ (left panel); (ii) 1985-1993 realized capital gains between $\$ 33,334-\$ 66,666$ (middle panel); (iii) 1985-1993 realized capital gains between $\$ 667-\$ 33,333$ (right panel). The sample in Panel B is restricted to tax filers with positive realized capital gains in the current tax year. Number of observations: (left, middle and right panels): 293,385; 532,890; 2,593,670; 105,100; 171,300; 800,900. 
Figure E.2: Adding Individual Fixed Effects

\section{Panel A: Unconditional Realized Capital Gains}
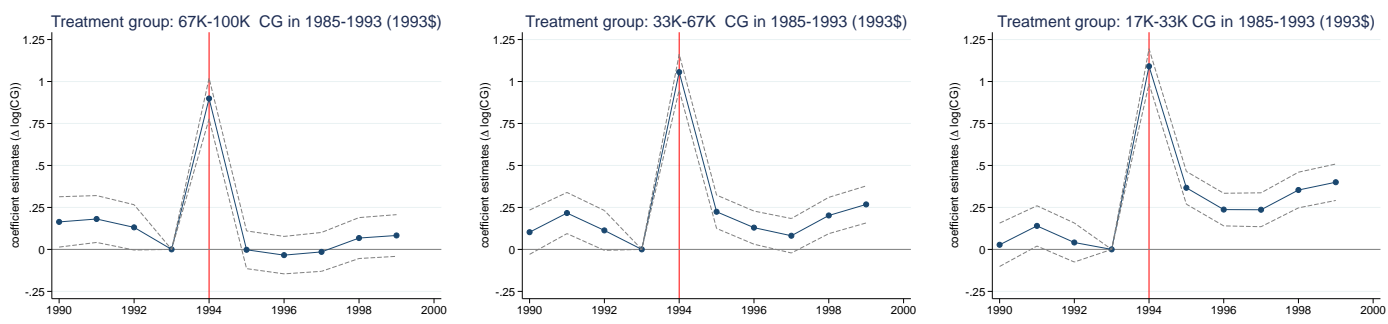

Panel B: Intensive Margin: Conditional on Positive Realized Capital Gains
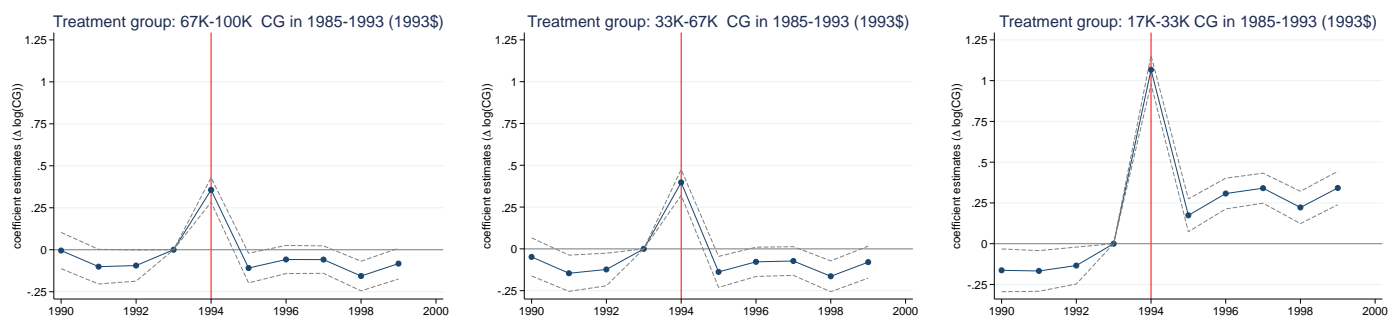

Panel C: Extensive Margin: Fraction with Positive Realized Capital Gains
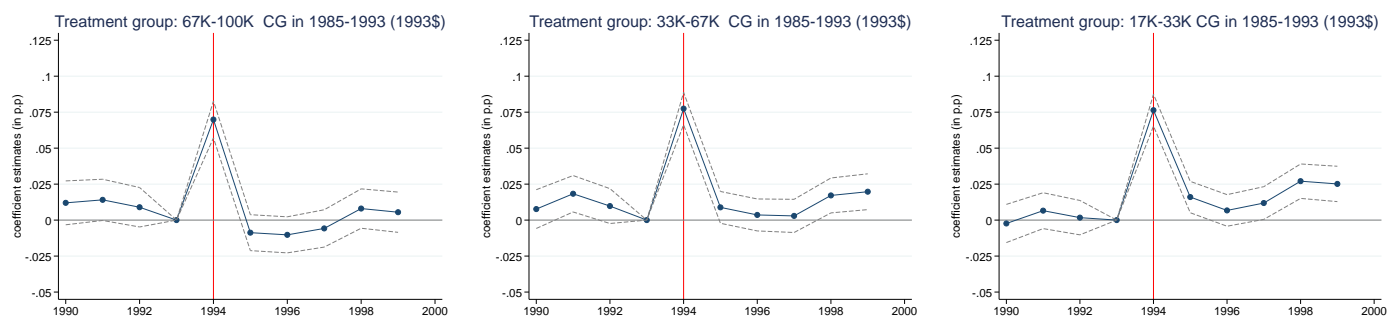

Notes: Each figure plots the estimates of coefficients $\gamma_{\tau}$ from a specification that augments equations (1) and (2) with individual fixed effects. In Panels A and B, the dependent variable is the natural logarithm of $\$ 1$ plus a tax filer's realized capital gain in the current tax year. In Panel C, the dependent variable is a binary variable equal to 1 for tax filers with positive realized capital gains in the current tax year and zero otherwise. The sample in Panels A and C is comprised of all tax filers with 1985-1993 realized capital gains between $\$ 100,000$ $\$ 133,333$ (the control group) and one of the following three treatment groups: (i) 1985-1993 realized capital gains between $\$ 66,667-\$ 100,000$ (left panel); (ii) $1985-1993$ realized capital gains between $\$ 33,334-\$ 66,666$ (middle panel); (iii) 1985-1993 realized capital gains between $\$ 16,666-\$ 33,333$ (right panel). The sample in Panel B is restricted to tax filers with positive realized capital gains in the current tax year. Number of observations (left, middle and right panels): 293,385; 532,890; 596,600; 105,100; 171,300; 186,100; 293,385; 532,890; 596,600. 


\section{Figure E.3: Adding Income Controls}

\section{Panel A: Unconditional Capital Gains}
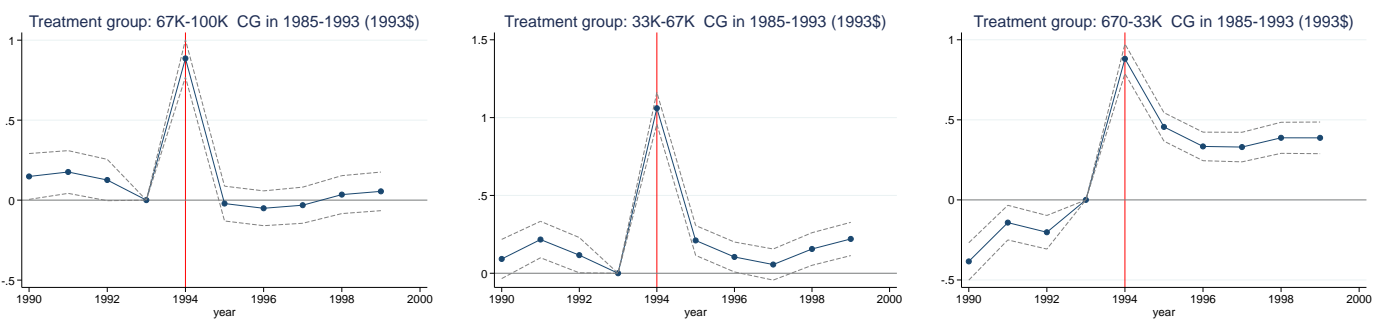

Panel B: Intensive Margin: Positive Capital Gains
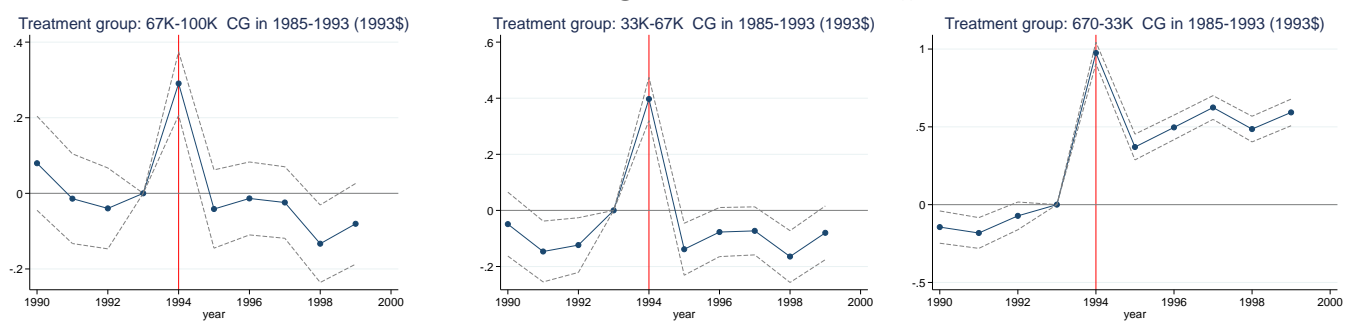

Panel C: Extensive Margin: Percent with Positive Capital Gains
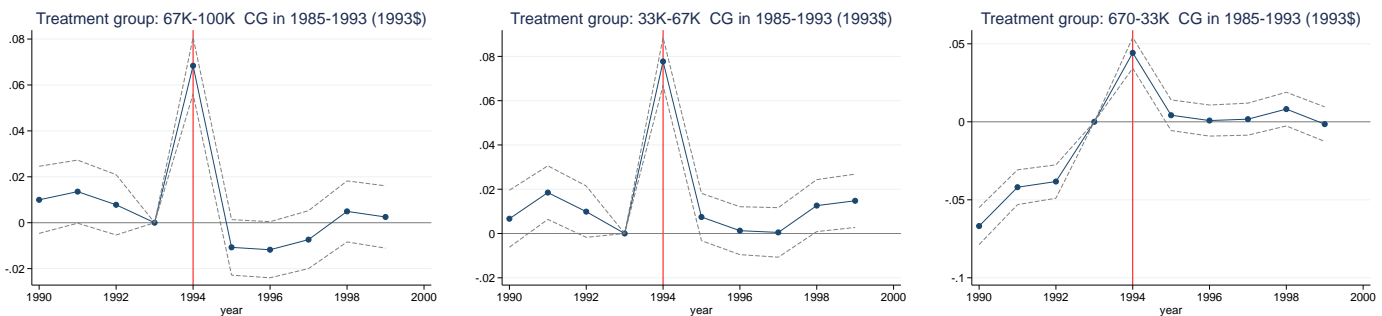

Notes: Each figure plots the estimates of coefficients $\gamma_{\tau}$ from a specification that augments equations (1) and (2) with the natural logarithm of a tax filer's total (broad) income as a control variable. In Panels $\mathrm{A}$ and $\mathrm{B}$, the dependent variable is the natural logarithm of $\$ 1$ plus a tax filer's realized capital gain in the current tax year. In Panel C, the dependent variable is a binary variable equal to 1 for tax filers with positive realized capital gains in the current tax year and zero otherwise. The sample in Panels A and C is comprised of all tax filers with 1985-1993 realized capital gains between $\$ 100,000-\$ 133,333$ (the control group) and one of the following three treatment groups: (i) 1985-1993 realized capital gains between $\$ 66,667-\$ 100,000$ (left panel); (ii) 1985 -1993 realized capital gains between $\$ 33,334-\$ 66,666$ (middle panel); (iii) 1985-1993 realized capital gains between $\$ 667$ $\$ 33,333$ (right panel). The sample in Panel B is restricted to tax filers with positive realized capital gains in the current tax year. Number of observations (left, middle and right panels): 293,385; 532,890; 2,593,700; 105,100; 171,300; 800,900; 293,385; 532,890; 2,534,700. 
Figure E.4: Sensitivity Check that Excludes 'Treated' Tax Filers Whose 1994 Realized Capital Gain Pushes Them Above The $\$ 100,000$ LCGE Threshold

\section{Panel A: Unconditional Capital Gains}
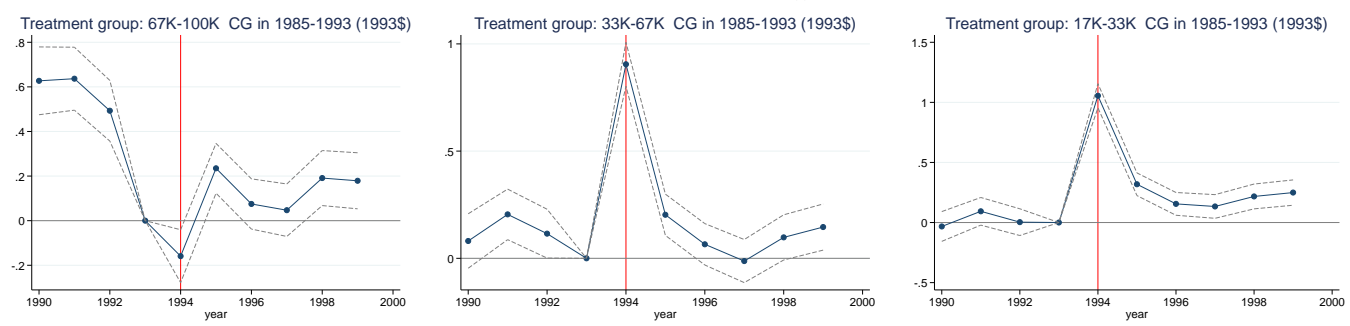

Panel B: Intensive Margin: Positive Capital Gains
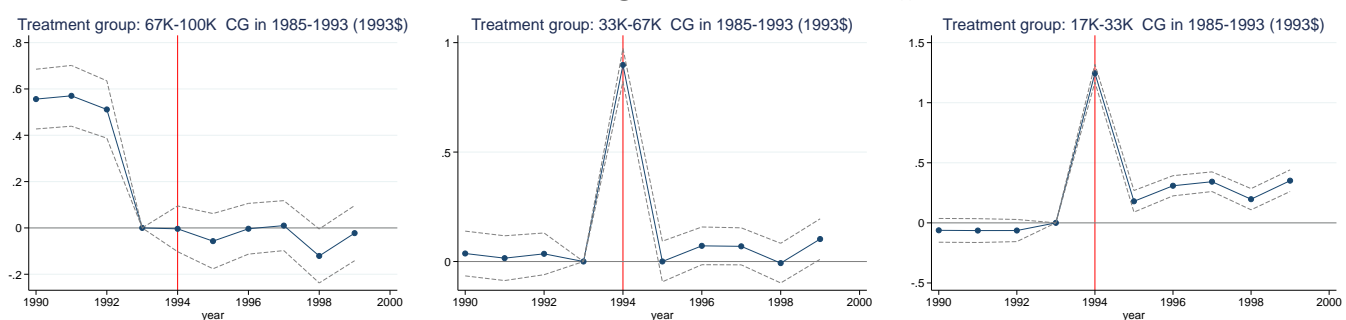

Notes: Each figure plots the estimates of coefficients $\gamma_{\tau}$ from specification (1) described in Section 4.1. In Panels $\mathrm{A}$ and $\mathrm{B}$, the dependent variable is the natural logarithm of $\$ 1$ plus a tax filer's realized capital gain in the current tax year. The sample in Panel A is comprised of all tax filers with 1985-1993 realized capital gains between $\$ 100,000-\$ 133,333$ (the control group) and one of the following three treatment groups: (i) 1985-1993 realized capital gains between $\$ 66,667-\$ 100,000$ and 1985-1994 realized capital gains less than $\$ 100,000$ (left panel); (ii) 1985-1993 realized capital gains between $\$ 33,333-\$ 66,667$ and 1985 1994 realized capital gains less than $\$ 100,000$ (middle panel); (iii) 1985-1993 realized capital gains between $\$ 16,666-\$ 33,334$ and $1985-1994$ realized capital gains less than $\$ 100,000$ (right panel). The sample in Panel B is the same as Panel A except that it is restricted to tax filers with positive realized capital gains in the current tax year. Number of observations (left, middle and right panels): 237,000; 484,100; 554,400; 78,700; 154,900; 174,200. 
Figure E.5: Extending Event Window

\section{Panel A: Unconditional Capital Gains}
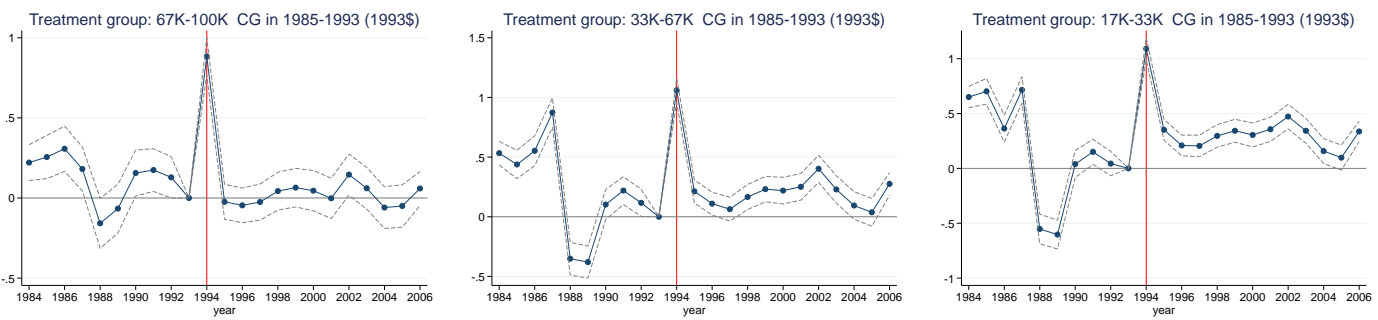

Panel B: Intensive Margin: Positive Capital Gains
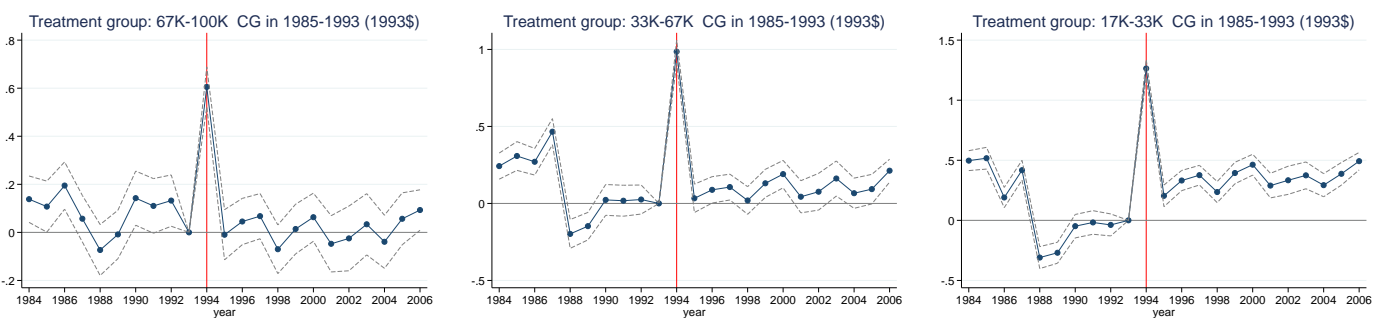

Panel C: Extensive Margin: Percent with Positive Capital Gains
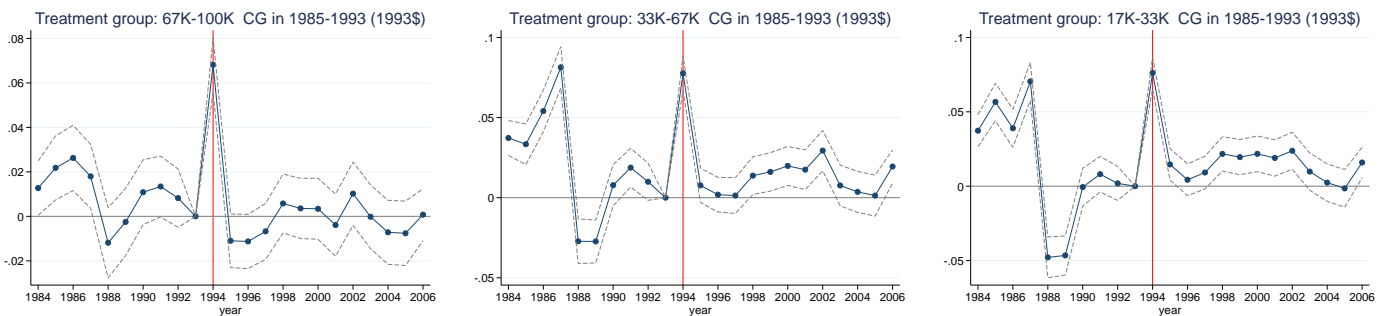

Notes: Each figure plots the estimates of coefficients $\gamma_{\tau}$ from a specification that augments equations (1) and (2) described in Section 4.1 by extending the event study window from 1990-1999 to 1984-2006. In Panels A and B, the dependent variable is the natural logarithm of $\$ 1$ plus a tax filer's realized capital gain in the current tax year. In Panel C, the dependent variable is a binary variable equal to 1 for tax filers with positive realized capital gains in the current tax year and zero otherwise. The sample in Panels A and C is comprised of all tax filers with 1985-1993 realized capital gains between $\$ 100,000-\$ 133,333$ (the control group) and one of the following three treatment groups: (i) 1985-1993 realized capital gains between $\$ 66,667-\$ 100,000$ (left panel); (ii) 1985 -1993 realized capital gains between $\$ 33,334-\$ 66,666$ (middle panel); (iii) 1985-1993 realized capital gains between $\$ 16,667$ $\$ 33,333$ (right panel). The sample in Panel B is restricted to tax filers with positive realized capital gains in the current tax year. Number of observations (left, middle and right panels): 918,$070 ; 1,672,620 ; 1,880,740 ; 319,070 ; 527,610 ; 571,030 ; 918,070 ; 1,672,620 ; 1,880,740$. 


\section{Figure E.6: Main Results: Adding Life Cycle Controls}

\section{Panel A: Unconditional Capital Gains}
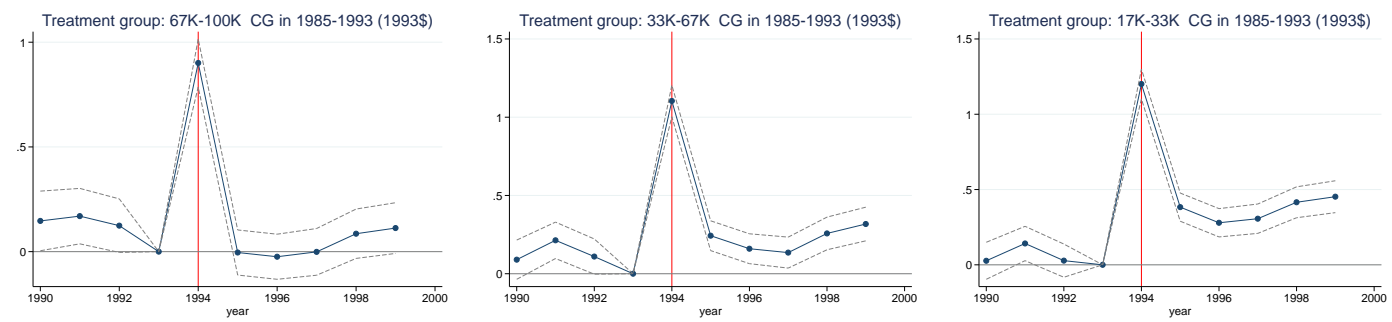

Panel B: Intensive Margin: Positive Capital Gains
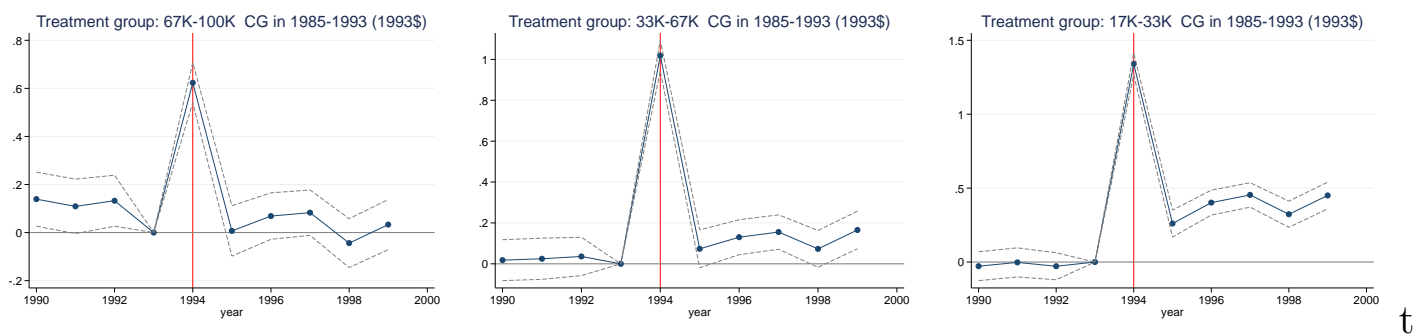

Notes: Each figure plots the estimates of coefficients $\gamma_{\tau}$ from a specification that augments equation (1) by replacing the cubic polynomial in age with group (treatment/control) by age fixed effects. In Panels $\mathrm{A}$ and $\mathrm{B}$, the dependent variable is the natural logarithm of $\$ 1$ plus a tax filer's realized capital gain in the current tax year. The sample in Panel A is comprised of all tax filers with 1985-1993 realized capital gains between $\$ 100,000-\$ 133,333$ (the control group) and one of the following three treatment groups: (i) $1985-1993$ realized capital gains between $\$ 66,667-\$ 100,000$ (left panel); (ii) $1985-1993$ realized capital gains between $\$ 33,334-\$ 66,666$ (middle panel); (iii) 1985-1993 realized capital gains between $\$ 16,667-\$ 33,333$ (right panel). The sample in Panel $\mathrm{B}$ is restricted to tax filers with positive realized capital gains in the current tax year. Number of observations (left, middle and right panels): 293,400; 532,900; 596,600; 105,100; 171,300; 186,100. 
Figure E.7: Heterogeneity by Age

Panel A: Total Response - Age $<50$
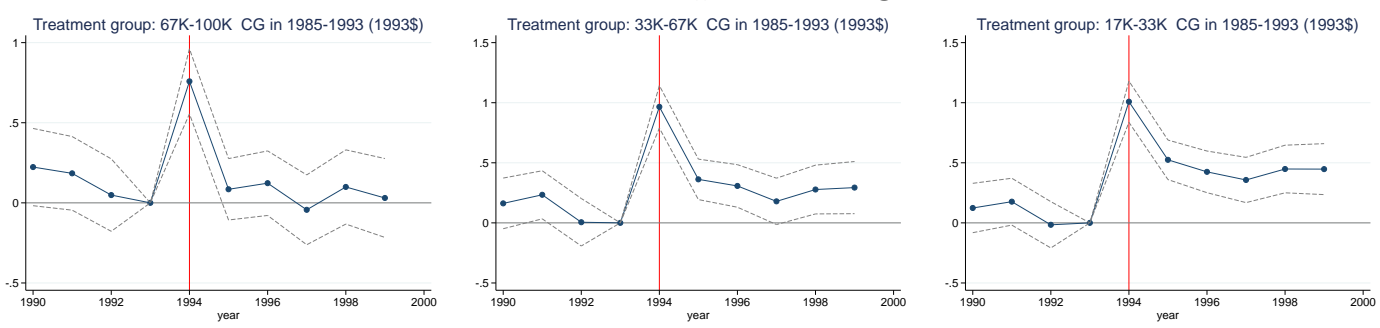

Panel B: Total Response $-50 \leq$ Age $<65$
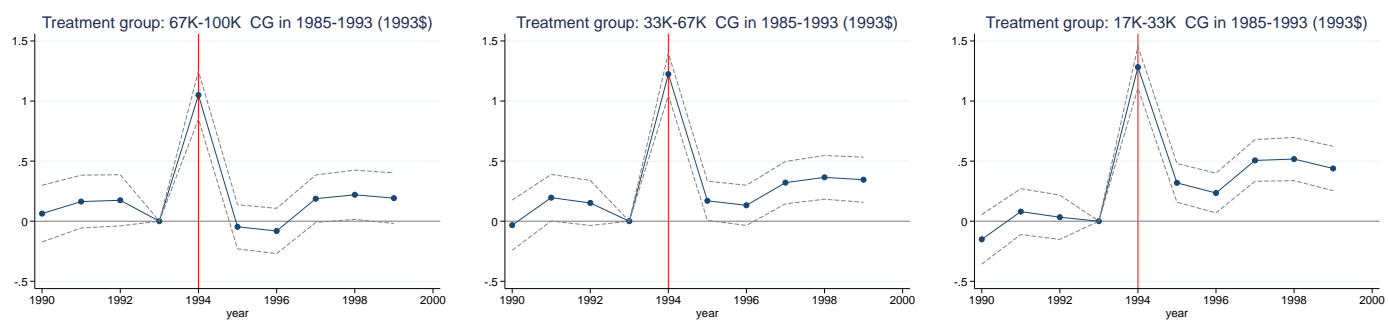

Panel C: Intensive Margin Response - Age $<50$
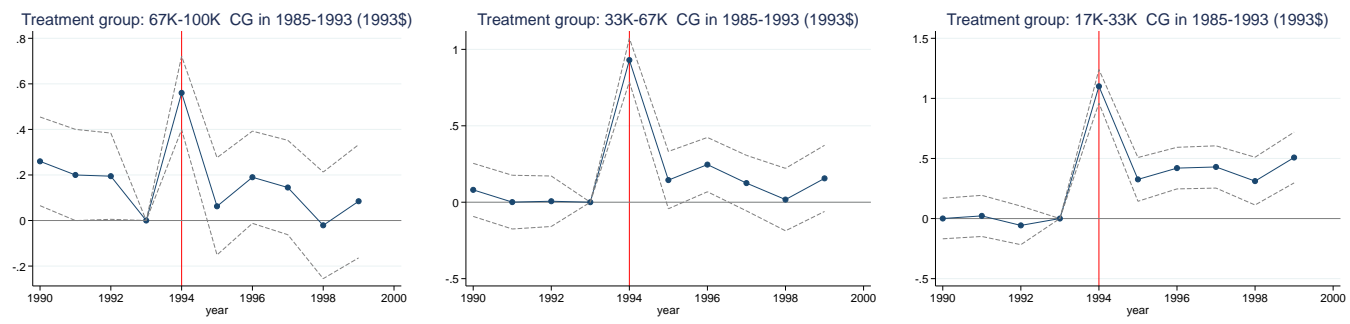

Panel D: Intensive Margin Response $-50 \leq$ Age $<65$
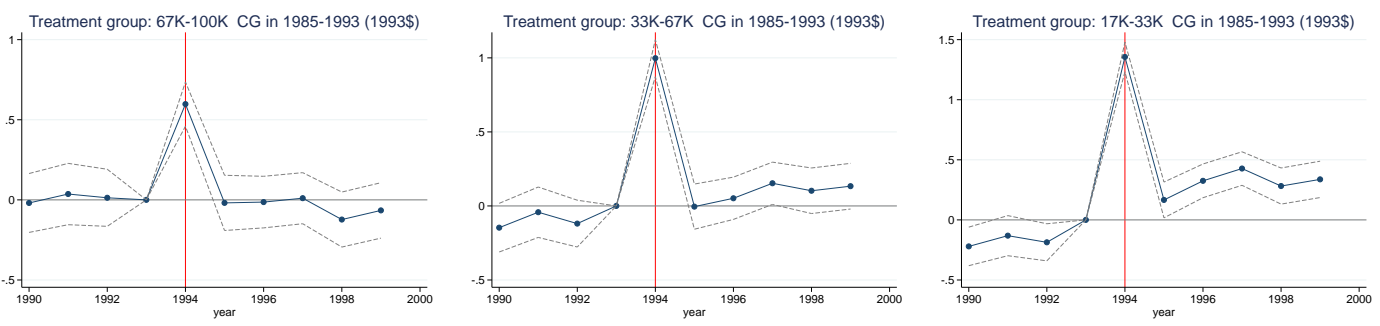

Notes: Each figure plots the estimates of coefficients $\gamma_{\tau}$ from specification (1) described in Section 4.1. The dependent variable is the natural logarithm of $\$ 1$ plus a tax filer's realized capital gain in the current tax year. The sample in Panel A is comprised of tax filers in the treatment and control groups between the ages of 19 and 49 . The sample in Panel B is comprised of tax filers in the treatment and control groups between the ages of 50 and 64. The sample in Panel $\mathrm{C}$ is comprised of tax filers in the treatment and control groups between the ages of 19 and 49 with positive realized capital gains in the current tax year. The sample in Panel D is comprised of tax filers in the treatment and control groups between the ages of 50 and 64 with positive realized capital gains in the current tax year. Number of observations (left, middle and right panels): 89,665; 176,660; 219,$325 ; 109,120 ; 192,410 ; 206,385 ; 27,610 ; 49,040 ; 58,530 ; 39,415 ; 63,870 ; 68,335$. 
Figure E.8: Heterogeneity by Marital Status

Panel A: Unconditional Capital Gains - Married
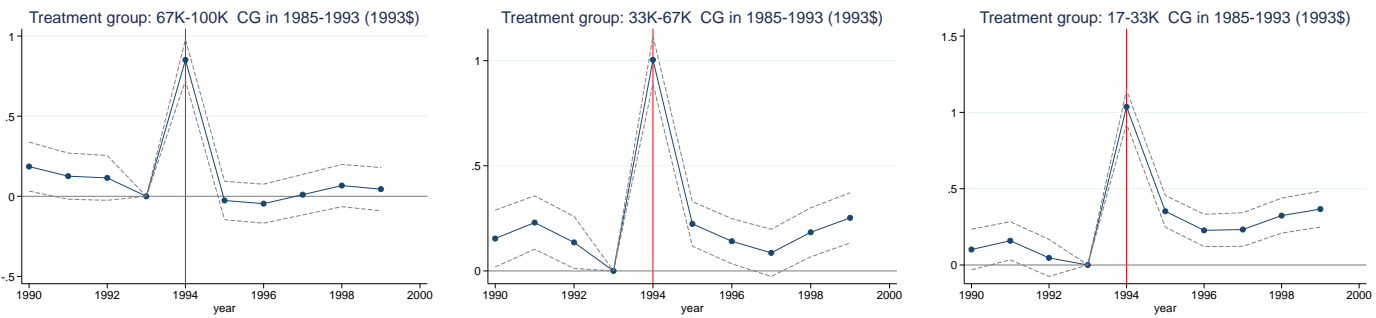

Panel B: Unconditional Capital Gains - Single
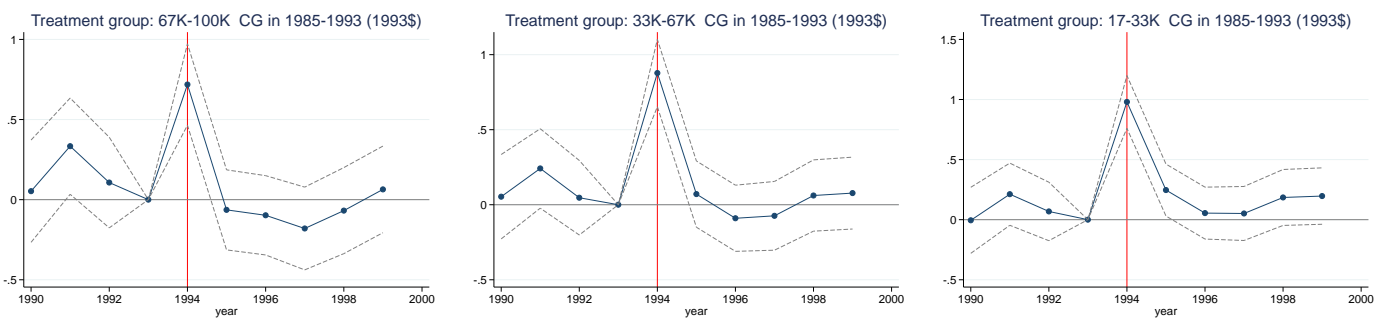

Panel C: Intensive Margin - Married
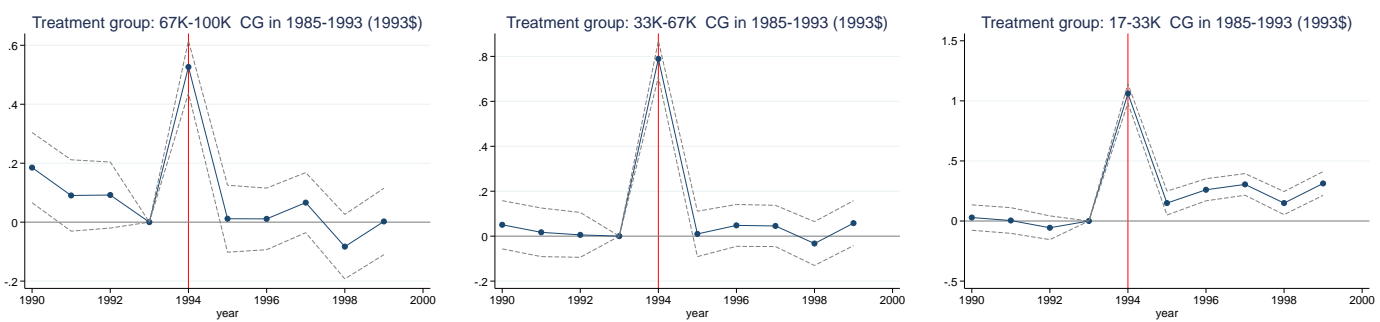

Panel D: Intensive Margin - Single
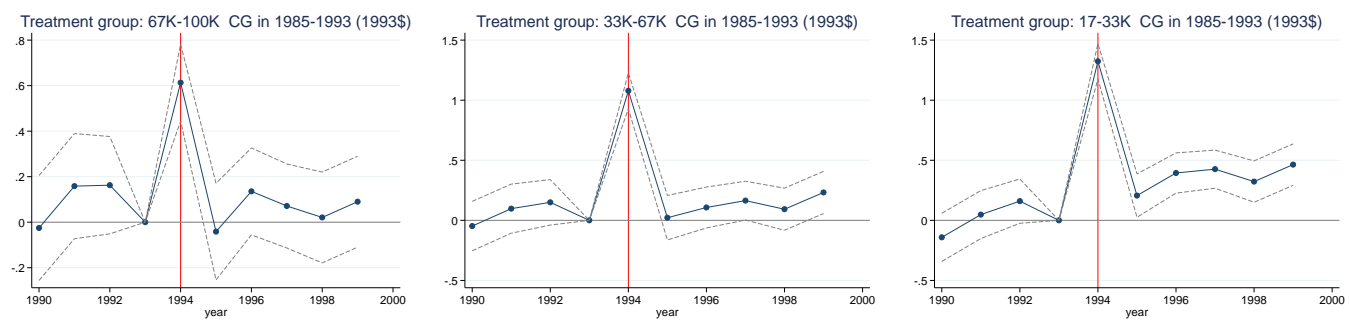

Notes: Each figure plots the estimates of coefficients $\gamma_{\tau}$ from specification (1) described in Section 4.1. The dependent variable is the natural logarithm of $\$ 1$ plus a tax filer's realized capital gain in the current tax year. The sample in Panel A is comprised of married tax filers in the treatment and control groups. The sample in Panel B is comprised of single (unmarried) tax filers in the treatment and control groups. The sample in Panel $\mathrm{C}$ is comprised of married tax filers in the treatment and control groups with positive realized capital gains in the current tax year. The sample in Panel D is comprised of single (unmarried) tax filers in the treatment and control groups. Number of observations (left, middle and right panels): 228,770; 414,$875 ; 463,710 ; 61,515 ; 112,665 ; 127,365 ; 80,165 ; 130,335 ; 141,200 ; 24,340 ; 40,000 ; 43,735$. 


\section{F Demographic Characteristics Over the Years}

Figure F.1: Demographic Characteristics

(a) Age

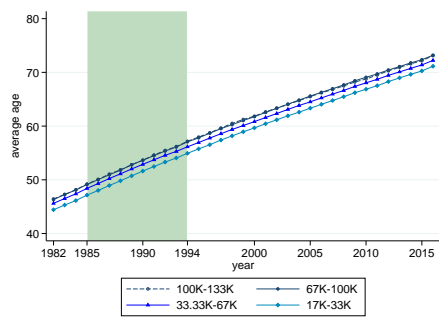

(d) Total Income

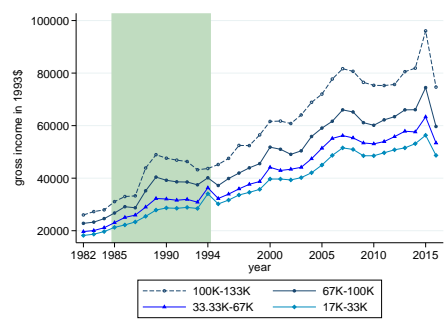

(b) Percent Married

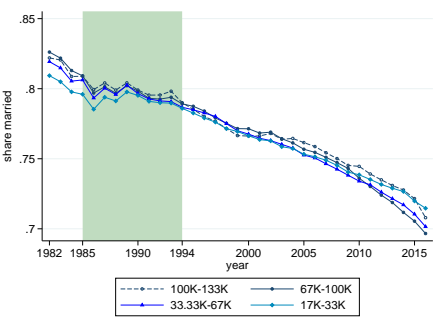

(e) Taxable Income

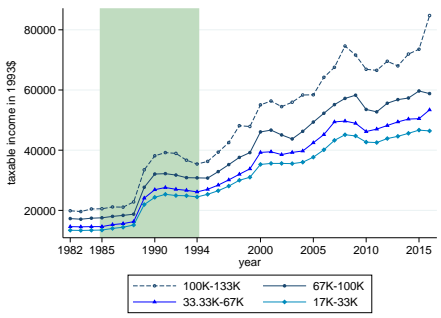

(c) Number of Kids

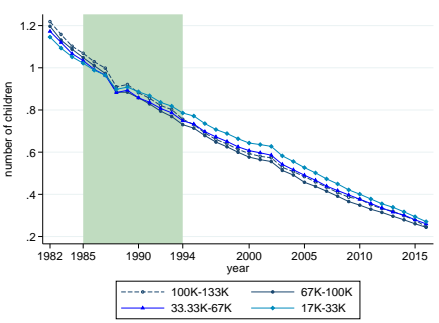

(f) Marginal Tax Rate

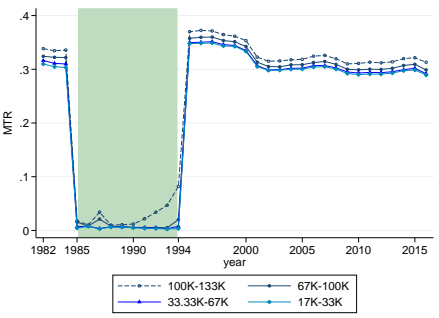

Notes: This figure plots the means for several demographic characteristics and two different income concepts from 1982-2016 in each of the four treatment and control groups. The figure in panel (f) plots average the effective marginal tax rate on capital gains income in each of the treatment and control groups from over time. Note that the effective marginal tax rate in any given year is based on reported taxable capital gains in that year and accounts for the capital losses taken and the available Lifetime Capital Gains Exemption (LCGE) space available to the tax filer in that year. Tax filers with remaining LCGE space or with enough capital losses to offset realized gains face an effective marginal tax rate of zero. The green shaded area marks the period of time (1985-1994) when the LCGE was available. 
Figure F.2: Demographic Characteristics - Individuals with Positive CGs

(a) Age

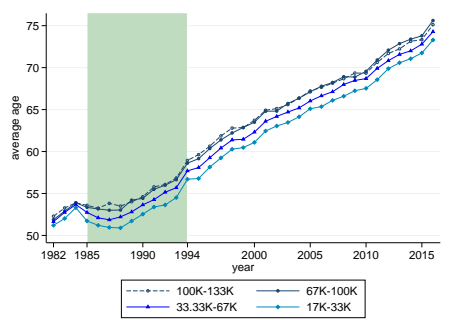

(d) Total Income

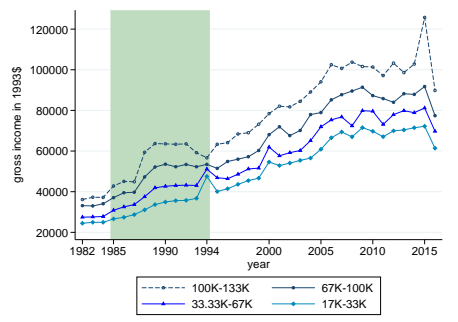

(b) Share Married

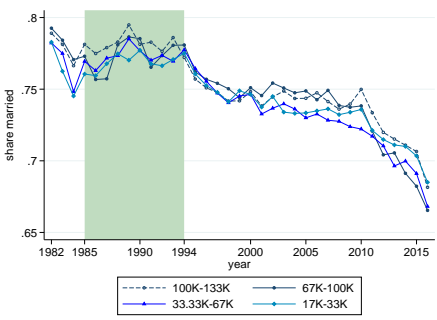

(e) Taxable Income

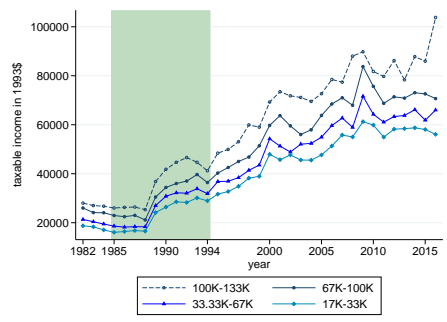

(c) Number of Kids

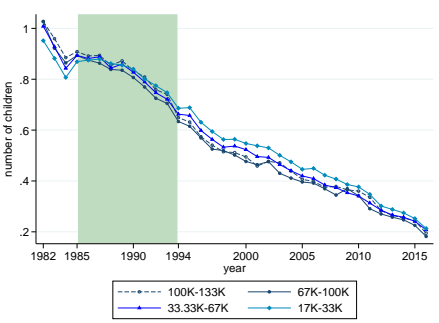

(f) Marginal Tax Rate

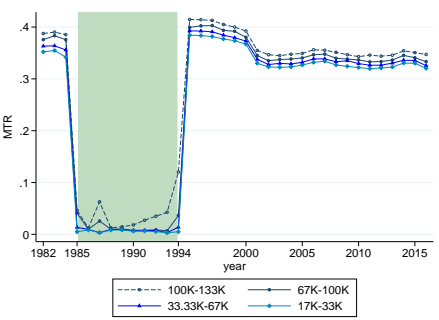

Notes: This figure plots the means for several demographic characteristics and two different income concepts for tax filers that report positive realized capital gains from 19822016, separately for each of the four treatment and control groups. The figure in panel (f) plots average the effective marginal tax rate on capital gains income in each of the treatment and control groups from over time. Note that the effective marginal tax rate in any given year is based on reported taxable capital gains in that year and accounts for the capital losses taken and the available Lifetime Capital Gains Exemption (LCGE) space available to the tax filer in that year. Tax filers with remaining LCGE space or with enough capital losses to offset realized gains face an effective marginal tax rate of zero. The green shaded area marks the period of time (1985-1994) when the LCGE was available. 


\section{G Substitution Effects}

Figure G.1: Time Series: Dividends, Investment Income and RRSP

(a) Average Dividends

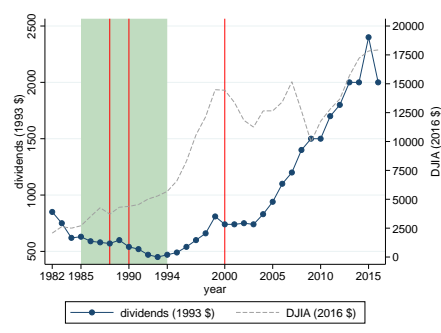

(d) Average Investment

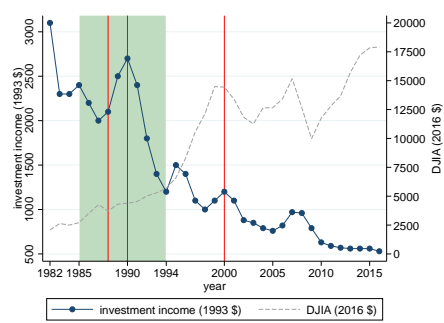

(g) Average RRSP

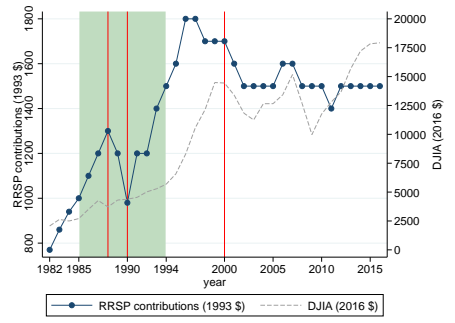

(b) $\%$ Positive Dividends

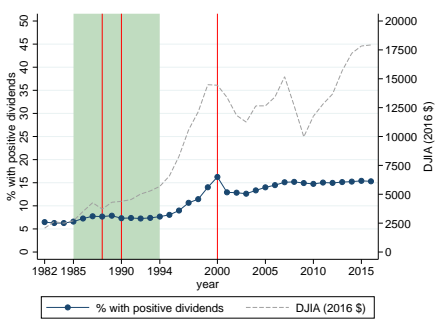

(e) \% Positive Investment

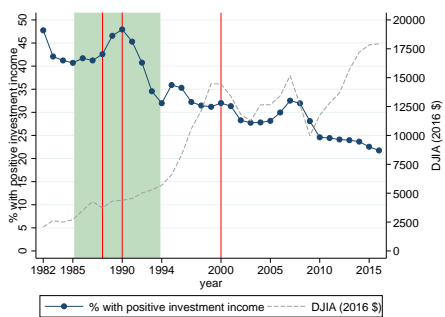

(h) \% Positive RRSP

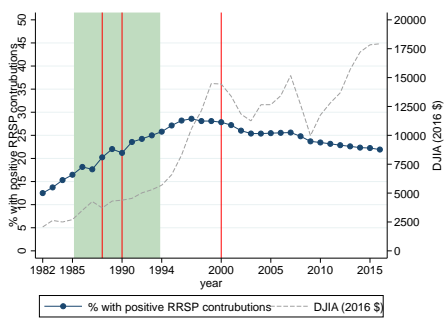

(c) Ave Positive Dividends

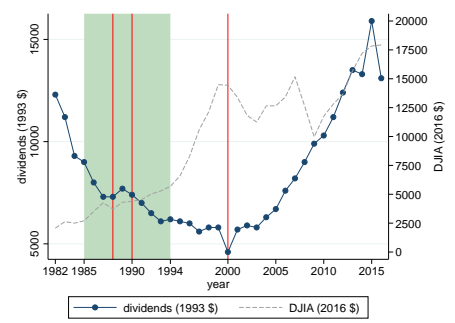

(f) Ave Positive Investment

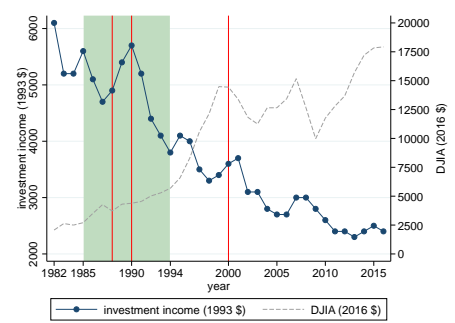

(i) Ave Positive RRSP

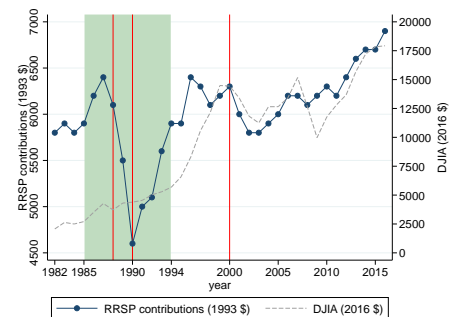

Notes: Figures F.1(a), (d) and (g) plot the average reported dividends, investment income (sum of dividend and interest income) and RRSP contributions from 1982-2016 for all tax filers. Figures F.1(b), (e) and (h) plot the fraction of all tax filers with positive values of the aforementioned variables. Figures F.1(c), (f) and (i) plot the average reported dividends, investment income and RRSP contributions for tax filers with positive values of those variables. The dashed grey line plots the inflation-adjusted values of the Standard and Poor's Toronto Stock Exchange Composite Index. The green shaded area marks the period of time (19851994) when the LCGE was available. The red vertical lines indicate the years where the capital gains inclusion rate changed (from $50 \%$ to $66.6 \%$ in 1988, from $66.6 \%$ to $75 \%$ in 1990 and from $75 \%$ to $50 \%$ in 2000 ). 


\section{Figure G.2: Substitution Responses - Total Response}

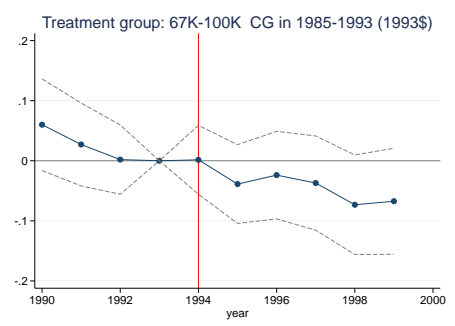

\section{Panel A: Dividends}
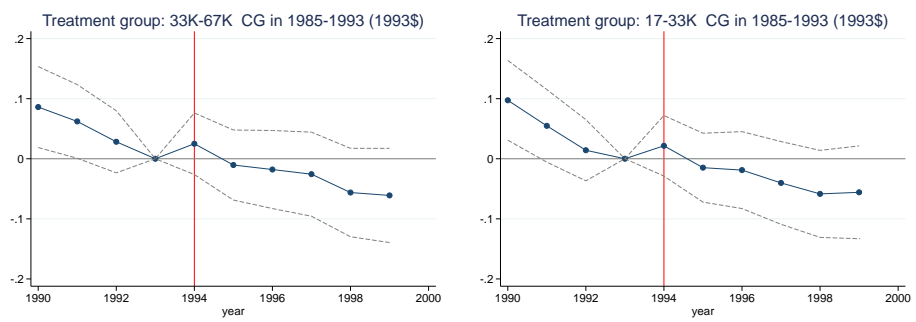

Panel B: Investment Income
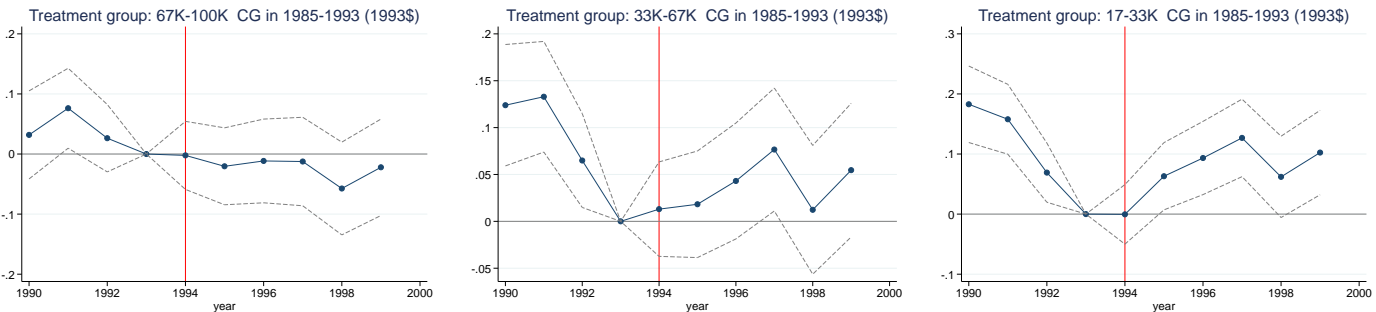

Panel C: RRSP

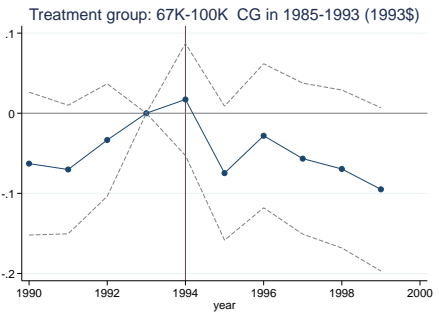

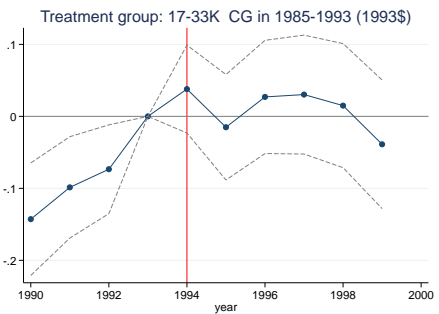

Notes: This figure plots the $\gamma_{\tau}$ coefficient estimates and the associated $95 \%$ confidence intervals from the estimation of specification (1) described in Section 4.1 for each of the three treatment groups. The dependent variables in Panels A, B and $\mathrm{C}$ are the natural logarithm of dividend income, investment income and RRSP contributions, respectively. $\$ 1$ is added to the value to all dollar values so that the natural logarithm is defined. For specifications where the treatment group is $\$ 66,667-\$ 100,000$ 1985-1993 capital gains, the number of observations is 293,385 . For specifications where the treatment group is $\$ 33,334-\$ 66,666$ (resp. $\$ 16,666-\$ 33,333$ ), the number of observations is 532,893 (resp. 596,595). 


\section{Figure G.3: Substitution Responses - Intensive Margin}

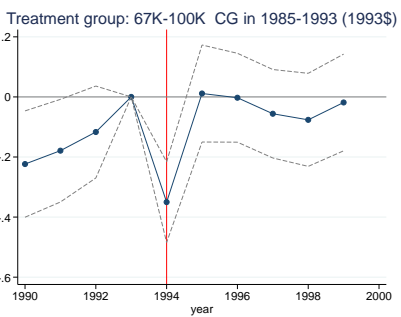

\section{Panel A: Dividends}
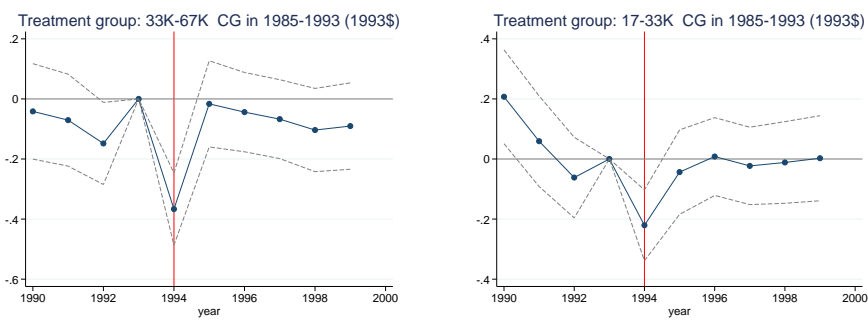

Panel B: Investment Income
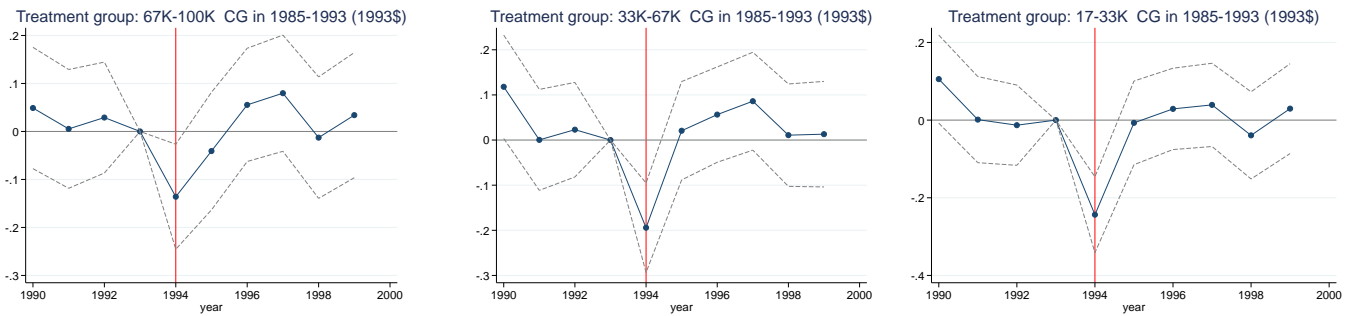

Panel C: RRSP

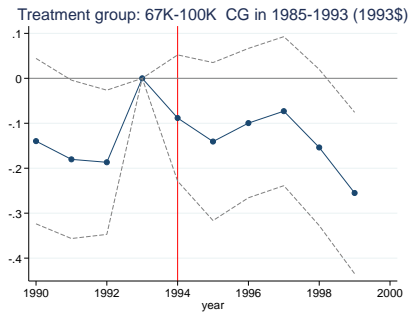

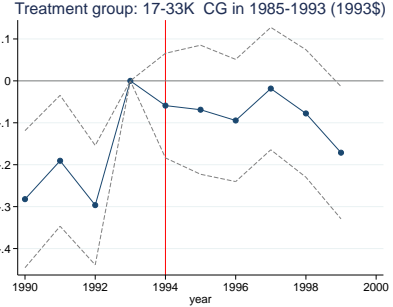

Notes: This figure plots the $\gamma_{\tau}$ coefficient estimates and the associated $95 \%$ confidence intervals from the estimation of specification (1) described in Section 4.1 for each of the three treatment groups. For all specifications, the sample is restricted to tax filers with positive realized capital gains. The dependent variables in Panels A, B and C are the natural logarithm of dividend income, investment income and RRSP contributions, respectively. $\$ 1$ is added to the value to all dollar values so that the natural logarithm is defined. For specifications where the treatment group is $\$ 66,667-\$ 100,000$ 1985-1993 capital gains, the number of observations is 105,105 . For specifications where the treatment group is $\$ 33,334$ $\$ 66,666$ (resp. $\$ 16,666-\$ 33,333$ ), the number of observations is 171,335 (resp. 186,125). 